\title{
SRL EXPERIMENTS FOR THE JAPANESE POWER REACTOR AND NUCLEAR FUEL DEVELOPMENT CORPORATION
}

\author{
J. L. JARRIEL \\ D. J. PELLARIN
}

SRL

RECORD COPY

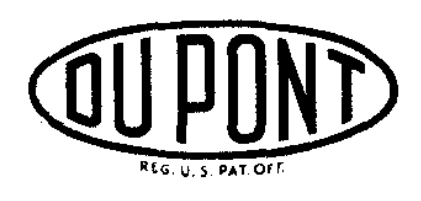

Savannah River Laboratory

Aiken, South Carolina 


\section{LEGAL NOTICE}

This report was prepared as an account of work sponsored by the United States Government. Neither the United States nor the United States Atomic Energy Commission, nor any of their employees, nor any of their contractors, subcontractors, or their employees, makes any warranty, express or implied, or assumes any legal liability or responsibility for the accuracy, completeness or usefulness of any information, apparatus, product or process disclosed, or represents that its use would not infringe privately owned rights.

Printed in the United States of America

Available from

Clearinghouse for Federal Scientific and Technical Information

National Bureau of Standards, U. S. Department of Commerce

Springfield, Virginia 22151

Price: Printed Copy $\$ 3.00$; Microfiche $\$ 0.65$ 


\title{
SRL EXPERIMENTS FOR THE JAPANESE POWER REACTOR AND NUCLEAR FUEL DEVELOPMENT CORPORATION
}

\author{
by \\ J. L. Jarriel and D. J. Pellarin \\ Work done by \\ N. P. Baumann J. D. Robertson \\ J. R. Hilley B. C. Rusche \\ J. L. Jarriel R. M. Satterfield \\ D. J. Pellarin J. D. Spencer
}

Approved by

B. C. Rusche, Research Manager

Experimental Physics Division

September 1970

E. I. DU PONT DE NEMOURS \& COMPANY

SAVANNAH RIVER LABORATORY

AIKEN, S. C. 29801

CONTRACT AT(07.2).1 WITH THE

UNITED STATES ATOMIC ENERGY COMMISSION 


\begin{abstract}
Experiments were performed in the Subcritical Experiment (SE) and the Process Development Pile (PDP) to determine the physics characteristics of a boiling $\mathrm{H}_{2} \mathrm{O}$-cooled, $\mathrm{D}_{2} \mathrm{O}$-moderated power reactor. The measurements, made in support of the Japanese power reactor program, included lattice bucklings, control assembly worths, and cell physics parameters. The measurements were made at 9 - and 10 -inch square lattice pitches with assemblies consisting of clusters of 31 natural $\mathrm{UO}_{2}$ rods surrounded by $\mathrm{H}_{2} \mathrm{O}, \mathrm{D}_{2} \mathrm{O}$, or mixtures of $\mathrm{H}_{2} \mathrm{O}$ and $\mathrm{D}_{2} \mathrm{O}$ as coolant to permit interpolation to a variety of lattice pitches and coolant conditions. The measurements indicated that the worth of the control assembly, a multitube assembly designed and constructed by the Japanese, was $17 \% \mathrm{k}$ eff in the case of most interest to the Japanese, a worth well in excess of that required for control. Detailed lattice parameters from foil activations gave generally good agreement with HAMMER computed reaction rates, cadmium ratios, and thermal flux distributions and spectra.
\end{abstract}




\section{CONTENTS}

Page

LIST OF TABLES . . . . . . . . . . . . . . . . 4

LIST OF FIGURES . . . . . . . . . . . . . . . 5

INTRODUCTION . . . . . . . . . . . . . 7

SUMMARY . . . . . . . . . . . . . . . . 7

EXPERIMENTAL FACILITIES . . . . . . . . . . . . 9

SP-SE Facility ................ . 9

SRL Mockup Fuel Assembly Design . . . . . . . . 12

Japanese Control Assembly Design . . . . . . . 13

SE EXPERIMENTS . . . . . . . . . . . . . . 15

Buck1ing Determinations .. . . . . . . . . 15

Vertical and Radial Flux Profile Measurements . 18

Analysis of SE Measurements with PDQ-HAMMER . . 22

HAMMER Mockup of Fuel Cell . . . . . . . . 22

HAMMER Mockup of Control Assembly Cell . . 24

PDQ Mockup of the SE . . . . . . . . . . . 25

Normalization to Experiment .. . . . . 26

Results of Measurements ......... . 30

Flux Ratio Measurements............ 34

Extension of Results to the ATR . . . . . . . 34

Activation Experiments . . . . . . . . . . 38

APPENDIX A - Control Tube Worth Measurements

in the PDP ..........61 61

APPENDIX B - Effectiveness of Cadmium Covers . . . . 65

APPENDIX C - Summary of SE Radial Flux Measurements . 67

APPENDIX D - Possible Systematic Error in Buckling

Measurements at Low Bucklings . . . . . 69

REFERENCES .................. 71 


\section{LIST OF TABLES}

Table $\quad \underline{\text { Page }}$

1 Summary of Control Rod Worth Measurements . . 8

2 Summary of Calculated and Experimental

Lattice Parameters . . . . . . . . . . . 8

3 List of SE Experiments . . . . . . . . . 15

$4 \quad$ Lattice Bucklings and Control Assembly Worths . . . . . . . . . . . . . . . 21

5 Measured and Calculated SE Radial Thermal

Flux Shape . . . . . . . . . . . 27

6 Relative Worths of Japanese Control Tubes . . 32

7 PDQ Flat Flux Calculations . . . . . . . 32

8 Measured Control Assembly: Fuel Assembly Activation Ratios . . . . . . . . . . 34

9 Cadmium Ratios With and Without Flux Booster Rods . . . . . . . . . . . . . 40

10 Fue1 Pellet Interval Distances and Average Foil Elevations. . . .'. . . . . . . . 43

11 Foil Elevation Corrections ........ 44

12 Description of Foils and Gamma Counting Procedures ............. . 50

13 Constants Used for $\mathrm{C}^{*}$........... 53

14 Comparison of Foil Rod and HAMMER Fuel Radii. 56

15 Radial Flux Shape Measurements Made in the SE . . . . . . . . . . . . 67 


\section{LIST OF FIGURES}

Figure $\quad \underline{\text { Page }}$

I Isometric of SP-SE . . . . . . . . . . . . 10

2 Traveling Monitor Gamma-Compensated Ion Chamber . 11

3 SRL Mockup of Japanese Fuel As sembly . . . . . . 12

4 Japanese Control Assembly . . . . . . . . . 13

5 Content of Japanese Control Assembly Coolant Channels... . . . . . . . . . . . . 14

6 SE Lattice Pattern Used in Buckling Measurements . 17

7 SE Tank Profile ............... 18

8 Typical Traveling Monitor Flux Data . . . . . 20

9 Concentric Ring Model for HAMMER Computations

10 Concentric Ring Model for HAMMER Computations
(Japanese Control Assembly) . . . . . . . 24

11 Cel1 Geometry for HAMMER-PDQ Calculations . . . 25

12 PDQ Mockup of SE .............. . 26

13 PDQ Mockup of Infinite Lattice . . . . . . . . 29

14 Dependence of Control Tube Worth on Tube Diameter............... 30

15 Dependence of Three-Tube Worth on Fuel Coolant Channe1 $\mathrm{H}_{2} \mathrm{O}$ Content . . . . . . . . . . . 31

16 Comparison of Measured and Calculated Bucklings . 33

17 SRL Concentric Ring Model for HAMMER Computations (Japanese ATR Fuel) .. . . . . . . . . . 36

18 PDQ Mockup of ATR . . . . . . . . . . . . 37 


\section{LIST OF FIGURES (Continued)}

$\underline{\text { Figure }}$

Page

19. SE Lattice Arrangements for Activation

Experiments ................ 39

20 Natural $\mathrm{UO}_{2}$ Rod Cluster............. 40

21 Foil Irradiation Rod .............. 41

22 Schematic of Foil Loading in Middle Rod Section . . 42

23 SP Thermal Column Reference........... 45

24 Aluminum Wire Frame and Foil Loading for

Moderator Traverse at $90^{\circ}$. . . . . . . . . 46

25 Aluminum Wire Frame and Foil Loading for

Moderator Traverse at $45^{\circ}$. . . . . . . . . . 47

26 Reference Elevations for Runs $12,17,36$, and 47 . 48

27 Reference Elevations for Run 50 . . . . . . . 49

28 Gamma Counting Arrangement . . . . . . . . 51

29 Reference Flux Position for $\delta_{0}$ Measurement . . . . 54

30 Thermal Neutron Activation Profiles . . . . . . . . 57

$31 \quad{ }^{176} \mathrm{Lu}-{ }^{63} \mathrm{Cu}$ Spectral Index Profiles . . . . . . . 59

$32{ }^{239} \mathrm{Pu}^{235} \mathrm{U}$ Spectral Index Profiles ........ 60

33 PDP Loading Used for Relative Control Rod Worth

Measurements .............. 61

34 Process Development Pile . . . . . . . . . 63

35 Experimental Apparatus for Checking Neutron

Leakage and Effective Cadmium Cutoff Energy . . . . 66 


\section{INTRODUCTION}

This report describes a set of experiments performed in the Subcritical Experiment ${ }^{1}$ (SE) and the Process Development Pile ${ }^{2}$ (PDP) at the Savannah River Laboratory (SRL) in support of the Japanese $D_{2} O$ power reactor program. The results of these experiments will be used by the Japanese in evaluating calculational techniques for the design of a prototype, boiling $\mathrm{H}_{2} \mathrm{O}$-cooled, $\mathrm{D}_{2} \mathrm{O}$ moderated Advanced Thermal Reactor (ATR). The experiments were undertaken to determine control assembly worth, lattice bucklings, and detailed nuclear parameters. The measurements were made with $\mathrm{D}_{2} \mathrm{O}, \mathrm{H}_{2} \mathrm{O}$, and $\mathrm{a}_{2} \mathrm{O}-\mathrm{D}_{2} \mathrm{O}$ mixture in the coolant channels of the fuel assemblies, and at both 9 - and 10-inch square lattice pitches, so that parameters for a variety of coolant conditions and lattice pitches of interest to the Japanese could be obtained by interpolation. The $\mathrm{H}_{2} \mathrm{O}-\mathrm{D}_{2} \mathrm{O}$ mixture was used as a mockup of boiling $\mathrm{H}_{2} \mathrm{O}$ coolant in the ATR.

The fuel assemblies proposed for the ATR will consist of 28 -rod clusters of $\mathrm{UO}_{2}$ enriched to $1.5 \mathrm{wt} \% 235 \mathrm{U}$ and arranged on a 225-mm (8.86-inch) square lattice pitch. Because none of this fuel was available at the time the experiments were performed, a mockup of the Japanese fuel was used in the SE experiments. The mockup consisted of a 31 -rod cluster containing natural $\mathrm{UO}_{2}$.

The control assemblies used in the experiments were fabricated by the Sumitomo Electric Industries Ltd., Tokyo, Japan. Rods of $\mathrm{B}_{4} \mathrm{C}$ compacted to $\sim 70 \%$ theoretical density and arranged to form a control cylinder or tube were used as the neutron absorber. A complete control assembly consisted of three nested control tubes. Measurements of the worth of both the individual tubes and the complete assembly were made.

Most of the experiments were performed in the SE. The relative worths of the individual control tubes were also determined by substitution techniques in the PDP.

\section{SUMMARY}

Buckling measurements were performed in the Subcritical Experiment (SE) to determine the worth of the Japanese control assemblies with either $\mathrm{D}_{2} \mathrm{O}, \mathrm{H}_{2} \mathrm{O}$, or a $70 \% \mathrm{H}_{2} \mathrm{O}-30 \% \mathrm{D}_{2} \mathrm{O}$ mixture in the fuel coolant channels and at 9- and 10-inch square lattice pitches. Detailed cell activation measurements were also made to provide information concerning the cell physics parameters. 
Table 1 summarizes the control rod worths. The worth of a full control assembly to the proposed ATR was calculated to be $17 \% \mathrm{k}$ eff using parameters normalized to the SE experiments for a case with $70 \% \mathrm{H}_{2} \mathrm{O}$ only in the fuel coolant channels.

The SE buckling measurements were accompanied by foil activations designed to measure the thermal neutron distributions in terms of copper activations, the thermal neutron spectral indices in terms of ${ }^{276} \mathrm{Lu}-{ }^{63} \mathrm{Cu}$ and ${ }^{239} \mathrm{Pu}-{ }^{235} \mathrm{U}$ activations, resonance neutron capture in ${ }^{23} \mathrm{U}$ in terms of the cadmium ratio for ${ }^{239} \mathrm{~Np}$ production, fast fissions in ${ }^{238} \mathrm{U}$ and total fissions in ${ }^{235} \mathrm{U}$ in terms of the induced fission product activities, fissile material conversion ratios in terms of the ${ }^{238} \mathrm{U}$ capture to ${ }^{235} \mathrm{U}$ fission ratios, and epithermal neutron fractions in terms of ${ }^{235} \mathrm{U}$ fission and ${ }^{2{ }^{3}} \mathrm{Pu}$ fission cadmium ratios. Table 2 summarizes the results of the lattice parameter measurements.

TABLE 1

Summary of Control Rod Worth Measurements ${ }^{a}$

Square Lattice

Pitch, in. Fuel Coolant ${ }^{b}$ Rod Worth, : $k_{\infty}$

$9 \quad \mathrm{D}_{2} \mathrm{O} \quad 30$

$9 \quad 70-30 \quad 23$

$9 \quad \mathrm{H}_{2} \mathrm{O} \quad 21$

$10 \quad 70-30 \quad 22$

a. Worths corrected to a flat flux condition for the complete control assembly

b. $70-30=70 \% \mathrm{H}_{2} \mathrm{O}-30 \% \mathrm{D}_{2} \mathrm{O}$

TABLE 2

Sumary of Calculated ${ }^{a}$ and Experimental Lattice Parameters

\begin{tabular}{|c|c|c|c|c|c|c|c|c|c|c|c|}
\hline \multirow[b]{2}{*}{ Run } & \multirow{2}{*}{$\begin{array}{c}\text { Square } \\
\text { Lattice } \\
\text { Pitch, in. } \\
\end{array}$} & \multirow{2}{*}{$\begin{array}{c}\text { Fuel } \\
\text { Coolant } \\
\end{array}$} & \multicolumn{2}{|c|}{$\bar{\delta}_{0}$} & \multicolumn{2}{|c|}{$\bar{\rho}$} & \multicolumn{2}{|c|}{$c^{*}$} & \multicolumn{2}{|c|}{$235 \mathrm{UCd} \mathrm{R}$} & \multirow{2}{*}{$\frac{{ }^{239} \mathrm{PuCd} R}{\operatorname{Ext}}$} \\
\hline & & & Calc & Expt & Calc & Expt & $\overline{\mathrm{Calc}}$ & Expt & $\overline{\mathrm{Ca} 1 \mathrm{c}}$ & Expt & \\
\hline 12 & 9 & $\mathrm{D}_{2} \mathrm{O}$ & 0.0520 & 0.052 & 0.560 & 0.540 & 1.011 & 1.014 & 24.5 & 20.5 & 37.8 \\
\hline 17 & 9 & $\mathrm{H}_{2} \mathrm{O}$ & 0.0503 & 0.052 & 0.444 & 0.430 & 0.942 & 11.937 & 34.9 & 36.2 & 17.8 \\
\hline 36 & 9 & $70-30$ & 0.0506 & 0.051 & 0.479 & 0.473 & 0.963 & 0.964 & 31.7 & 35.3 & 40.8 \\
\hline 47 & 10 & $70-30$ & 0.0500 & 0.052 & 0.425 & 0.407 & 0.930 & 0.918 & 35.9 & 41.3 & 51.8 \\
\hline 50 & 10 & $70-30$ & - & 0.053 & - & 0.438 & - & 0.942 & - & 37.8 & 48.2 \\
\hline
\end{tabular}




\section{EXPERIMENTAL FACILITIES}

\section{SP-SE FACILITY}

The Standard $\mathrm{Pile}^{4}$ (SP) is an enriched-uranium fueled, graphite-moderated, $\mathrm{H}_{2} \mathrm{O}$-cooled reactor. The core consists of a graphite-filled cylinder inside a 5-ft graphite cube. A 4-ft graphite cube on one side of the SP forms a thermal column. A 3 -inch-diameter thimble is centered on the horizontal axis of the fuel container in which foils and other materials can be irradiated in a maximum thermal neutron flux of $\sim 3 \times 10^{11} \mathrm{n} /\left(\mathrm{cm}^{2}\right)(\mathrm{sec})$.

The Subcritical Experiment ${ }^{1}$ (SE) vessel is a $3 / 8$-inch-thick aluminum cylinder, $5 \mathrm{ft}$ in diameter, and $7 \mathrm{ft}$ high. The sides of the tank are covered with $1 / 8$ inch of cadmium and 2 inches of glass wool thermal insulation. The tank is supported from above by structural steel beams. A cylindrical graphite pedestal is mounted between the $S E$ tank and the $S P$ reactor to minimize spatial harmonics in the SE. Because of leakage of fast neutrons in to the SE tank from the SP (through the graphite pedestal and from scatter off the walls in the reactor room), an 1/8-inch-thick cadmium shutter can be inserted between the pedestal and the SE tank to permit the measurement of the distribution of these leakage neutrons. This distribution can be used to correct the flux shape measured in the SE without the shutter in place. An isometric of the SP-SE is given in Figure 1.

The axial flux shape in the SE is determined with a small, boron-lined, gamma-compensated ion chamber (Figure 2) attached to a constant speed, vertical drive mechanism ${ }^{5}$ mounted on top of the SE tank. Control and recording equipment for the detector and drive mechanism (traveling monitor) are located in the control room. The ion chamber traverses the lattice inside a 7/8-inch-ID aluminum dry well which is plumbed vertical before each run. The output current and vertical position of the detector are continuously transmitted to the control room. Digitized current readings, taken at $2-\mathrm{cm}$ intervals, are transferred to computer data cards. 


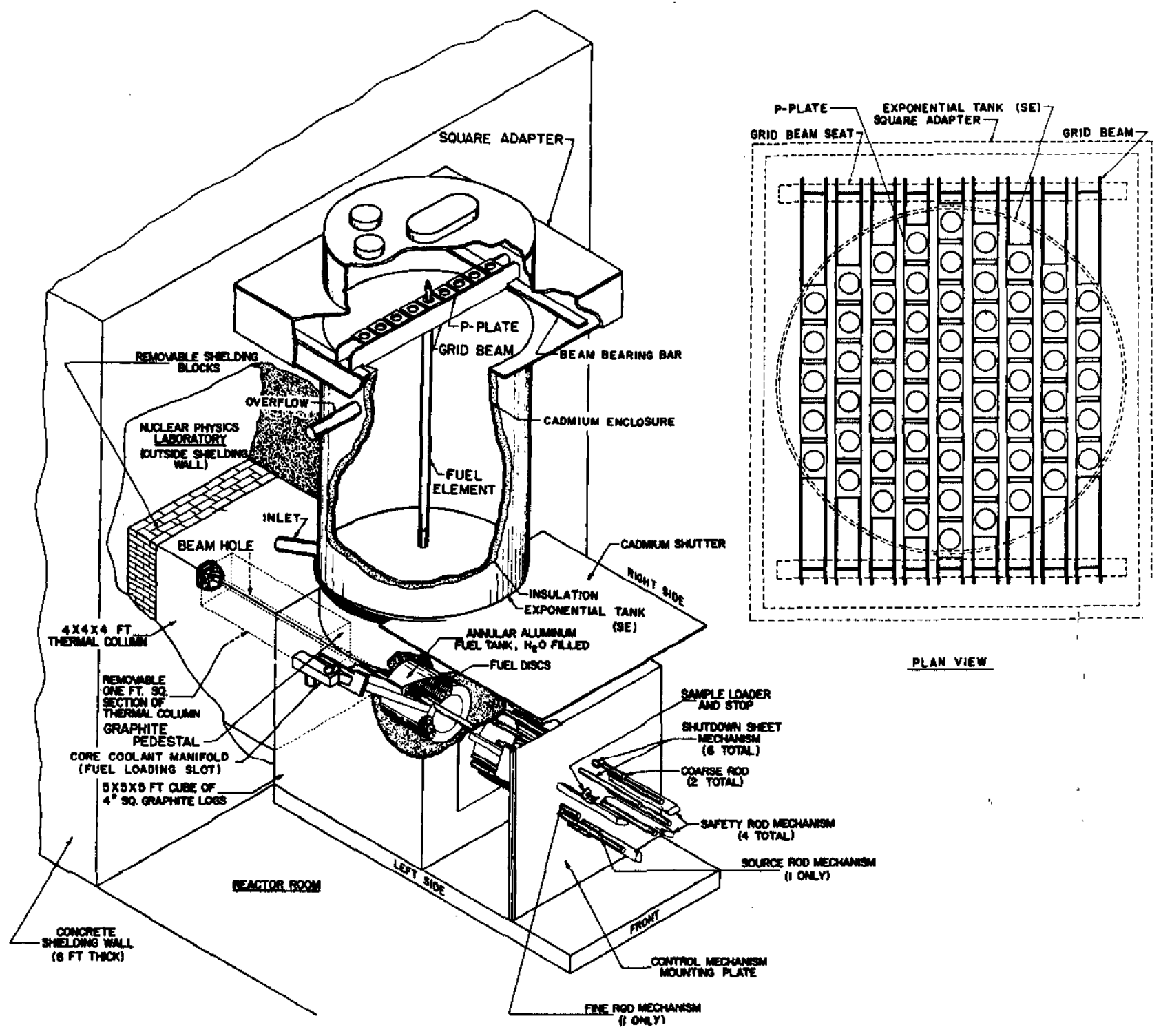

FIG. I ISOMETRIC OF SP-SE 


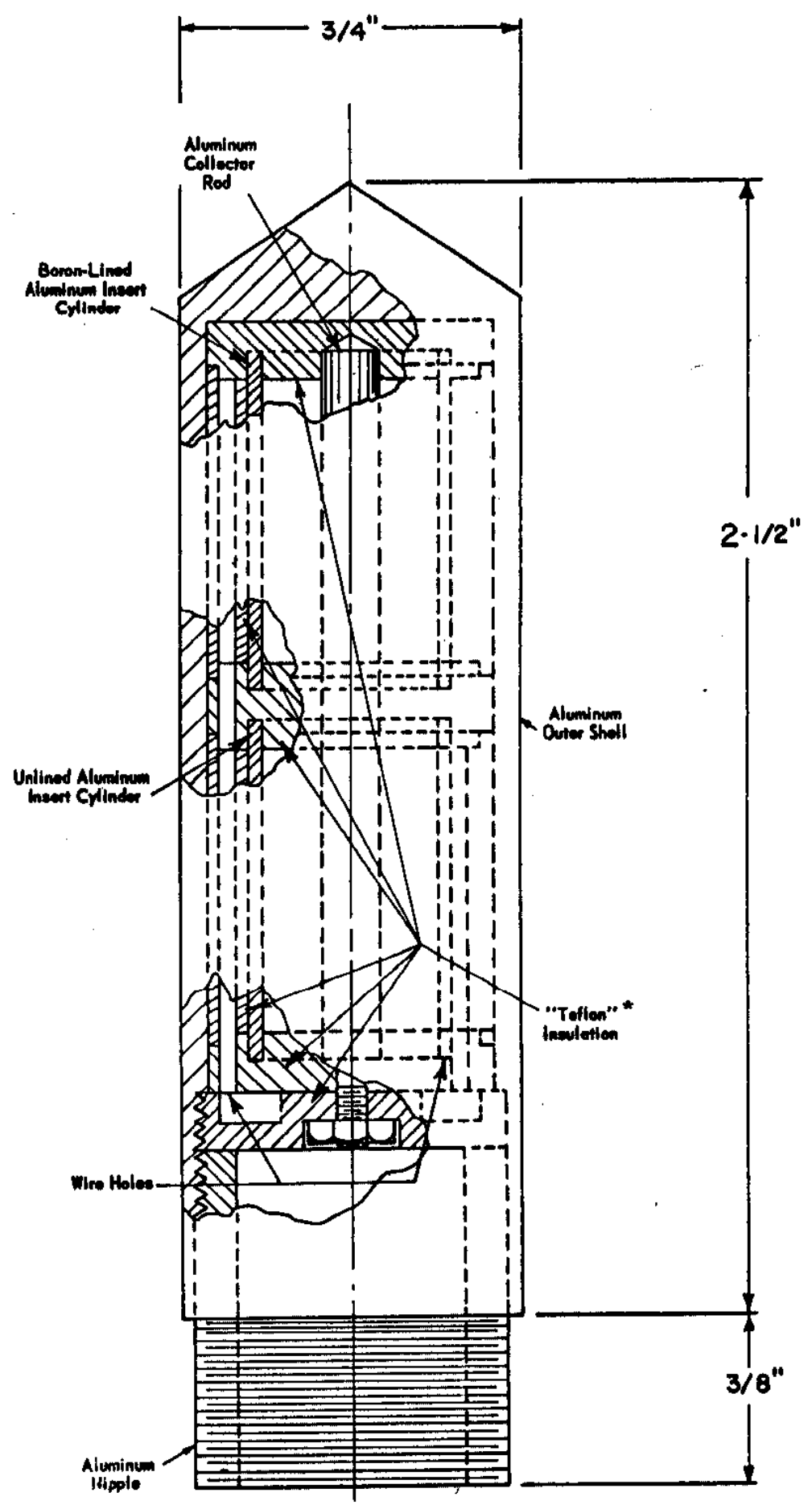

FIG. 2 TRAVELING MONITOR GAMMA-COMPENSATED ION CHAMBER

* Du Pont's trademark for its fluorocarbon plastic 
SRL MOCKUP FUEL ASSEMBLY DESIGN

The fuel assembly used in the SE experiments consisted of a $31-$ rod bundle of natural $\mathrm{UO}_{2}$ rods at a 0.597 -inch center-to-center triangular spacing (Figure 3 ). The rods were formed from $0.500-$ inch-OD sintered pellets with a mean density of $10.4 \mathrm{~g} / \mathrm{cm}^{3}$. The pellets were stacked in tubes of 6063 aluminum with an outside diameter of $0.547 \mathrm{inch}$ and a wall thickness of $0.020 \mathrm{inch}$. The active fuel length was 72 inches. The rod-to-rod spacing was maintained by small nylon rings encircling selected rods in the cluster at three elevations. A 4.500-inch-OD, 6063 aluminum housing tube with a nominal wall thickness of 0.120 inch was used to contain the coolant for the fuel cluster.

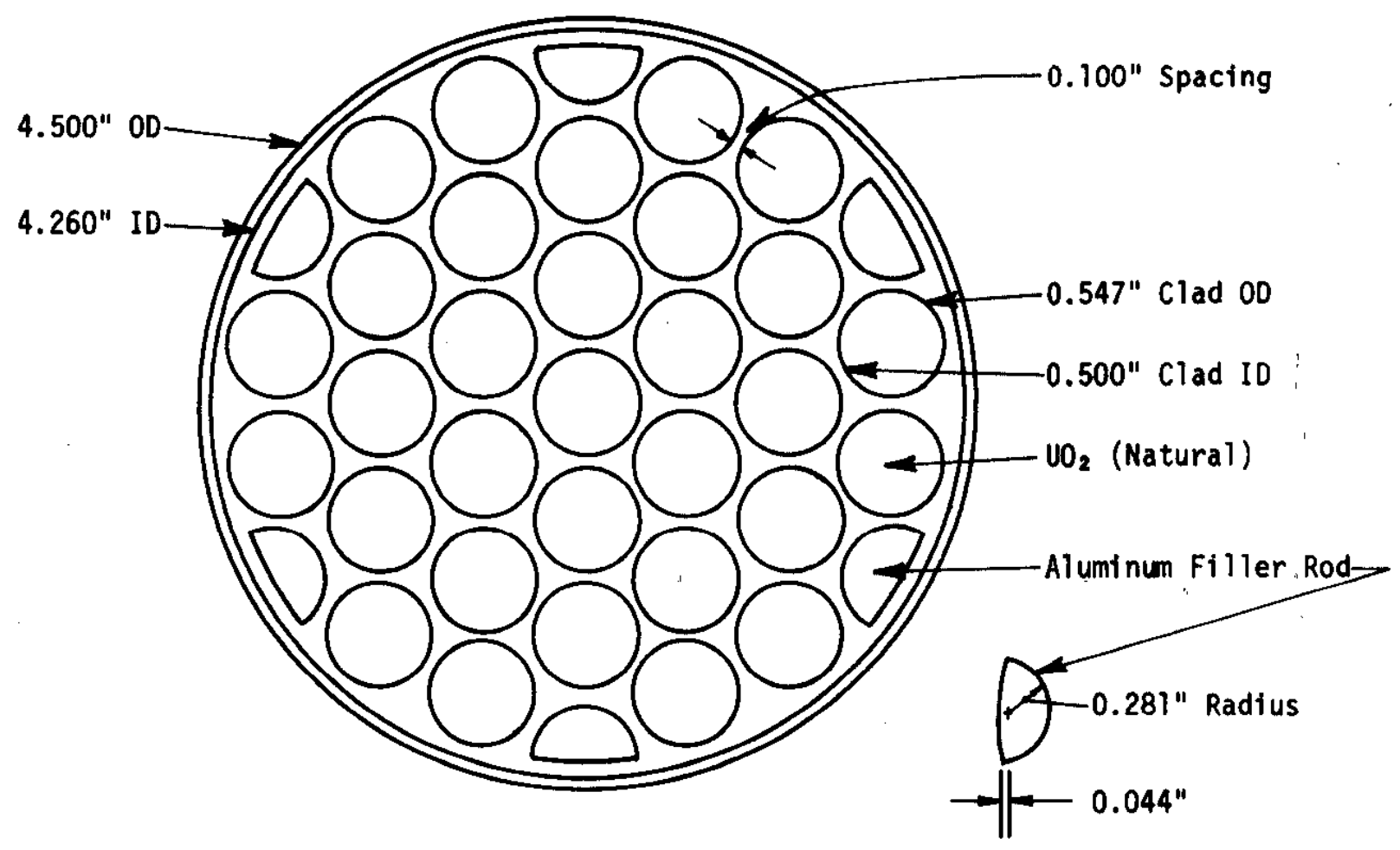

FIG. 3 SRL MOCKUP OF JAPANESE FUEL ASSEMBLY 


\section{JAPANESE CONTROL ASSEMBLY DESIGN}

The control assemblies used in the SE experiments were designed and constructed by the Japanese. The assembly consisted of three nested cylinders or tubes as shown in Figure 4. Each of these stainless steel tubes was filled with $\mathrm{B}_{4} \mathrm{C}$ absorber elements. A 0.500 -inch-OD stainless steel rod at the center of the assembly served to support the control assembly in the lattice. Provision for experiments using either single control tubes or combinations was made by utilizing spacers at the top and bottom of the assembly. Most of the measurements were made with $\mathrm{D}_{2} \mathrm{O}$ serving as the control tube coolant. Two additional experiments were performed utilizing $\mathrm{H}_{2} \mathrm{O}$ coolant. In these two measurements, the control cylinders were inserted in aluminum housing tubes (4.995inch OD and 4.628-inch ID), which were then filled with $\mathrm{H}_{2} \mathrm{O}$. A diagram of control tube arrangements and coolant channel locations for each case is given in Figure 5 .

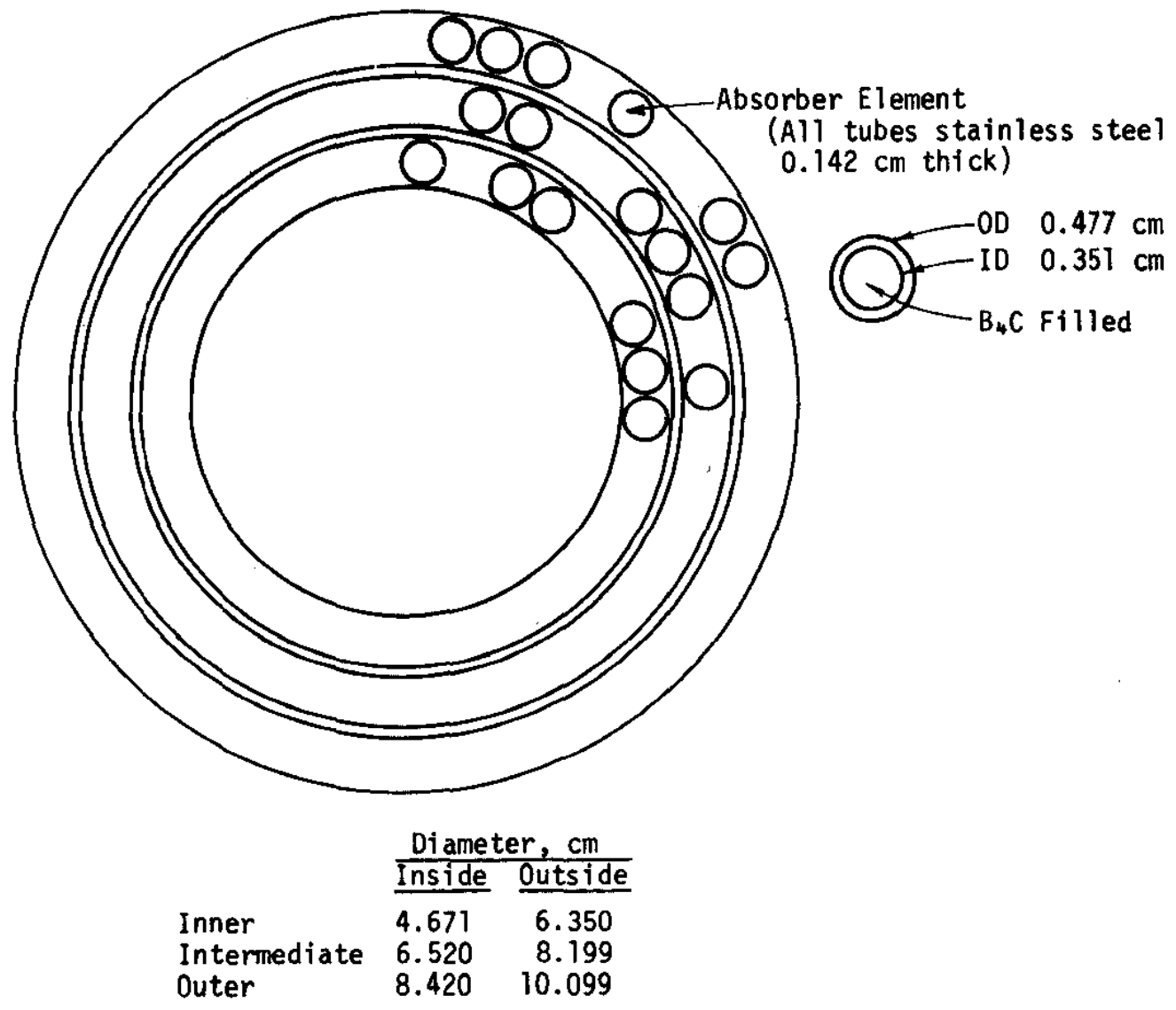

FIG. 4 JAPANESE CONTROL ASSEMBLY 


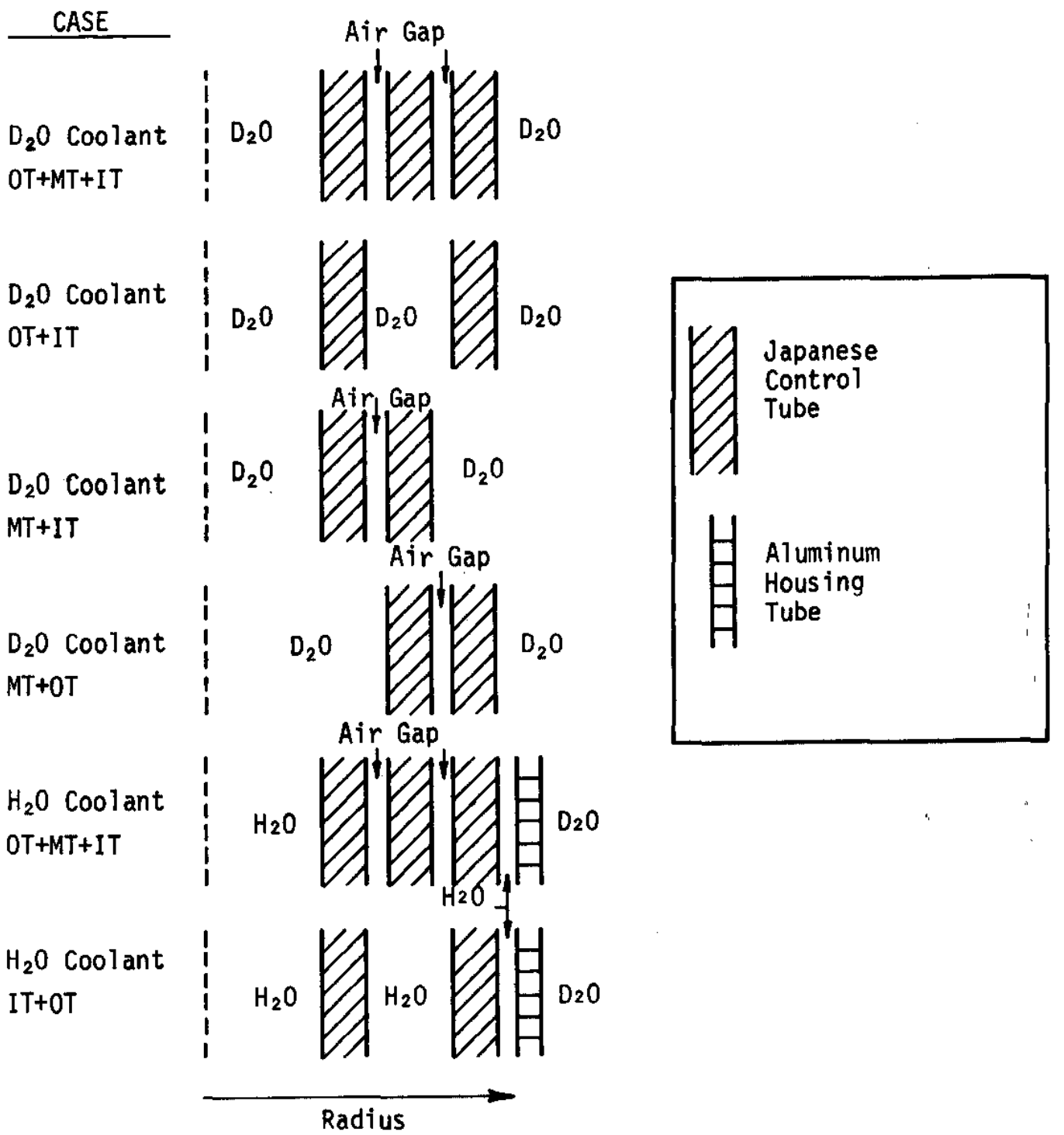

FIG. 5 CONTENT OF JAPANESE CONTROL ASSEMBLY COOLANT CHANNELS 


\section{SE EXPERIMENTS}

\section{BUCKLING DETERMINATIONS}

Table 3 lists the measurements made in the SE. The moderator purity was 99.50 mol $\% \mathrm{D}_{2} \mathrm{O}$ at the start of the program and had degraded to $99.28 \mathrm{~mol} \% \mathrm{D}_{2} \mathrm{O}$ at the conclusion. The bucklings have not been corrected for moderator degradation over the course of the experiments. The SE experiments consisted of three separate sets of measurements. Measurements of the vertical and radial flux shapes were made to determine material bucklings and control assembly worths. Copper wires, taped to fuel and control assemblies, were activated to measure approximate flux ratios.

Finally, measurements of macroscopic parameters of the fuel assemblies were made using foils placed inside individual fuel rods.

TABLE 3

List of SE Experiments

\begin{tabular}{|c|c|c|c|c|c|c|}
\hline \multirow[b]{2}{*}{ kun } & \multirow[b]{2}{*}{$\begin{array}{c}\text { SE } \\
\text { Lattice } \\
\end{array}$} & \multirow{2}{*}{$\begin{array}{l}\text { Lontrol } \\
\text { Tube } \\
\text { Type } \\
\end{array}$} & \multicolumn{2}{|c|}{ Cool ant } & \multirow{2}{*}{$\begin{array}{c}\mathrm{D}_{2} \mathrm{O} \\
\text { Purity, } \\
\text { mol }{ }^{2}\end{array}$} & \multirow[b]{2}{*}{$\begin{array}{c}\text { Type } \\
\text { Measurement }\end{array}$} \\
\hline & & & Fue $^{c}$ & $\begin{array}{l}\text { Control } \\
\text { Tube } \\
\end{array}$ & & \\
\hline 1 & $9-\mathrm{C}$ & - & $\mathrm{D}_{2} \mathrm{O}$ & & 99.49 & $B_{R}^{2}$ \\
\hline$\therefore$ & $9-\mathrm{C}$ & - & $\mathrm{D}_{2} \mathrm{O}$ & & 99.49 & $\mathrm{~B}_{\mathrm{R}}^{2}$ \\
\hline 3 & $9-\mathrm{C}$ & - & $\mathrm{D}_{2} \mathrm{O}$ & & 99.49 & $k^{2}$ \\
\hline 4 & $9-\mathrm{C}$ & $O T+M T+I T$ & $1)_{2} \mathrm{O}$ & $\mathrm{D}_{2} \mathrm{O}$ & 99.49 & $k^{2}$ \\
\hline 5 & $9-\mathrm{C}$ & $O^{\prime} \mathrm{I}^{\prime}+\mathrm{M} \mathrm{T}^{\prime}+\mathrm{I}^{\prime} \mathrm{T}$ & $\mathrm{D}_{2} \mathrm{O}$ & $\mathrm{J}_{2} \mathrm{O}$ & 99.48 & Flux Ratio \\
\hline 6 & $9-\mathrm{C}$ & $O T+M I I+I T$ & $\mathrm{U}_{2} \mathrm{O}$ & $\mathrm{D}_{2} \mathrm{O}$ & 99.48 & Flux Ratio \\
\hline 7 & $9-A$ & - & $\mathrm{U}_{2} \mathrm{O}$ & & 99.48 & $k^{2}$ \\
\hline 8 & $9-A$ & - & $\mathrm{D}_{2} \mathrm{O}$ & & 99.46 & $\mathrm{~B}_{\mathrm{R}}^{2}$ \\
\hline$?$ & $9 \cdot \mathrm{A}$ & - & $\mathrm{D}_{2} \mathrm{O}$ & & 99.46 & $B_{R}^{2}$ \\
\hline 10 & $9-\mathrm{A}$ & $\mathrm{O} \mathrm{T}^{+}+\mathrm{MT}+\mathrm{IT}$ & $\mathrm{D}_{2} \mathrm{O}$ & $\mathrm{D}_{2} \mathrm{O}$ & 99.46 & $k^{2}$ \\
\hline 11 & $9-\mathrm{A}$ & - & $\mathrm{IJ}_{2} \mathrm{O}$ & & 99.46 & Activation Run 1 \\
\hline 12 & $9-\mathrm{A}$ & - & $\mathrm{U}_{2} \mathrm{O}$ & & 99.46 & Activation Run 1 \\
\hline 13 & $9-A$ & - & $\mathrm{H}_{2} \mathrm{O}$ & & 99.45 & $B_{R}^{2}$ \\
\hline 14 & $9-\mathrm{A}$ & - & $\mathrm{H}_{2} \mathrm{O}$ & & 99.45 & $B k^{2}$ \\
\hline 15 & $9-A$ & - & $\mathrm{H}_{2} \mathrm{O}$ & & 99.45 & $k^{2}$ \\
\hline 16 & $9-\mathrm{A}$ & $O T+M T+I T$ & $\mathrm{H}_{2} \mathrm{O}$ & $\mathrm{v}_{2} \mathrm{O}$ & 99.45 & $k^{2}$ \\
\hline 17 & $9-A$ & - & $\mathrm{H}_{2} \mathrm{O}$ & & 99.44 & Activation Run 2 \\
\hline 18 & $9-A$ & - & $75-25$ & & 99.43 & $\mathrm{~B}_{\mathrm{R}}^{2}$ \\
\hline 19 & $9-A$ & - & $75-25$ & & 99.43 & $B_{\mathrm{R}}^{2}$ \\
\hline 20 & $9-A$ & - & $70-30$ & & 99.43 & $\kappa^{2}$ \\
\hline 21 & $9-A$ & $O^{\prime} T+M T+I T$ & $70-30$ & $\mathrm{D}_{2} \mathrm{O}$ & 99.42 & $k^{2}$ \\
\hline 22 & $9-\mathrm{A}$ & oT & $70-30$ & $\mathrm{D}_{2} \mathrm{O}$ & 99.42 & $k^{2}$ \\
\hline 23 & $9-A$ & - & $70-30$ & & 99.42 & $B_{R}^{2}$ \\
\hline 24 & $9-\mathrm{A}$ & - & $70-30$ & & 99.42 & $\mathrm{~B}_{\mathrm{R}}^{2}$ \\
\hline
\end{tabular}


TABLE 3 (Continued)

\begin{tabular}{|c|c|c|c|c|c|c|}
\hline \multirow[b]{2}{*}{ Run } & \multirow[b]{2}{*}{$\begin{array}{c}\mathrm{SE} \\
\text { Lattice } \\
\end{array}$} & \multirow{2}{*}{$\begin{array}{l}\text { Control } \\
\text { Tube } \\
\text { Type } \\
\end{array}$} & \multicolumn{2}{|c|}{ Coolant } & \multirow{2}{*}{$\begin{array}{c}\mathrm{D}_{2} \mathrm{O} \\
\text { Purity, } \\
\text { mol } \frac{\mathrm{a}}{\mathrm{s}} \\
\end{array}$} & \multirow[b]{2}{*}{$\begin{array}{c}\text { Type } \\
\text { Measurement }\end{array}$} \\
\hline & & & Fuel $^{\circ}$ & $\begin{array}{l}\text { Control } \\
\text { Tube } \\
\end{array}$ & & \\
\hline 25 & $9-A$ & Fe Pipe & $70-30$ & $\mathrm{D}_{2} \mathrm{O}$ & 99.42 & $\kappa^{2}$ \\
\hline 26 & $9-\mathrm{A}^{d}$ & - & $70-30$ & & 99.42 & $\kappa^{2}$ \\
\hline 27 & $9-A$ & $\mathrm{OT}+\mathrm{MT}$ & $70-30$ & $\mathrm{D}_{2} \mathrm{O}$ & 99.41 & $\kappa^{2}$ \\
\hline 28 & $9-\mathrm{A}$ & Fe Pipe & $70-30$ & $\mathrm{D}_{2} \mathrm{O}$ & 99.41 & Flux Ratio \\
\hline 29 & $9-\mathrm{A}$ & Fe Pipe & $70-30$ & $\mathrm{D}_{2} \mathrm{O}$ & 99.41 & Flux Ratio \\
\hline 30 & $9-\mathrm{A}$ & IT & $70-30$ & $\mathrm{D}_{2} \mathrm{O}$ & 99.40 & $k^{2}$ \\
\hline 31 & $9-A$ & MT & $70-30$ & $\mathrm{D}_{2} \mathrm{O}$ & 99.40 & $k^{2}$ \\
\hline 32 & $9-\mathrm{A}$ & $O T+I T$ & $70-30$ & $\mathrm{D}_{2} \mathrm{O}$ & 99.40 & $k^{2}$ \\
\hline 33 & 9-A & oT & $70-30$ & $\mathrm{D}_{2} \mathrm{O}$ & 99.40 & Flux Ratio \\
\hline 34 & $9-\mathrm{A}^{e}$ & - & $70-30$ & & 99.40 & $k^{2}$ \\
\hline 35 & $9-\mathrm{A}$ & $\mathrm{OT}+\mathrm{MT}+\mathrm{IT}$ & $70-30$ & $\mathrm{D}_{2} \mathrm{O}$ & 99.39 & Flux Ratio \\
\hline 36 & $9-\mathrm{A}$ & - & $70-30$ & & 99.37 & Activation Run 3 \\
\hline 37 & 9-A & $\mathrm{OT}+\mathrm{MT}+\mathrm{IT}$ & $70-30$ & $\mathrm{H}_{2} \mathrm{O}$ & 99.36 & $k^{2}$ \\
\hline 38 & $9-\mathrm{A}$ & $O T+I T$ & $70-30$ & $\mathrm{H}_{2} \mathrm{O}$ & 99.34 & $\kappa^{2}$ \\
\hline 39 & $10-\mathrm{A}$ & or & $70-30$ & $\mathrm{D}_{2} \mathrm{O}$ & 99.34 & Flux Ratio \\
\hline 40 & $10-\mathrm{A}$ & OT & $70-30$ & $\mathrm{D}_{2} \mathrm{O}$ & 99.34 & $k^{2}$ \\
\hline 41 & $10-\mathrm{A}$ & - & $70-30$ & $\mathrm{D}_{2} \mathrm{O}$ & 99.33 & $k^{2}$ \\
\hline 42 & $10-\mathrm{A}$ & MT & $70-30$ & $\mathrm{D}_{2} \mathrm{O}$ & 99.33 & $k^{2}$ \\
\hline 43 & $10-\mathrm{A}$ & IT & $70-30$ & $\mathrm{D}_{2} \mathrm{O}$ & 99.33 & $\kappa^{2}$ \\
\hline 44 & $10-\mathrm{A}$ & - & $70-30$ & & 99.32 & $B_{R}^{2}$ \\
\hline 45 & $10-A$ & - & $70-30$ & & 99.31 & $B_{R}^{2}$ \\
\hline 46 & $10-\mathrm{A}$ & $\mathrm{OT}+\mathrm{MT}+\mathrm{IT}$ & $70-30$ & $\mathrm{D}_{2} \mathrm{O}$ & 99.31 & Flux Ratio \\
\hline 47 & $10-\mathrm{A}$ & - & $70-30$ & & 99.31 & Activation Run 4 \\
\hline 48 & $10-A$ & or & $70-30$ & $\mathrm{D}_{2} \mathrm{O}$ & 99.29 & $\mathrm{~B}_{\mathrm{R}}^{2}$ \\
\hline 49 & $10-\mathrm{A}$ & OT & $70-30$ & $\mathrm{D}_{2} \mathrm{O}$ & 99,28 & $B_{R}^{2}$ \\
\hline 50 & $10-B$ & oT $^{f}$ & $70-30$ & $\mathrm{O}_{2} \mathrm{O}$ & 99,28 & Activation Run 5 \\
\hline 51 & $10-\mathrm{A}$ & $O T+M T+I T$ & $70-30$ & $\mathrm{D}_{2} \mathrm{O}$ & 99.28 & $k^{2}$ \\
\hline
\end{tabular}

a. See Figure 6 for lattice patterns.

$b$. OT, MT, and IT refer to outer, middle, and inner control tubes.

c. $70-30=70 \% \mathrm{H}_{2} \mathrm{O}-30 \% \mathrm{D}_{2} \mathrm{O} ; 75-25=75 \% \mathrm{H}_{2} \mathrm{O}-25 \% \mathrm{D}_{2} \mathrm{O}$.

d. Nine vacant fuel positions.

$e$. Center fuel position vacant.

$f$. OT in center position only.

Bucklings of the SRL mockup lattice, both with and without control assemblies in place, were measured at both 9 - and 10-inch square lattice pitches (Figure 6). In most cases, the buckling measurements were made in a lattice centered on a fuel assembly, since this arrangement facilitated neutron activation measurements being performed at the same time. Because the control assembly loading pattern in the fuel-centered lattice is not symmetric (Figure 6a), additional measurements were made early in the program to ensure that the bucklings and control assembly worths measured in the fuel-centered lattice agreed with those measured in the control-centered lattice (Figure 6b). Additional details are given on page 32 . 

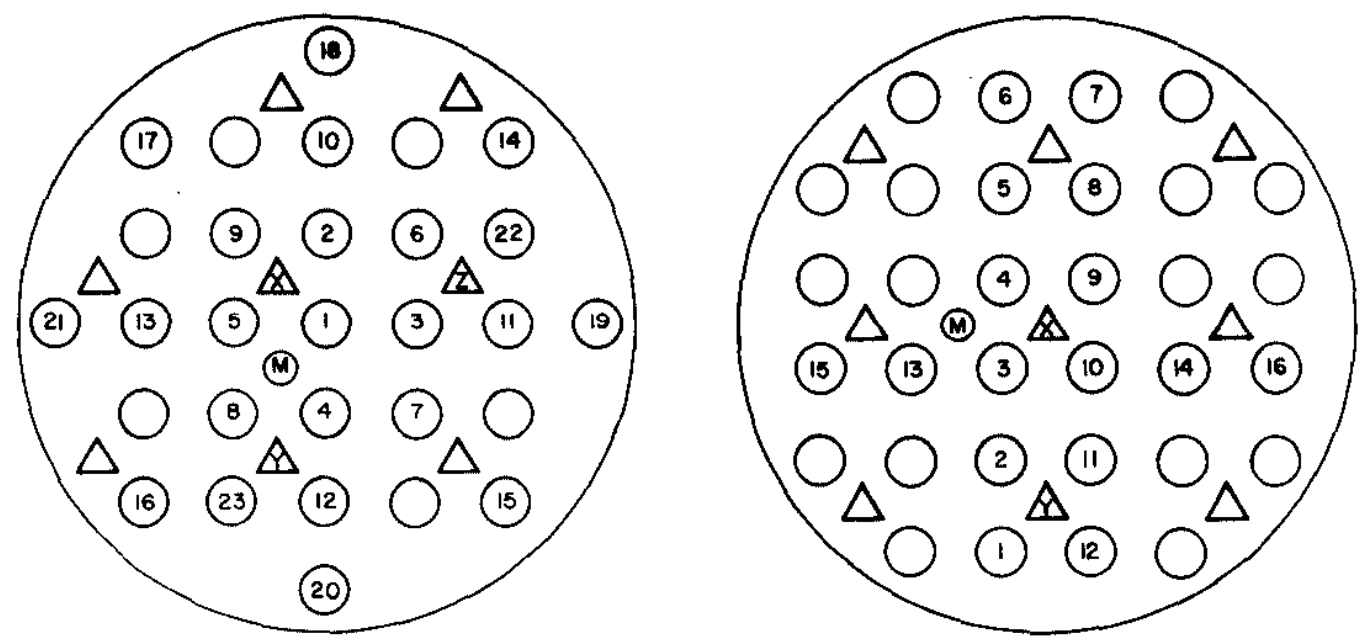

a. Lattice 9-A

Fuel-Centered 9" Square Lattice Pitch

b. Lattice 9-C

Control-Centered 9" Square Lattice Pitch

$\triangle \quad$ Control Tubes

(may or may not

(14) (10)

(15)

(21) (9) (2)

$\triangle \Delta$

(6) (16)

$\Delta$

be present)

Fuel

(M) Traveling Monitor

(13) (5) (1) (3) (11)

(20) (8)

(i)

(7) $\triangle(17)$

(19)

(12)

(18)

Numbers on fuel assemblies and letters on control assemblies denote positions where copper wire was irradiated.

c. Lattice 10-A

Fuel-Centered 10" Square

Lattice Pitch

FIG. 6 SE LATTICE PATTERN USED IN BUCKLING MEASUREMENTS 
Vertical and Radial Flux Profile Measurements

A profile of the SE tank (Figure 7) shows the vertical positioning of fuel and control assemblies as well as the region scanned by the traveling monitor (TM). The region over which the vertical traverses were made begins $\sim 44 \mathrm{~cm}$ above the tank bottom and extends upward a distance of $106 \mathrm{~cm}$. The distance from the top of the scan to the top of the water was $\sim 25 \mathrm{~cm}$. (Previous $\mathrm{SE}$ measurements in similar lattices using bare and cadmium-covered foils indicate that the flux is asymptotic in the region where the vertical flux traverses were made.?

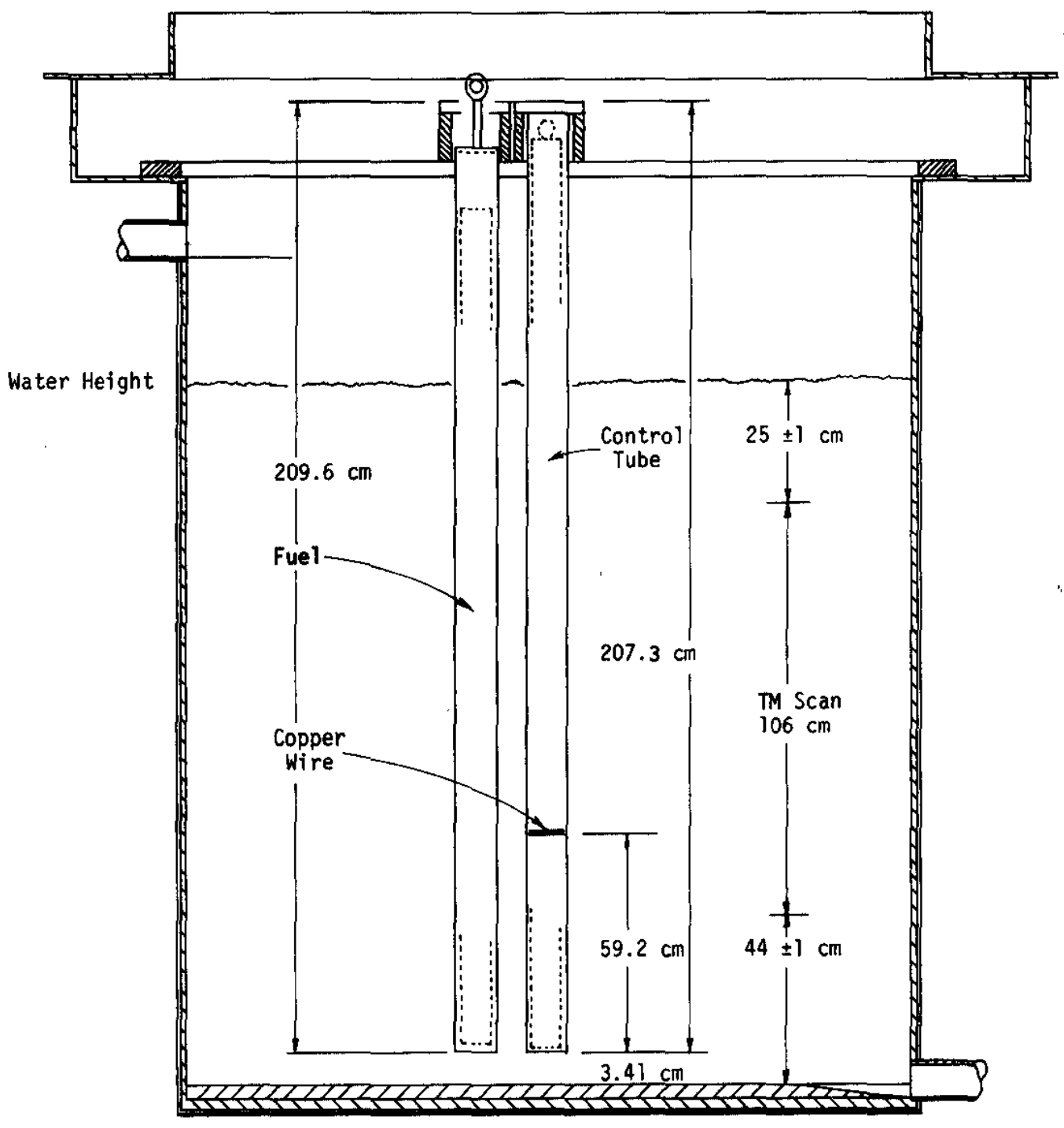

FIG. 7 SE TANK PROFILE 
Ion chamber currents, taken at $2-\mathrm{cm}$ intervals within the $106-\mathrm{cm}$ scan, were digitized and transferred to computer data cards and tape. These readings were fitted numerically by a least squares method using the SRL SETM code. The code fits the data points to a flux shape of the form $A$ sin $\beta\left(X-Z_{j}\right)$ or $A \sinh k\left(X-Z_{j}\right)$, where $A$ is a normalization factor, $K^{2}$ (or $\beta^{2}$ ) is the axial buckling of the $S E, X$ is the extrapolated water height, and $Z_{i}$ is the relative vertical position of each data point. Prior to the fitting process, the code averages the shuttered scans (i.e., with the cadmium shutter in place between the SP and SE) and the unshuttered scans and obtains an average corrected flux which is the difference between the two averaged scans. One option of the code assumes a constant (input) extrapolated water height $(X)$ and solves simultaneously for $K$ (or $\beta$ ) and $A$. Another option solves simultaneously for $K$ (or $B$ ), $A$, and $X$. Flux points may be sequentially dropped from the top and bottom of the scan to obtain a total of 16 fits for each selected traverse. In the analysis of the experiments, calculations performed with input values of the extrapolated water height were compared with the cases in which the extrapolated water height was calculated by the code. The value of $k^{2}$ assigned to each scan was determined by using the extrapolated height that gave the best fit, i.e., the smallest deviation between the smooth fit and the measured data. In all cases, the calculated value of extrapolated height gave a better fit to the data than the fixed values. Typical axial traverses for cases with and without control tubes are presented in Figure 8 , where the measured data points are compared with smooth fits to the function $A \sinh k(X-Z)$.

Values of $\mathrm{K}^{2}$ are listed in Table 4 for all of the measurements. They were chosen from the SETM code output. If the fitted value of $k^{2}$ increased or decreased slightly and then leveled out as data points from the top or bottom of the scan were eliminated, the asymptotic value was used. If the $k^{2}$ values oscillated slightly about some average value as the data points were dropped, the average value was used.

The material buckling in an exponential facility such as the $\mathrm{SE}$ can be obtained from the relation $B_{m}^{2}=B_{r}^{2}-\kappa^{2}$, where $B_{r}^{2}$ is the radial buckling and $x^{2}$ is the axial buckling. The axial buckling was obtained from an analytic fit of the measured axial flux shape as discussed in the previous section. The small number of assemblies in the SE lattices considered made it impractical to measure the radial flux shape and fit the results to a $J_{0}$ function. Therefore, an indirect method was used to determine the material buckling which employs the use of both measured and calculated SE radial flux shapes, in conjunction with the measured vertical shape. It has been employed with success in previous SE measurements and is discussed in detail in the next section. 


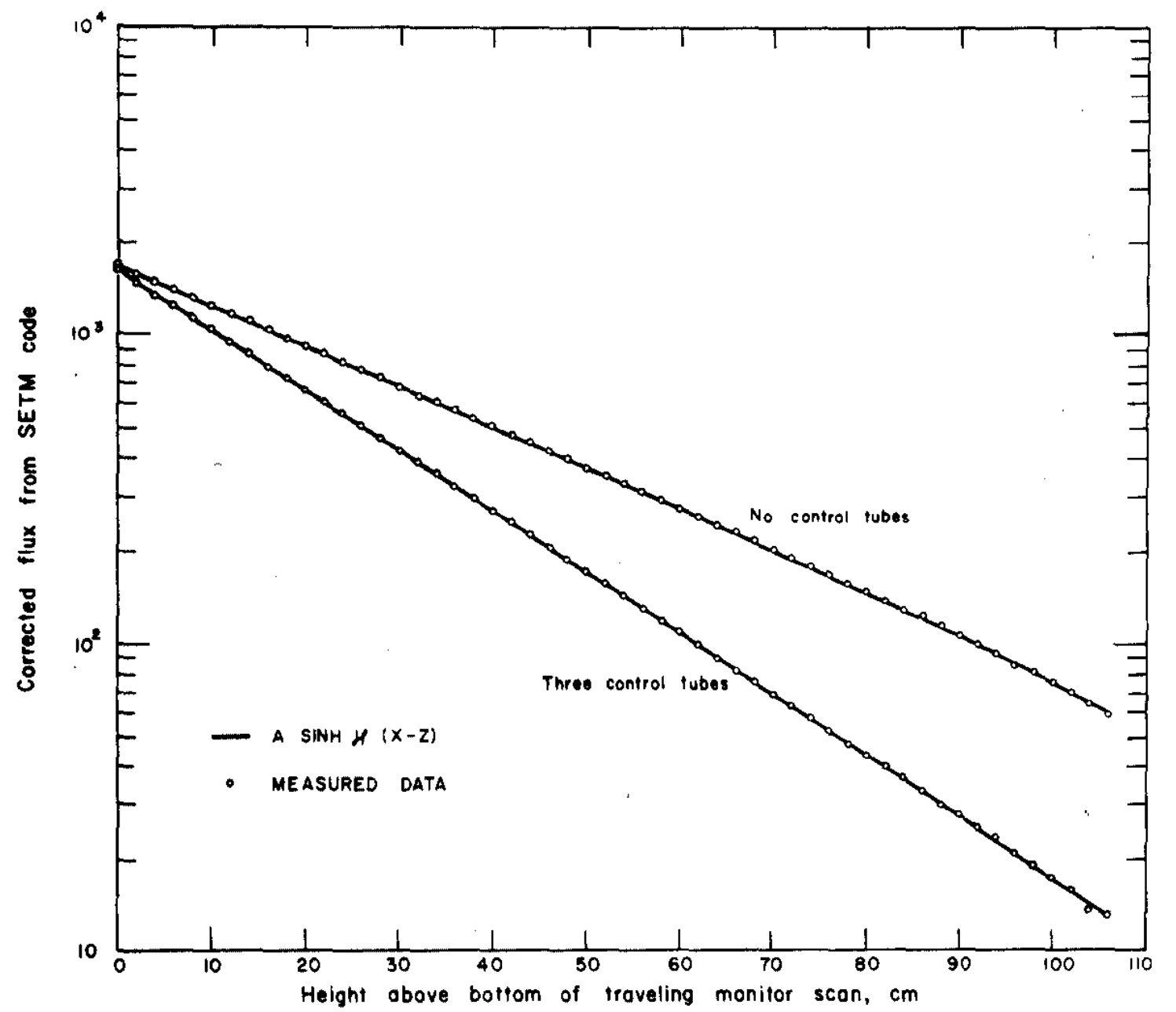

FIG. 8 TYPICAL TRAVELING MONITOR FLUX DATA ( $70 \% \mathrm{H}_{2} \mathrm{O}-30 \% \mathrm{D}_{2} \mathrm{O}$ in Fuel coolant, $\mathrm{D}_{2} \mathrm{O}$ in Control Assembly Coolant, 10-inch Square Lattice Pitch) 
TABLE 4

Lattice Bucklings and Control Assembly Worths

\begin{tabular}{|c|c|c|c|c|c|c|c|c|c|}
\hline \multirow[b]{2}{*}{ Run } & \multirow{2}{*}{$\begin{array}{c}\text { SE } \\
\text { Lattice } a \\
\end{array}$} & \multirow{2}{*}{$\begin{array}{l}\text { Contrgl } \\
\text { Tube }\end{array}$} & \multicolumn{2}{|c|}{ Coolant } & \multirow{2}{*}{$\begin{array}{c}\text { SE } \\
\text { Measured } \\
\kappa^{2}, \mu B d \\
\end{array}$} & \multicolumn{4}{|c|}{$\begin{array}{l}\text { Calculated Extension } \\
\text { to an Infinite Lattice }\end{array}$} \\
\hline & & & Fue ${ }^{c}$ & Tube & & $\mathrm{B}_{m}^{2}, \mu \mathrm{B} d$ & $\Delta \mathrm{B}_{n}^{2}, \mu \mathrm{B} d$ & $k_{\infty}$ & $\Delta \mathrm{k}_{\infty}$ \\
\hline 3 & $9-\mathrm{C}$ & None & $\mathrm{D}_{2} \mathrm{O}$ & - & $590 \pm 5$ & 338 & 0 & 1.0845 & 0 \\
\hline 4 & $9-\mathrm{C}$ & $\mathrm{OT}+\mathrm{MT}+\mathrm{IT}$ & $\mathrm{D}_{2} \mathrm{O}$ & $\mathrm{D}_{2} \mathrm{O}$ & $2016 \pm 9$ & -1095 & -1433 & 0.7794 & -0.3051 \\
\hline 7 & $9-\mathrm{A}$ & None & $\mathrm{D}_{2} \mathrm{O}$ & - & $599 \pm 7$ & 336 & 0 & 1.0839 & 0 \\
\hline 10 & $9-A$ & $\mathrm{OT}+\mathrm{MT}+\mathrm{IT}$ & $\mathrm{D}_{2} \mathrm{O}$ & $\mathrm{D}_{2} \mathrm{O}$ & $2005 \pm 19$ & -1078 & -1414 & 0.7824 & -0.3015 \\
\hline 15 & $9-A$ & None & $\mathrm{H}_{2} \mathrm{O}$ & - & $1079 \pm 9$ & -120 & 0 & 0.9794 & 0 \\
\hline 16 & $9-\mathrm{A}$ & $\mathrm{OT}+\mathrm{MT}+\mathrm{IT}$ & $\mathrm{H}_{2} \mathrm{O}$ & $\mathrm{D}_{2} \mathrm{O}$ & $2548 \pm 17$ & -1585 & -1465 & 0.7669 & -0.2125 \\
\hline 20 & $9-A$ & None & $70-30$ & - & $911 \pm 6$ & 45 & 0 & 1.0086 & 0 \\
\hline 21 & $9-\mathrm{A}$ & $\mathrm{OT}+\mathrm{MT}+\mathrm{IT}$ & $70-30$ & $\mathrm{D}_{2} \mathrm{O}$ & $2341 \pm 18$ & -1391 & -1436 & 0.7789 & -0.2297 \\
\hline 25 & $9-A$ & Fe Pipe & $70-30$ & $\mathrm{D}_{2} \mathrm{O}$ & $1555 \pm 9$ & -595 & -640 & 0.8982 & -0.1104 \\
\hline 22 & $9-A$ & OT & $70-30$ & $\mathrm{D}_{2} \mathrm{O}$ & $2340 \pm 10$ & -1386 & -1431 & 0.7794 & -0.2292 \\
\hline 31 & $9-A$ & $\mathrm{MT}$ & $70-30$ & $\mathrm{D}_{2} \mathrm{O}$ & $2098 \pm 7$ & -1141 & -1186 & 0.8136 & -0.1950 \\
\hline 30 & $9-A$ & IT & $70-30$ & $\mathrm{D}_{2} \mathrm{O}$ & $1881 \pm 9$ & -923 & -968 & 0.8456 & -0.1630 \\
\hline 27 & $9-A$ & $\mathrm{OT}+\mathrm{MT}$ & $70-30$ & $\mathrm{D}_{2} \mathrm{O}$ & $2367 \pm 6$ & -1413 & -1458 & 0.7761 & -0.2325 \\
\hline 32 & $9-A$ & $\mathrm{OT}+\mathrm{IT}$ & $70-30$ & $\mathrm{D}_{2} \mathrm{O}$ & $2349 \pm 13$ & -1396 & -1441 & 0.7786 & -0.2300 \\
\hline 37 & $9-A$ & $\mathrm{OT}+\mathrm{MT}+\mathrm{IT}$ & $70-30$ & $\mathrm{H}_{2} \mathrm{O}$ & $2200 \pm 10$ & -1254 & -1299 & 0.8038 & -0.2048 \\
\hline 38 & $9-\mathrm{A}$ & $\mathrm{OT}+\mathrm{IT}$ & $70-30$ & $\mathrm{H}_{2} \mathrm{O}$ & $2220 \pm 30$ & -1222 & -1267 & 0.8030 & -0.2056 \\
\hline 26 & $9-\mathrm{A}^{e}$ & None & $70-30$ & - & $925 \pm 5$ & 30 & -15 & 1.0073 & -0.0013 \\
\hline 34 & $9-A^{f}$ & None & $70-30$ & - & $903 \pm 7$ & & & & \\
\hline 41 & $10-A$ & None & $70-30$ & - & $912 \pm 8$ & 49 & 0 & 1.0110 & 0 \\
\hline 51 & $10-A$ & $\mathrm{OT}+\mathrm{MT}+\mathrm{IT}$ & $70-30$ & $\mathrm{D}_{2} \mathrm{O}$ & $2045 \pm 10$ & -1120 & -1169 & 0.7933 & -0.2177 \\
\hline 40 & $10-\mathrm{A}$ & OT & $70-30$ & $\mathrm{D}_{2} \mathrm{O}$ & $2042 \pm 9$ & -1115 & -1164 & 0.7910 & -0.2200 \\
\hline 42 & $10-\mathrm{A}$ & MT & $70-30$ & $\mathrm{D}_{2} \mathrm{O}$ & $1853 \pm 11$ & -915 & -964 & 0.8237 & -0.1873 \\
\hline 43 & $10-A$ & IT & $70-30$ & $\mathrm{D}_{2} \mathrm{O}$ & $1695 \pm 6$ & -748 & - 797 & 0.8522 & -0.1588 \\
\hline
\end{tabular}

a. See Figure 6 for lattice patterns,

b. OT, MT, and IT refer to outer, middle, and inner control tubes, respectively.

c. $70-30=70 \% \mathrm{H}_{2} \mathrm{O}-30 \% \mathrm{D}_{2} \mathrm{O}$.

d. $1 \mu \mathrm{B}=1 \times 10^{-6} \mathrm{~cm}^{-2}$.

e. Nine vacant lattice positions.

$f$. Center lattice position vacant. 
The measured radial fluxes that were used in this analysis were obtained by irradiating copper wire taped to the housing tubes of selected assemblies. The vertical placement of the copper wires in the lattice was $265 \mathrm{~cm}$ above the tank bottom (Figure 7). The radial placement of the wires is given in Figure 6.

\section{Analysis of SE Measurements with PDQ-HAMMER}

The analysis of buckling experiments performed in the SE was made using the PDQ-5 code, ${ }^{6}$ which solves the two-dimensional neutron diffusion equation for up to five energy groups. Cell parameters for PDQ input were obtained using the HAMMER code. ${ }^{7}$ This code performs one-dimensional, integral transport theory cell calculations using 54 fast energy groups (10 Mev to $0.625 \mathrm{ev}$ ) and 30 thermal groups $(<0.625 \mathrm{ev})$.

The method utilizes a series of PDQ calculations to produce a normalized set of PDQ, two-group, diffusion parameters for each lattice component present in any particular SE buckling measurement. The buckling to be determined in this measurement can then be calculated with these parameters. The normalization of the parameters to the experiment is accomplished by first adjusting the radial boundary conditions in the PDQ calculation until the calculated and measured radial flux shapes agree (PDQ could, at this point, be used to calculate the $S E$ radial buckling for each case but this is unnecessary). Selected diffusion parameters $\left(\nu \Sigma_{f}\right.$ or $\Sigma_{a}$ for each group) of each lattice component are then adjusted until the measured and calculated vertical bucklings are in agreement. These normalized parameters, together with those which were not adjusted, make up the normalized parameter set used to calculate (with PDQ) the buckling of interest.

The calculational models used to mock up both the SE loading and individual components are described in the following sections. A more detailed discussion of the methods of normalization and the results of the analysis is given on page 26 .

\section{HAMMER Mockup of Fuel Cell}

The HAMMER code is restricted to a single geometric dimension. It was necessary, therefore, to construct a suitable mockup of the $\mathrm{UO}_{2}$ rod clusters for treatment with HAMMER. The model chosen was composed of rings of coolant, aluminum, or fuel. This model was expected to be more accurate than homogenizing the entire fuel cluster into a single region because the spatial distribution of the fuel would give better thermal neutron flux distributions and 
the fuel surfaces would better approximate conditions for resonance capture. The concentric ring model used for cell calculations is presented in Figure 9. Regions 1, 3, 5, and 7 consist entirely of $\mathrm{UO}_{2}$ fuel. Regions $2,4,6$, and 8 are composed of aluminum cladding and coolant. The dimensions of the rings are such that the proper atom concentration of each element is conserved.

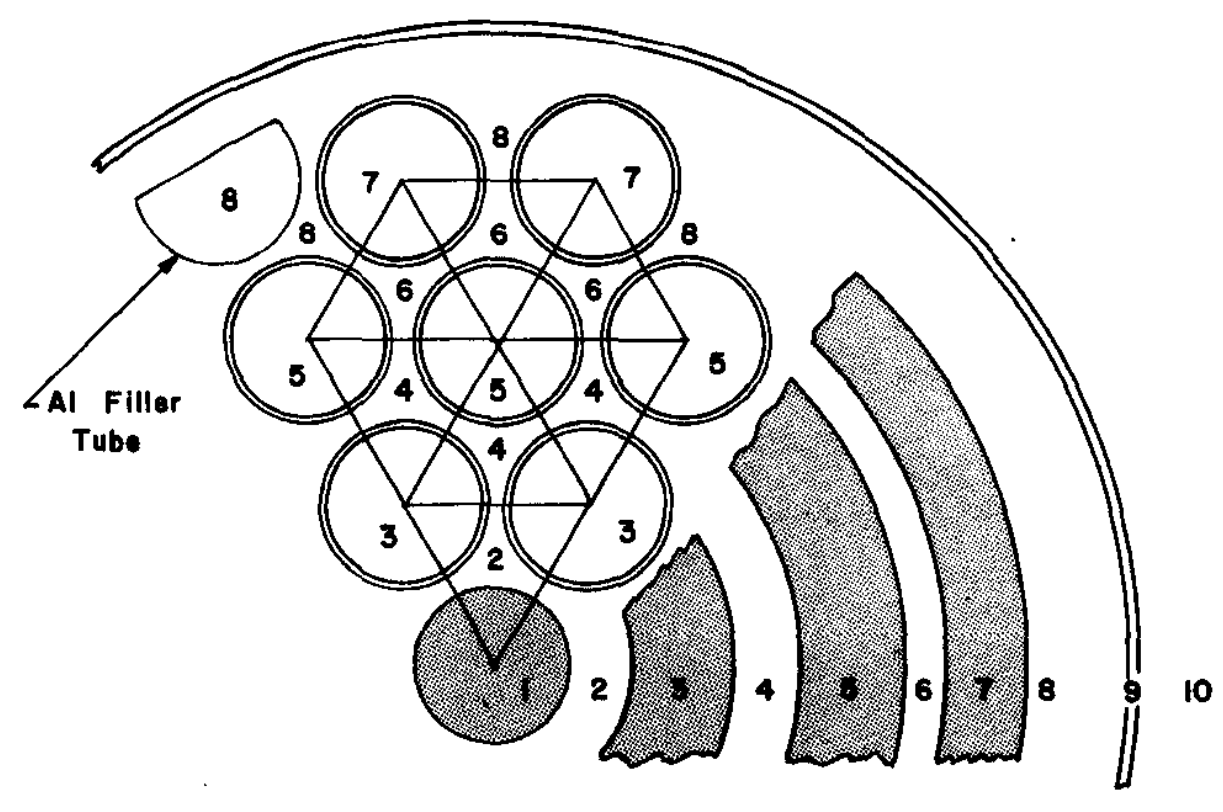

\begin{tabular}{|c|c|c|}
\hline Region & Material & OD, in. \\
\hline 1 & $\mathrm{UO}_{2}$ & 0.5000 \\
\hline 2 & Coolant, Al & 0.9406 \\
\hline 3 & $\mathrm{UO}_{2}$ & 1.5443 \\
\hline 4 & Coolant, A.l & 2.0710 \\
\hline 5 & $\mathrm{UO}_{2}$ & 2.6998 \\
\hline 6 & Coolant, Al & 3.0320 \\
\hline 7 & $\mathrm{UO}_{2}$ & 3.4919 \\
\hline 8 & Coolant, Al & 4.2600 \\
\hline 9 & Al & 4.5000 \\
\hline 10 & Moderator & $6.364 c$ \\
\hline
\end{tabular}

FIG. 9 CONCENTRIC RING MODEL FOR HAMMER COMPUTATIONS (SRL Fuel Assembly) 
HAMMER Mockup of Control Assembly Cell

The Japanese control assembly has been described on page 13 . A pictorial presentation of the ring model used in the HAMMER computations is given in Figure 10. Region 1 consists of the steel hanger rod, and Region 2 contains coolant. Regions 3 and 9 contain stainless steel from the annular cylinders and from onehalf of the cladding on the inner and outer $\mathrm{B}_{4} \mathrm{C}$ tubes. Regions 4 , 6 , and 8 consist of $\mathrm{B}_{4} \mathrm{C}$ and air. Regions 5 and 7 contain stee 1 from both annuli and rod cladding and the air gap between the individual tubes. The purity used in the computations was 99.5 mol $\% \mathrm{D}_{2} \mathrm{O}$.

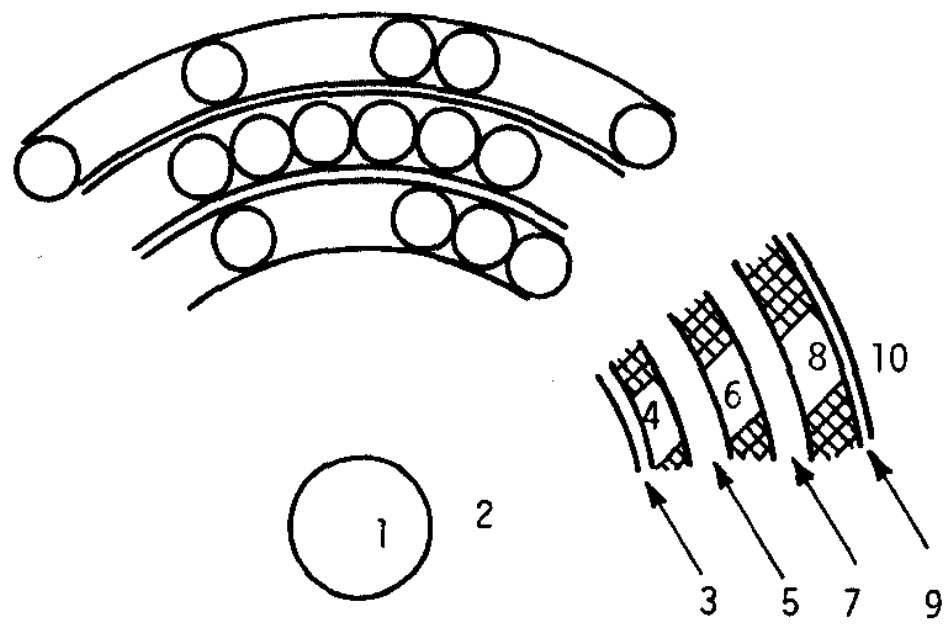

\begin{tabular}{cll} 
Region & \multicolumn{1}{c}{ Material } & OD, in. \\
\cline { 1 - 2 } 1 & Stainless Steel & 0.5000 \\
2 & Coolant & 1.8386 \\
3 & Stainless Steel & 2.0362 \\
4 & B ${ }_{4}$ C, Void & 2.3116 \\
5 & Stainless Steel, Void & 2.7626 \\
6 & B ${ }_{4}$ C, Void & 3.0346 \\
7 & Stainless Steel, Void & 3.5102 \\
8 & B ${ }_{4}$ C, Void & 3.7810 \\
9 & Stainless Steel & 3.9804 \\
10 & Moderator & 6.3640
\end{tabular}

FIG. 10 CONCENTRIC RING MODEL FOR HAMMER COMPUTATIONS (Japanese Control Assembly) 
PDQ Mockup of the SE

The lattice patterns used in the SE buckling and rod worth measurements are presented in Figure 6 . The control tubes were spaced interstitially between four fuel assemblies. In the PDQ mockup of each SE lattice, the 9- and 10-inch cells were subdivided into smaller microcells (6.364 and 7.071 inches square, respectively) in order to include interstitial control positions in lattice computations. HAMMER parameters for the control

assembly and fuel assembly were obtained for rectangles $e-f-g-h$ and $f-i-1-g$, respectively, in Figure 11 . Rectangle $i-j-k-1$ contained moderator only and parameters were generated with HAMMER for this cell also. The fuel, control, and moderator microcells were then used in the PDQ mockup of the SE. A PDQ mockup of a 10 -inch lattice pitch is shown in Figure 12. The other lattices were mocked up in a similar manner.

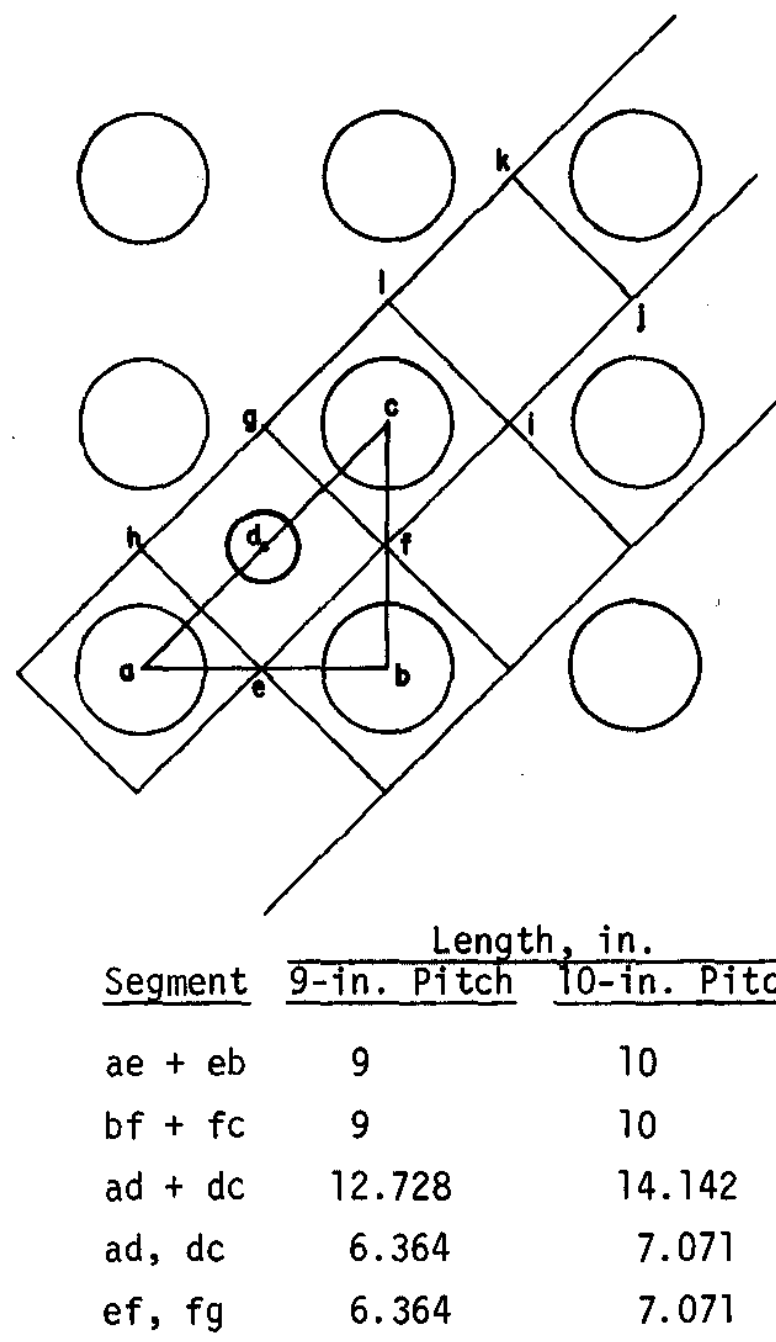

FIG. 11 CELL GEOMETRY FOR HAMMER-PDQ CALCULATIONS 


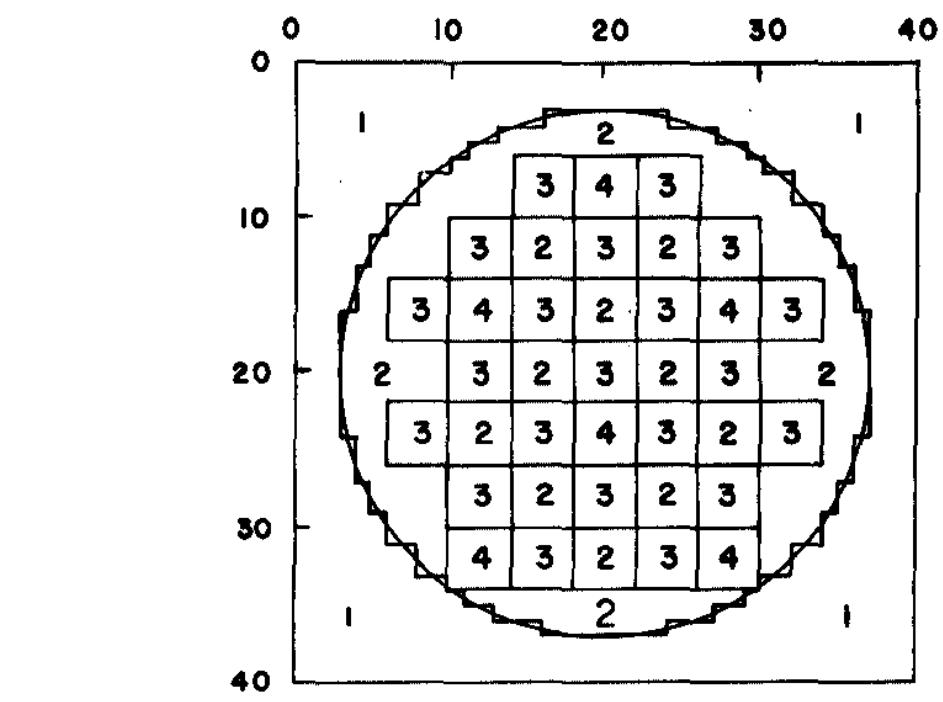

\begin{tabular}{|c|c|c|c|}
\hline Material & Composition & Mesh Interval & $\begin{array}{l}\text { Mesh Spacing, } \\
\text { in. } \\
\end{array}$ \\
\hline 1 & Boundary & $0-3$ & 3.0000 \\
\hline 2 & Moderator & $3-6$ & 1.7505 \\
\hline 3 & Fuel Assembly & $6-34$ & 1.7677 \\
\hline 4 & Control Assembly & $\begin{array}{l}34-37 \\
37-40\end{array}$ & $\begin{array}{l}1.7505 \\
3.0000\end{array}$ \\
\hline
\end{tabular}

FIG. 12 PDQ MOCKUP OF SE

(Fue1-Centered 10-inch Square Lattice Pitch)

Material 1 in Figure 12 represents a void or vacuum boundary. Material 2 is $99.5 \mathrm{~mol} \div \mathrm{D}_{2} \mathrm{O}$ moderator. Materials 3 and 4 are fuel and control positions, respectively.

Normalization to Experiment

In the PDQ calculation, a vacuum boundary condition was applied to the boundary of the SE by making the region surrounding the lattice a rod region. In such a region, the flux is not defined but satisfies the logarithmic derivative condition,

$$
-C_{g}=\frac{D_{g}}{\phi_{g}(R)} \frac{d \phi_{g}(R)}{d R}
$$

on its boundary for each energy group, $g . \quad\left(D_{g}\right.$ and $\phi_{g}$ are the group-dependent diffusion coefficient and fluxes, respectively.) This permits the slope of the flux at the interface between the 
lattice and the boundary to be changed by adjusting. $C_{g}$ until the measured and calculated radial flux shapes are in agreement. The PDQ fluxes were computed using several values of $\mathrm{C}_{\mathrm{g}}$ and were compared with the experimental values to determine the optimum value of $\mathrm{C}_{\mathrm{g}}$. (It was assumed that $\mathrm{C}_{1}=\mathrm{C}_{2}$.) Measured and calculated fluxes are compared in Table 5 for two typical cases. The fluxes calculated using the optimum value of $\mathrm{C}_{\mathrm{g}}$ are those tabulated in Table 5. Appendix $C$ discusses SE radial flux measurements. Because it became obvious early in the analysis of the experiments that the value of $C_{g}$ used varied only slightly with control assembly loading, the same value of $C_{g}$ was used for the analysis of all measurements in which the pitch remained constant.

TABLE 5

Measured and Calculated SE Radial Thermal Flux Shape

10-inch Pitch, Figure 6c, $70 \% \mathrm{H}_{2} \mathrm{O}-30 \% \mathrm{D}_{2} \mathrm{O}$ in Fuel Coolant Channels

\begin{tabular}{|c|c|c|c|c|c|c|}
\hline \multirow{2}{*}{$\begin{array}{c}\text { Radius, } \\
\text { in. }\end{array}$} & \multicolumn{4}{|l|}{ SE } & \multicolumn{2}{|c|}{ Measured/PDQ } \\
\hline & Measured & 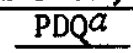 & Measured $b$ & PDQ & & \\
\hline 0 & $0 \pm$ & 7 & $000 \pm .009$ & & 1.009 & 1.012 \\
\hline 10 & 010 & 20 & $356 \pm .011$ & 0 & 1.000 & 0.989 \\
\hline 14 & $40 \pm .011$ & 52 & $0.7192 \pm .011$ & 0 & 8 & 08 \\
\hline 20 & 2 & 3 & 1 & 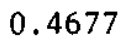 & 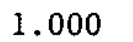 & 7 \\
\hline 22.3 & $.3600 \pm .010$ & .3601 & $0.3719 \pm .010$ & 0.3739 & 1.000 & 0.995 \\
\hline
\end{tabular}

a. No control tubes in control positions.

$b$. Outer control tube (OT) only in control positions $\left(D_{2} O\right.$ coolant in control assembly).

Normalized diffusion parameters for the fuel were then obtained by requiring that the calculated and measured axial bucklings $\left(\kappa^{2}\right)$ agree in each of the two cases in which no control tubes were included in the lattice, i.e., the uniform 9- and 10-inch square pitch loadings. This was accomplished by varying only the values of $\nu \Sigma_{f}$ (for both fast and thermal energy groups in the same proportion) assigned to the fuel assembly cell. The resulting normalized cross sections, together with the other unnormalized diffusion parameters of the fuel cell calculated with HAMMER (D, $\Sigma_{a}$, and $\Sigma_{R}$ ), made up the normalized fuel parameter set, one set for each pitch.

Normalized parameters applicable to the various control assemblies considered were generated in a similar manner. The normalized fuel parameter sets described above and control assembly parameters generated with HAMMER were used to calculate the vertical buckling 
$\left(K^{2}\right)$ of each SE lattice with control assemblies in place. The calculated vertical buckling was then changed by iterating on a single multiplicative factor for both $\sum_{\mathrm{a}}^{\mathrm{fast}}$ and $\Sigma_{\mathrm{a}}^{\mathrm{th}}$ of the control cell until the calculated and measured vertical bucklings agreed. The normalized values of the absorption cross sections (product of HAMMER $\Sigma_{a}$ 's and multiplicative factor) together with the unnormalized values of $D$ and $\Sigma_{R}$ then made up the normalized set of diffusion parameters for the control assembly. This method was applied to each control assembly loading considered.

The purpose of the analysis scheme was to obtain sets of normalized, few-group diffusion parameters for the fuel cell and each of the control cells considered. The parameters were then used to calculate the bucklings and control assembly worths using the PDQ code. A larger PDQ lattice, shown in Figure 13, was used for these calculations. The lattice consisted of a uniform arrangement of fuel-control assembly supercells in which each supercell contained one control as sembly and four adjacent fuel assemblies. This is the same control-to-fuel assembly ratio as is to be used in the proposed Japanese power reactor, the ATR. The logarithmic derivative boundary condition was again applied at the boundary of the lattice. In this case, $\mathrm{C}_{\mathrm{g}}$ was set equal to zero for each of the two energy groups to flatten the radial flux shape and force the effective radial buckling of the lattice to zero. This zero current boundary condition eliminated the radial flux shape correction which would normally be made to the control assembly worths if zero-flux boundary conditions had been used.

The normalized parameter sets for the control and fuel assemblies were used as input, and the input buckling, $\mathrm{B}_{V}^{2}$, was allowed to vary until the calculated keff was unity. Because the radial buckling for each case was zero, the material buckling of each lattice considered was then equivalent to the input vertical buckling when $k_{\text {eff }}=1.0$. The control assembly worths were simply the difference between bucklings with and without control assemblies in place. The worths, in terms of $k_{\infty}$, were simply the differences between the $k_{\infty}$ of each lattice as calculated with PDQ. 

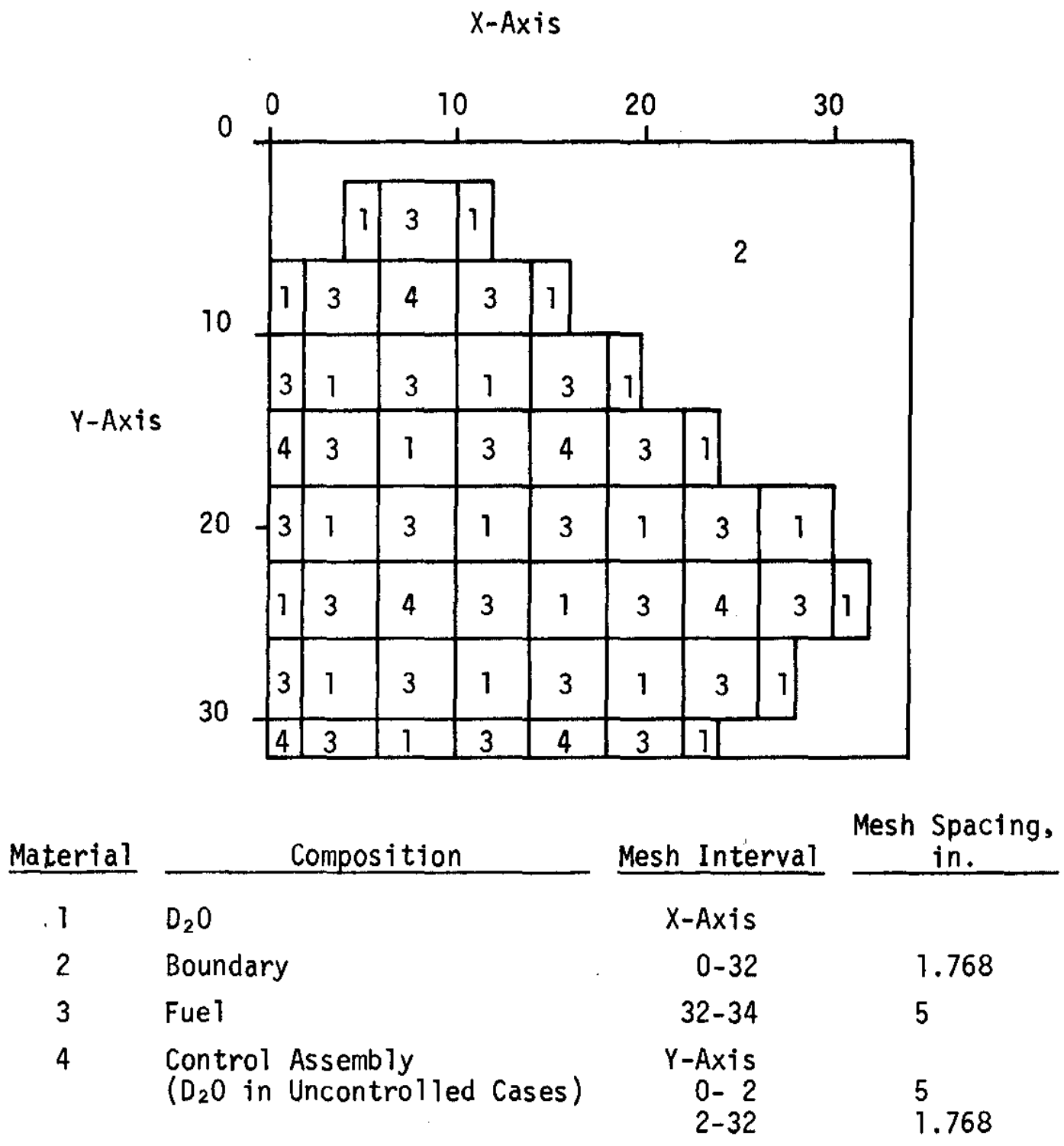

FIG. 13 PDQ MOCKUP OF INFINITE LATTICE (10-inch Square Lattice Pitch) 


\section{Results of Measurements}

A summary of the results of SE buckling and control tube worth measurements is given in Table 4. From analysis of the results, it is apparent that the worths of individual tubes or combinations of tubes are determined by the diameter of the outermost control tube. This nearly linear relationship between the tube worth and diameter can be seen in Figure 14, where the data are presented for two lattice pitches with $70 \% \mathrm{H}_{2} \mathrm{O}-30 \% \mathrm{D}_{2} \mathrm{O}$ in fuel coolant channels and $\mathrm{D}_{2} \mathrm{O}$ in control tube coolant channels.

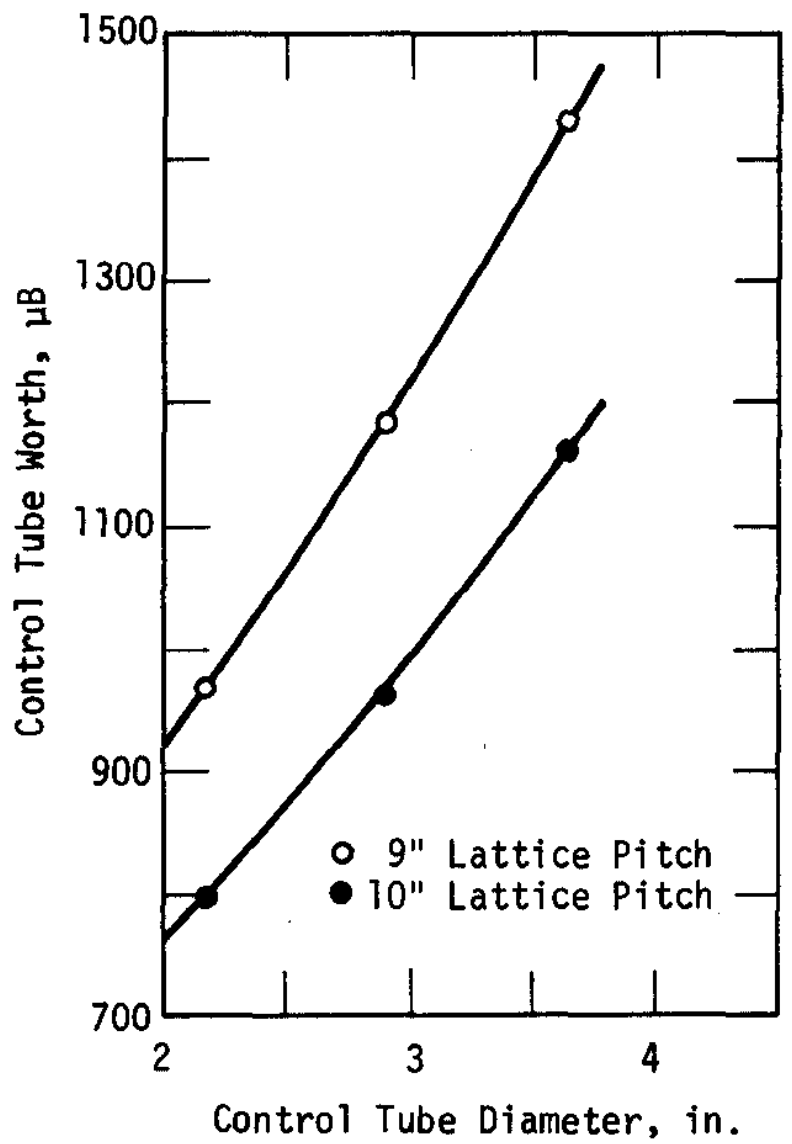

FIG. 14 DEPENDENCE OF CONTROL TUBE WORTH ON TUBE DIAMETER (Single Control Tube) 
The Japanese, who plan to cool the control tubes with light water, requested that measurements be made to determine the tube worth with $\mathrm{H}_{2} \mathrm{O}$ in the coolant channels. The results of these measurements are also given in Table 4. A comparison of the results of Run 21 with Run 37 and of Run 32 with Run 38 in Table 4 indicates that the presence of the $\mathrm{H}_{2} \mathrm{O}$ in the control assembly decreases the cylinder worths to $290 \%$ of the values with $\mathrm{D}_{2} \mathrm{O}$ in the coolant channels.

Control assembly worths decreased when $\mathrm{H}_{2} \mathrm{O}$ or the $70 \% \mathrm{H}_{2} \mathrm{O}$ $30 \% \mathrm{D}_{2} \mathrm{O}$ mixture replaced $\mathrm{D}_{2} \mathrm{O}$ in the fuel coolant channels for cases with the control assembly coolant channels filled with $\mathrm{D}_{2} \mathrm{O}$ (Figure 15).

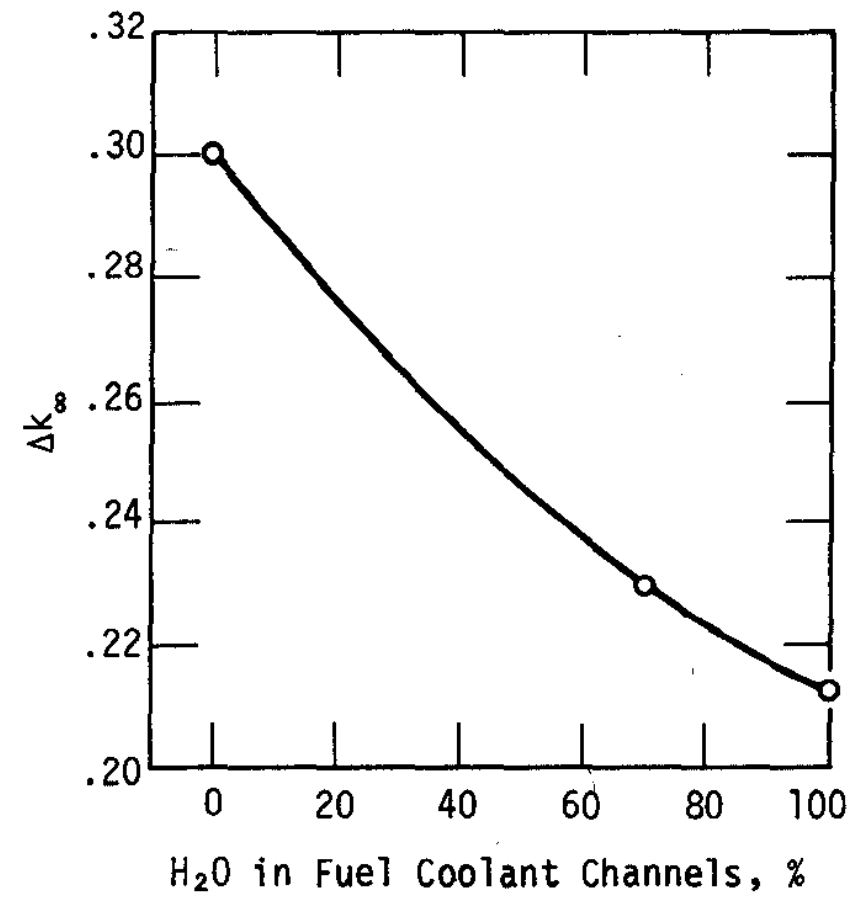

FIG. 15 DEPENDENCE OF THREE-TUBE WORTH ON FUEL COOLANT CHANNEL $\mathrm{H}_{2} \mathrm{O}$ CONTENT

The worth of $\mathrm{D}_{2} \mathrm{O}$-filled iron pipe with an outside diameter of 4 inches and a wall thickness of 0.226 inch was determined to be $11 \% \mathrm{k}_{\infty}$ (Run 25, Table 4). This measurement was made so that the Japanese could evaluate their calculational techniques for control assemblies weaker than the $\mathrm{B}_{4} \mathrm{C}$-filled cylinders. Run 26 (Table 4) was a measurement designed to determine the material buckling when $1 / 4$ of the fuel assemblies are removed from lattice without control assemblies. Fue1 was removed from position $1,10,11,12,13,14$, 15, 16, and 17 in Figure $6 a$ for the $\kappa^{2}$ measurement. 
The worth of control tubes measured in a fuel-centered lattice (Figure 6a) was about $1 \%$ less than was measured in a control-assembly-centered lattice (Figure 6c). This slight discrepancy was judged to be within the accuracy of the measurements. For this reason most of the measurements were made in the fuelcentered lattice because this facilitated the detailed cell measurements to be discussed later.

The relative worth of the individual control tubes was measured in a different lattice in the PDP using substitution techniques. The results of the experiment are summarized in Tables 6 and 7 . Details of the measurements and a description of the PDP facility are given in Appendix A.

TABLE 6

Relative Worths of Japanese Control Tubes

$\begin{array}{cc}\text { Tube Inserted } & \frac{\Delta B^{2}, \mu B}{} \\ \text { Outer } & 50 \\ \text { Middle } & 42 \\ \text { Inner } & 38\end{array}$

TABLE 7

PDQ Flat Flux Calculations

\begin{tabular}{|c|c|c|}
\hline & $\Delta \mathrm{k}$ & $\Delta B^{2}, \mu B$ \\
\hline Control positions vacant (base) & 0 & 0 \\
\hline Inner tube & 0.129 & 864 \\
\hline Middle tube & 0.149 & 1000 \\
\hline Outer tube & 0.197 & 1320 \\
\hline
\end{tabular}

Differences between measured and computed bucklings are presented in Figure 16 for the lattices with no control tubes present. A systematic increase of the quantity ( $\left.B_{\text {expt }}^{2}-B_{\text {HAMMER }}^{2}\right)$ with the amount of $\mathrm{H}_{2} \mathrm{O}$ present in the coolant channels was observed. The HAMMER calculated buckling was $56 \mu \mathrm{B}$ lower than that measured for the $\mathrm{D}_{2} \mathrm{O}$ case at a 9 -inch square lattice pitch. With $\mathrm{H}_{2} \mathrm{O}$ coolant, the HAMMER value was $223 \mu \mathrm{B}$ lower than the measured value. The HAMMER bucklings were in better agreement with experiment by $40 \mu \mathrm{B}$ at the 10 -inch pitch than at the 9 -inch pitch for fuel with $70 \% \mathrm{H}_{2} \mathrm{O}-30 \% \mathrm{D}_{2} \mathrm{O}$ in the coolant channels. This systematic difference between the measured and calculated bucklings is due in part to the difficulty in representing the rod cluster fuel assembly in annular geometry. This discrepancy has not been fully resolved. Systematic experimental errors may arise in the buckling measurements for the deeply poisoned lattices. This effect is discussed in more detail in Appendix D. 


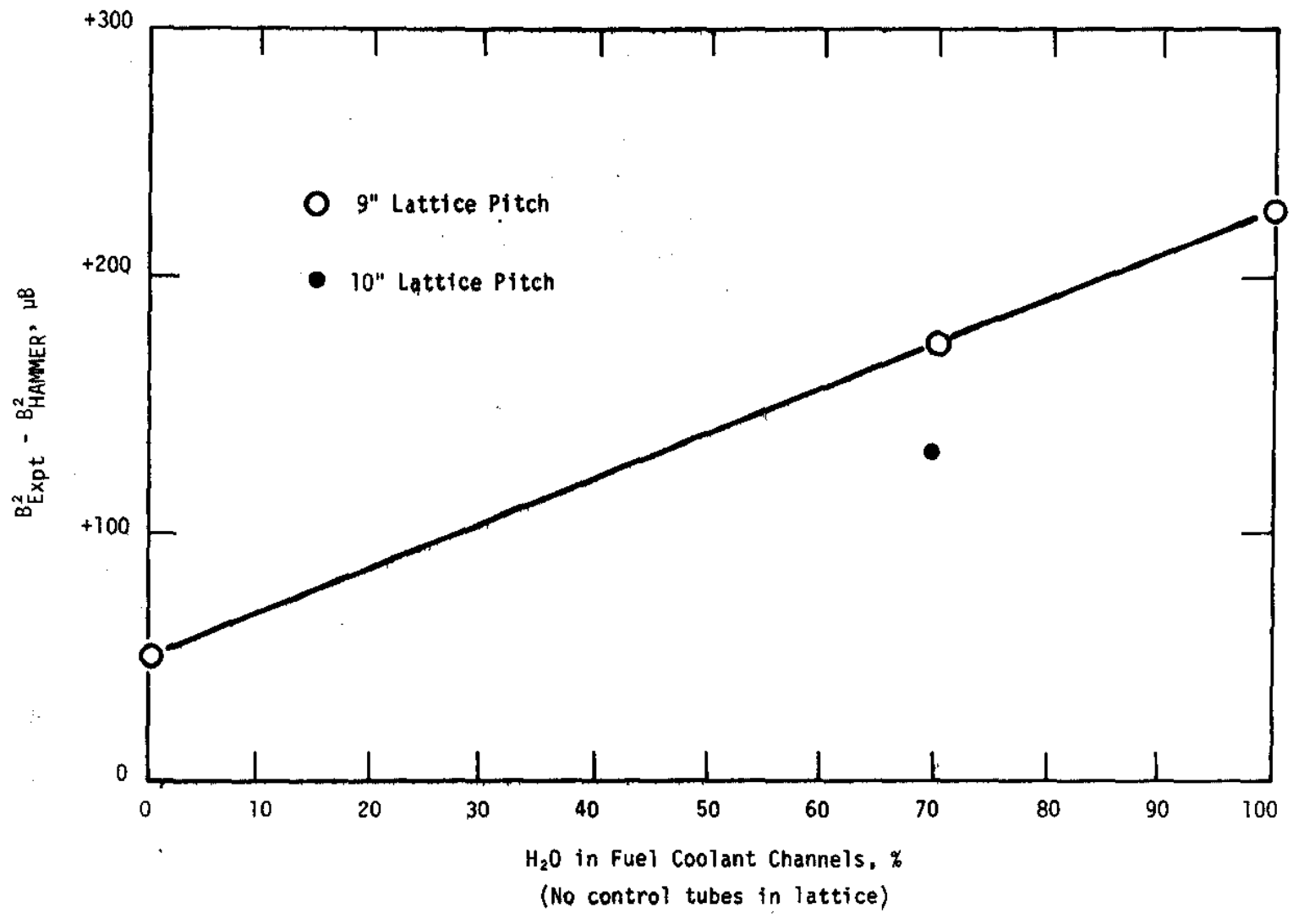

FIG. 16 COMPARISON OF MEASURED AND CALCULATED BUCKLINGS

(A11 Bucklings Computed for $99.50 \mathrm{~mol} \% \mathrm{D}_{2} \mathrm{O}$ ) 


\section{FLUX RATIO MEASUREMENTS}

Copper wires taped to the outer housing of fuel assemblies and the outer surface of control assemblies were irradiated, coiled, and counted to provide data useful to the Japanese in evaluating their calculational techniques as applied to fuel assembly-control assembly interaction. This method of determining average neutron densities at fuel or target surfaces has been employed in the past at SRL with success. A summary of the results of these measurements is given in Table 8 . Wire locations and lattice patterns are given in Figure 6.

TABLE 8

Measured Control Assembly: Full Assembly Activation Ratios

\begin{tabular}{|c|c|c|c|c|c|c|c|}
\hline$\underline{\text { Run }}$ & Lattice & $\begin{array}{c}\text { Contro } 1 \\
\text { Tube }\end{array}$ & $\begin{array}{l}\frac{\text { Wire Lor }}{\text { Fuel }} \\
\text { Assembly }\end{array}$ & $\begin{array}{l}\text { ation }{ }^{\alpha} \\
\text { Control } \\
\text { Assembly }\end{array}$ & $\begin{array}{c}\text { Specific Act } \\
\text { Fuel Assembly } \\
\text { (Average) }\end{array}$ & $\begin{array}{l}\frac{\text { vity, } \mathrm{C} / \mathrm{M}}{\text { Control }} \\
\text { Assembly } \\
\end{array}$ & $\begin{array}{c}\text { Average Activity } \\
\text { Ratio } \\
\text { (Control/Fuel) } \\
\end{array}$ \\
\hline 5,6 & $9-C$ & $\mathrm{OT}+\mathrm{MT}+\mathrm{IT}$ & $\begin{array}{l}3,4,9,10 \\
1,2,11,12\end{array}$ & $\begin{array}{l}X \\
Y\end{array}$ & $\begin{array}{r}15820 \pm 228 \\
8840 \pm 329\end{array}$ & $\begin{array}{l}5980 \pm 29 \\
3250 \pm 64\end{array}$ & $\begin{array}{l}0.378 \pm .006 \\
0.368 \pm .015\end{array}$ \\
\hline 35 & $9-\mathrm{A}$ & $\mathrm{OT}+\mathrm{MT}+\mathrm{IT}$ & $\begin{array}{l}1,2,5,9 \\
4,8,12,23 \\
3,6,11,22\end{array}$ & $\begin{array}{l}X \\
y \\
Z\end{array}$ & $\begin{array}{l}45610 \pm 1086 \\
34370 \pm 1358 \\
40760 \pm 1610\end{array}$ & $\begin{array}{l}14630 \pm 129 \\
10770 \pm 164 \\
12920 \pm 196\end{array}$ & $\begin{array}{l}0.321 \pm .008 \\
0.313 \pm .012 \\
0.317 \pm .013\end{array}$ \\
\hline 33 & $9-\mathrm{A}$ & OT & $\begin{array}{l}1,2,5,9 \\
4,8,12,23 \\
3,6,11,22\end{array}$ & $\begin{array}{l}X \\
Y \\
Z\end{array}$ & $\begin{array}{l}14150 \pm 313 \\
10670 \pm 389 \\
12660 \pm 462\end{array}$ & $\begin{array}{l}4670 \pm 41 \\
3450 \pm 52 \\
4090 \pm 62\end{array}$ & $\begin{array}{l}0.330 \pm .008 \\
0.323 \pm .013 \\
0.323 \pm .013\end{array}$ \\
\hline 28,29 & $9-\mathrm{A}$ & Fe Pipe & $\begin{array}{l}1,2,5,9 \\
4,8,12,23\end{array}$ & $\begin{array}{l}X \\
Y\end{array}$ & $\begin{array}{l}41580 \pm 919 \\
31360 \pm 1145\end{array}$ & $\begin{array}{l}33810 \pm 298 \\
25420 \pm 386\end{array}$ & $\begin{array}{l}0.813 \pm .019 \\
0.811 \pm .032\end{array}$ \\
\hline 39 & $10-A$ & OT & $\begin{array}{l}1,2,5,9 \\
4,8,12,19 \\
3,6,11,16\end{array}$ & $\begin{array}{l}X \\
Y \\
Z\end{array}$ & $\begin{array}{l}26460 \pm 712 \\
17661 \pm 761 \\
18170 \pm 783\end{array}$ & $\begin{array}{l}8770 \pm 100 \\
5900 \pm 109 \\
6140 \pm 113\end{array}$ & $\begin{array}{l}0.331 \pm .010 \\
0.334 \pm .016 \\
0.338 \pm .016\end{array}$ \\
\hline 46 & $10-\mathrm{A}$ & $\mathrm{OT}+\mathrm{MT}+\mathrm{IT}$ & $\begin{array}{l}1,2,5,9 \\
4,8,12,19 \\
3,6,11,16\end{array}$ & $\begin{array}{l}X \\
Y \\
Z\end{array}$ & $\begin{array}{l}29140 \pm 784 \\
20150 \pm 868 \\
23811 \pm 1026\end{array}$ & $\begin{array}{l}9350 \pm 107 \\
6400 \pm 118 \\
7601 \pm 140\end{array}$ & $\begin{array}{l}0.321 \pm .009 \\
0.318 \pm .015 \\
0.319 \pm .015\end{array}$ \\
\hline
\end{tabular}

$\overline{a \text {. See Figure } 6}$ for lattice patterns

\section{EXTENSION OF RESULTS TO THE ATR}

The control tube worths reported in Table 4 were measured using a mockup of the Japanese fuel. This section of the report gives the results of calculations that extend the results of the SE measurements to the ATR through the use of HAMMER-calculated parameters normalized to the SE experiments. 
The ATR rrototype was assumed to contain 276 fuel assemblies arranged on a $22.5-\mathrm{cm}$ square lattice pitch. Control tubes will be in interstitial positions on a $45-\mathrm{cm}$ square pitch. The effective core diameter will be $422 \mathrm{~cm}$ with a $60-\mathrm{cm}$-thick $\mathrm{D}_{2} \mathrm{O}$ reflector. The tank ID will be $542 \mathrm{~cm}$. The fuel will consist of a $28 \mathrm{rod}$ cluster containing $\mathrm{WO}_{2}$ enriched to $1.5 \mathrm{wt} \%{ }^{235} \mathrm{U}$ and arranged on a $1.88-\mathrm{cm}$ internal square pitch. The pressure tube will be a zirconium-niobium alloy with a 4.9764-inch OD and a 4.6378-inch ID. The OD and ID of a Zircaloy-2 calandria tube will be 5.5276 and 5.370 inches, respectively.

A representation of the concentric ring model of the fue 1 assembly used in the HAMMER computations is given in Figure 17. Parameters were calculated with $70 \%$ density $\mathrm{H}_{2} \mathrm{O}$ in the fuel coolant channels at a 6.264-inch square lattice pitch. Parameters for a fully loaded control assembly were calculated in the manner described previously for the SE mockup fuel at a 6.264-inch pitch. The control assembly (three tubes) employed in the SE measurements was used as the control assembly in the ATR calculation. HAMMER calculations were made for the control cell on the 6.264-inch pitch, and the calculated $\Sigma_{a}$ 's, after normalization, were used as input to the PDQ-ATR mockup. Normalization of these absorption cross sections was based on similar normalizations discussed previously. In the SE measurements, the adjustment of the absorption cross section necessitated a reduction of the HAMMER $\Sigma_{a}$ 's by about $10 \%$ for a case similar to the ATR. This same fraction was used to reduce the ATR control assembly $\Sigma_{a}$ 's. The coolant channels of the control assembly contained $\mathrm{D}_{2} \mathrm{O}$ in this computation.

A $90^{\circ}$ sector of the PDQ mockup of the ATR is presented in Figure 18. Region 4 is a boundary region in which the neutron flux is undefined. The keff's of the lattice with no control assemblies and with control assemblies inserted were calculated. In each of these two cases, the input buckling (to account for vertical leakage) was held constant $(72 \mu \mathrm{B}$ for an effective reactor height of $370 \mathrm{~cm}$ ). The worth of the three tube control assemblies was simply the difference between the keff's of the two lattices or $217 \% \mathrm{keff}$. 


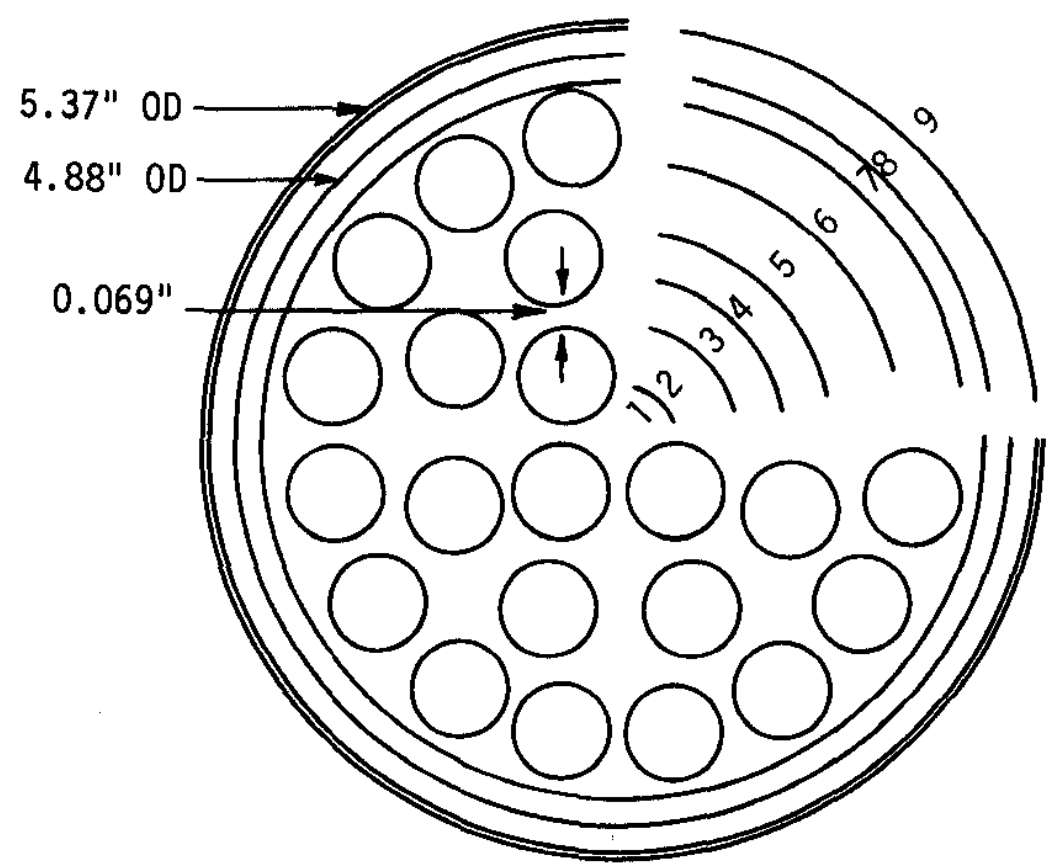

\begin{tabular}{|c|c|c|}
\hline Region & Material & $O D$, in. \\
\hline 1 & Zircaloy-2 $+70 \%$ Density $\mathrm{H}_{2} \mathrm{O}$ & 0.5990 \\
\hline 2 & $\mathrm{UO}_{2}$ & 1.3102 \\
\hline 3 & Same as Region 1 & 2.0342 \\
\hline 4 & $\mathrm{UO}_{2}$ & 2.6180 \\
\hline 5 & Same as Region 1 & 3.4155 \\
\hline 6 & $\mathrm{UO}_{2}$ & 4.1539 \\
\hline 7 & Same as Region 1 & 4.6378 \\
\hline 8 & Zircaloy-2 & 5.5275 \\
\hline 9 & $\mathrm{D}_{2} \mathrm{O}$ & 6.264 \\
\hline
\end{tabular}

FIG. 17 SRL CONCENTRIC RING MODEL FOR HAMMER COMPUTATIONS (Japanese ATR Fuel) 

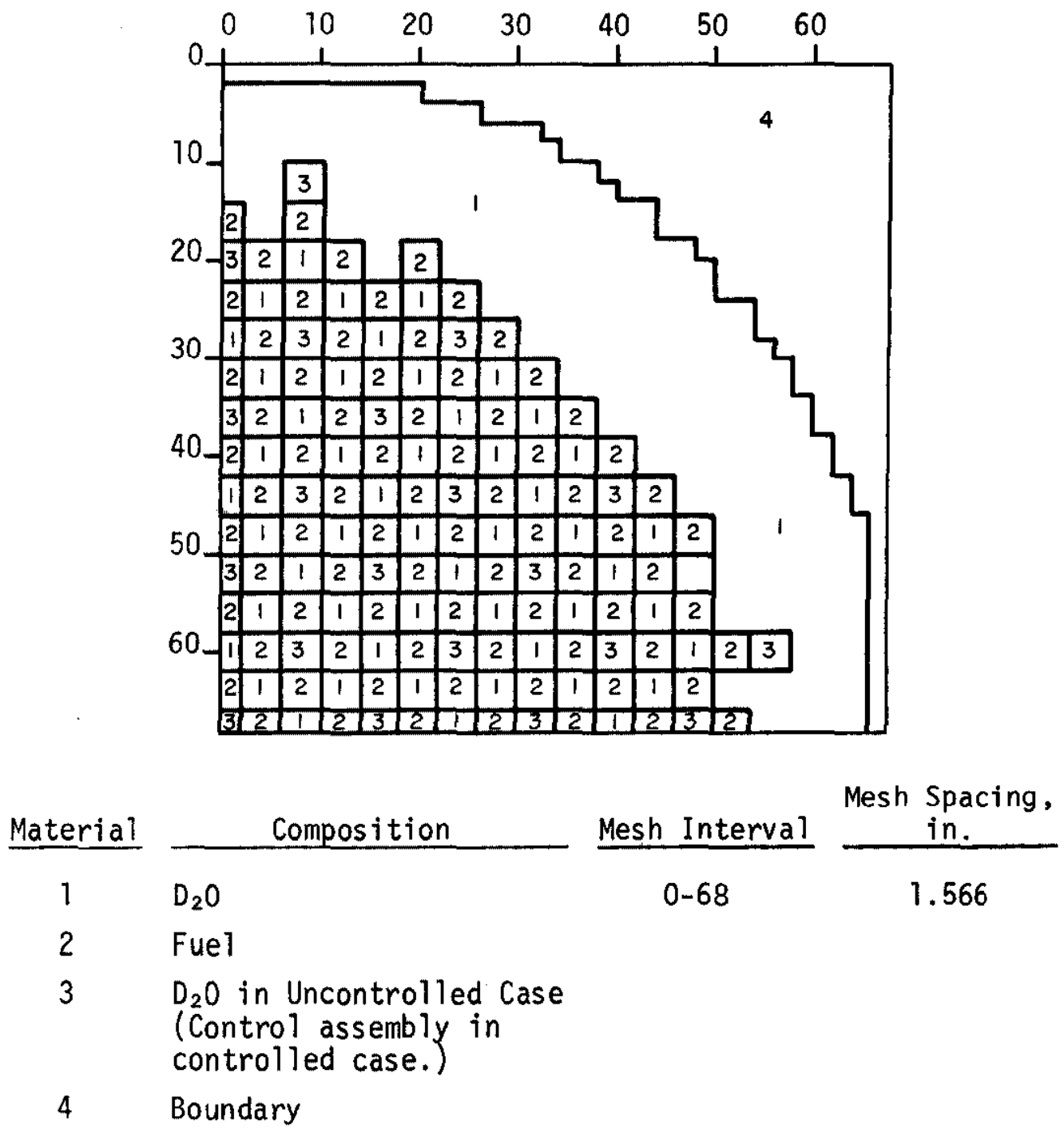

FIG. 18 PDQ MOCKUP OF ATR 


\section{ACTIVATION EXPERIMENTS}

Five foil activation experiments were completed in the SE to measure the detailed neutron reaction rates in the mockup ATR lattices. The lattice conditions for the experiments are summarized in Runs $12,17,36,47$, and 50 (Table 3). The moderator and coolant temperatures were $24^{\circ} \mathrm{C}$ for these experiments.

The SE lattice arrangement corresponding to each of the activation experiments is shown in Figure 19. Various numbers of 5 wt $\% 235 \mathrm{U}-\mathrm{Al}$ fuel rods were included in the lattices to increase the neutron flux at the foil irradiation assembly. This was done because previous experience indicated that low counting rates occur with low reactivity lattices (i.e., less than $5.00 \mathrm{~m}^{-2}$ ) in the SE. The "flux booster" fuel rod was composed of six, 12-inch 1ong x 1.00-inch-diameter fuel pieces contained in a 77-inch-1ong aluminum tube with a 1.035-inch ID and a 1.090-inch OD.

No adverse effect on reaction rate measurements occurs from the use of flux booster fuel rods provided the neutron spectrum within the cell containing the foil detectors remains unchanged. Cadmium ratio measurements were made using gold, ${ }^{235} \mathrm{U}$, and tungsten foil detectors located in the moderator (at the cell boundary of the center cell) and on the surface of the central fuel assembly for the case of 24 added flux booster fuel rods in the geometry shown in Figure 19a. The results of these measurements are summarized in Table 9 . No appreciable spectrum distortion is observed from the cadmium ratio results. The flux level at the central cell was increased by a factor of approximately five. The number and location of flux booster rods were altered for each lattice measured as shown in Figure 19. The number was varied to compensate for differences in lattice reactivity. The location was dictated by the arrangement of the SE grid beam support mechanism and the desire to place the flux booster rods at the same radius as for the case checked.

Six special irradiation rods containing foils were included with normal $\mathrm{UO}_{2}$ fuel rods in the irradiation assembly. The rods were placed within the 31-rod fuel cluster to represent each of the various radii as shown in Figure 20. (Two foil rods were used to represent the twelve rods in the outer fuel ring.) The foil irradiation rods consisted of three sections of tubing with removable end fittings (Figure 21). The sections were fastened together to form a full-length rod, and the foils were placed in the middle rod section between individual fuel pellets that had been ground and polished to smooth faces with square edges. 


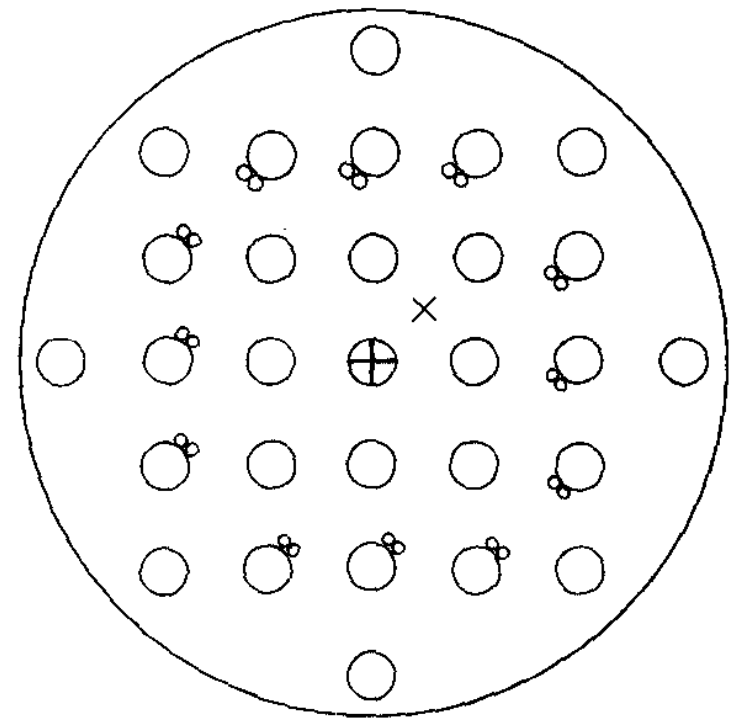

a. Run 12

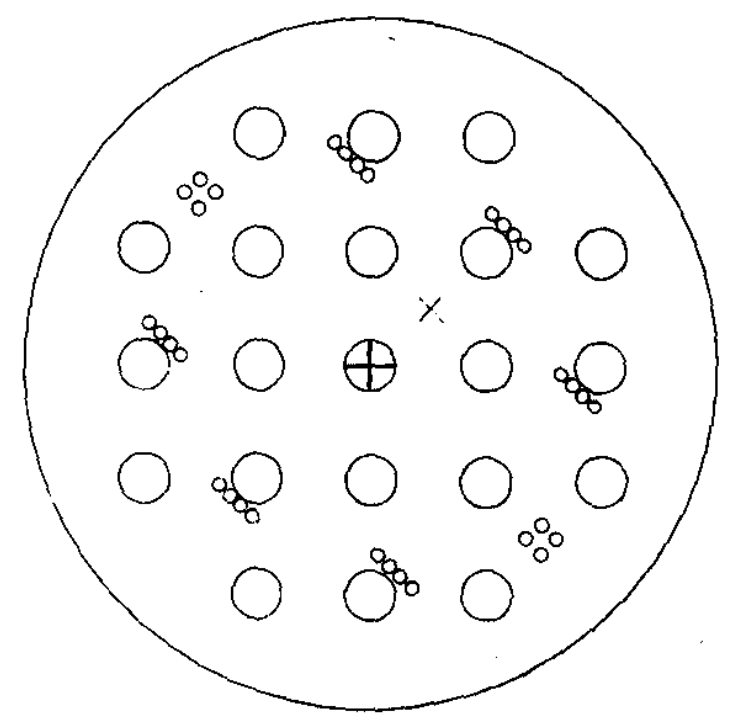

c. Run 47

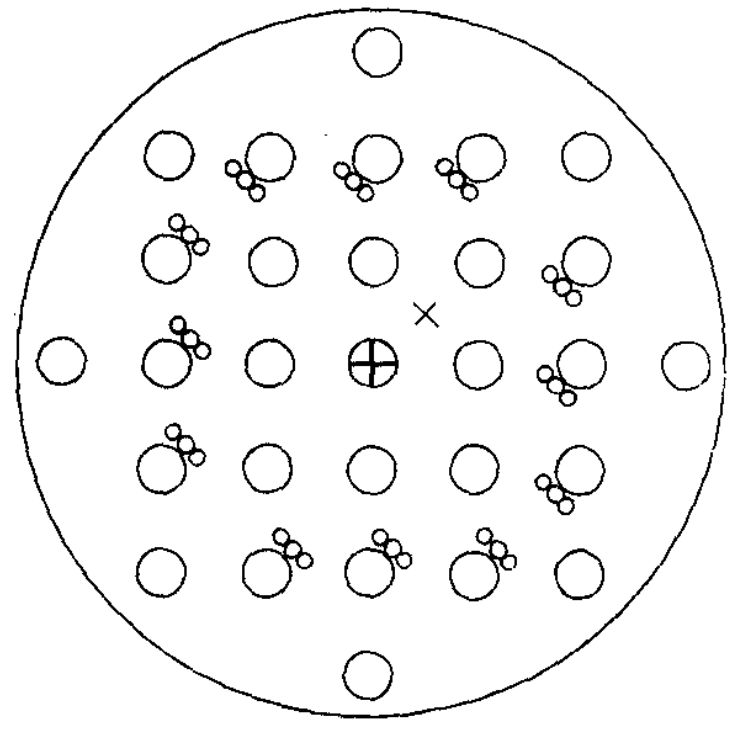

b. Runs 17 and 36

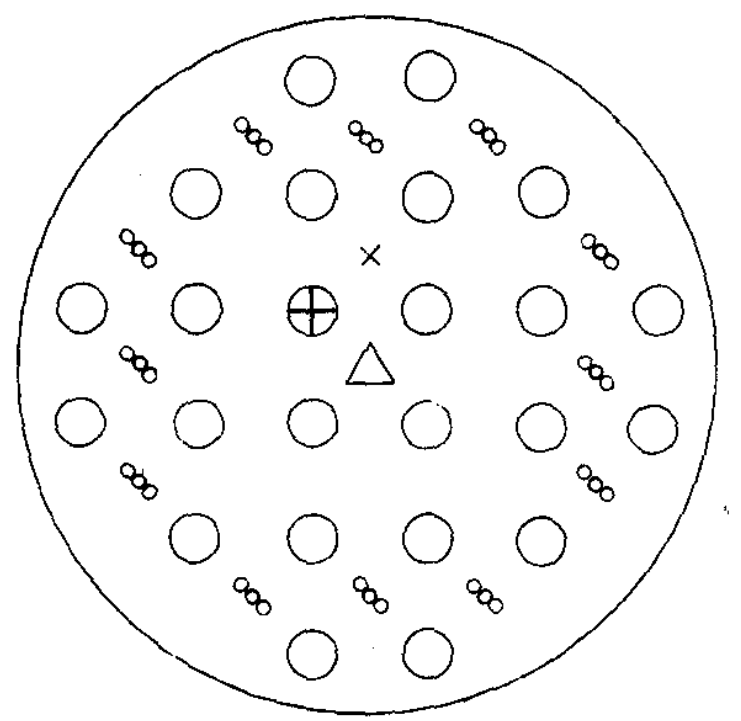

d. Run 50

Natural $\mathrm{UO}_{2}$ 31-Rod Fuel Cluster

( Foil Irradiation Fuel cluster

O ${ }^{235} U$-Al Fuel Rod

$X$ Interstitial Foil Holder

$\triangle$ Outer Control Tube

FIG. 19 SE LATTICE ARRANGEMENTS FOR ACTIVATION EXPERIMENTS 


\section{TABLE 9}

Cadmi um Ratios With and Without Flux Booster Rods

Average Cadmium Ratios

Detector Cel1 Boundary in Moderator Surface of Irradiation Assembly

Foil With Spikes Without Spikes With Spikes Without Spikes

$\begin{array}{ccccc}\mathrm{W} & 4.31 & 4.38 & 3.73 & 3.72 \\ 235 \mathrm{U}-\mathrm{Al} & 40.3 & 40.8 & 31.9 & 31.6 \\ \mathrm{Au} & 9.34 & 9.47 & 7.45 & 7.51\end{array}$

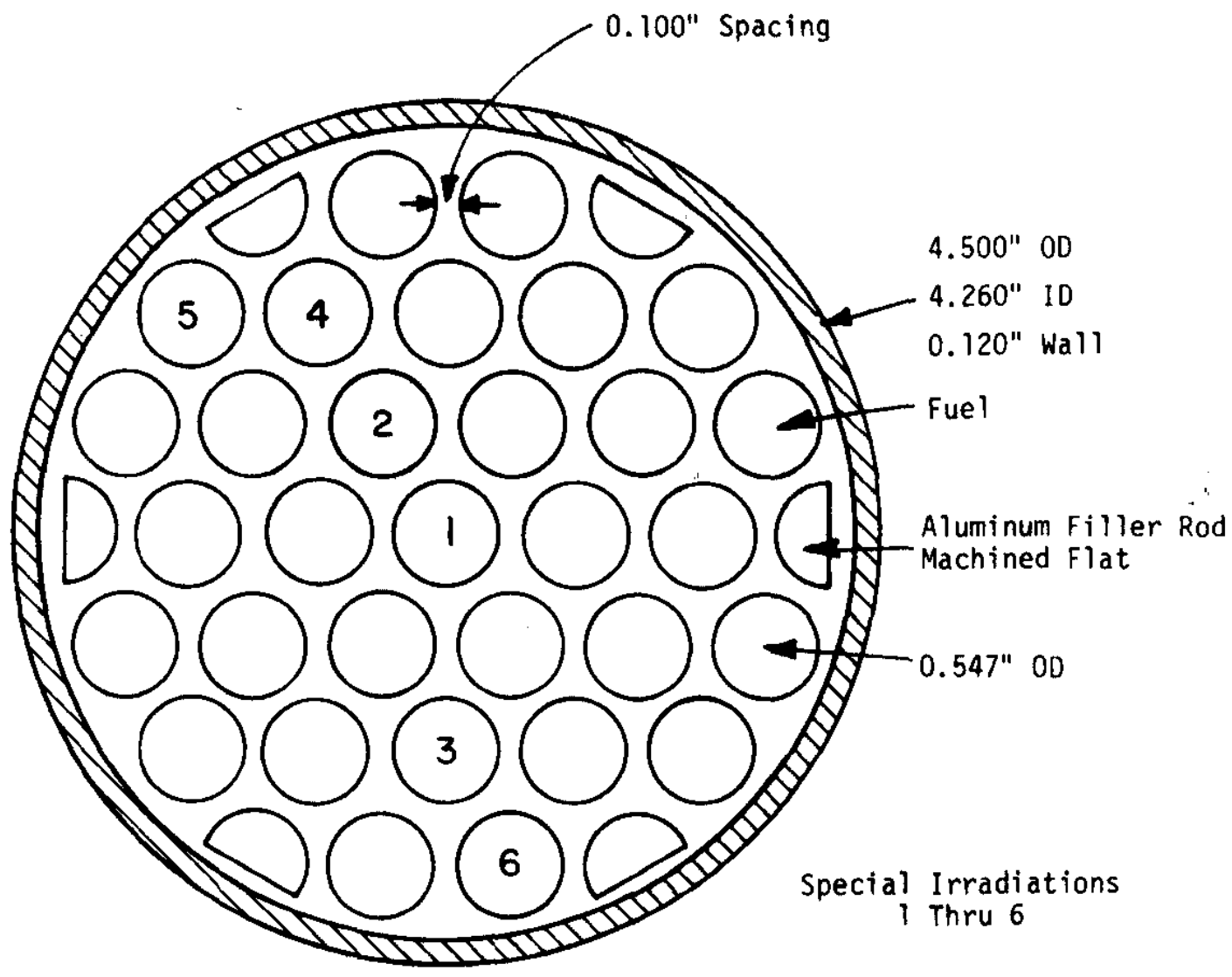

FIG. 20 NATURAL UO 2 ROD CLUSTER 


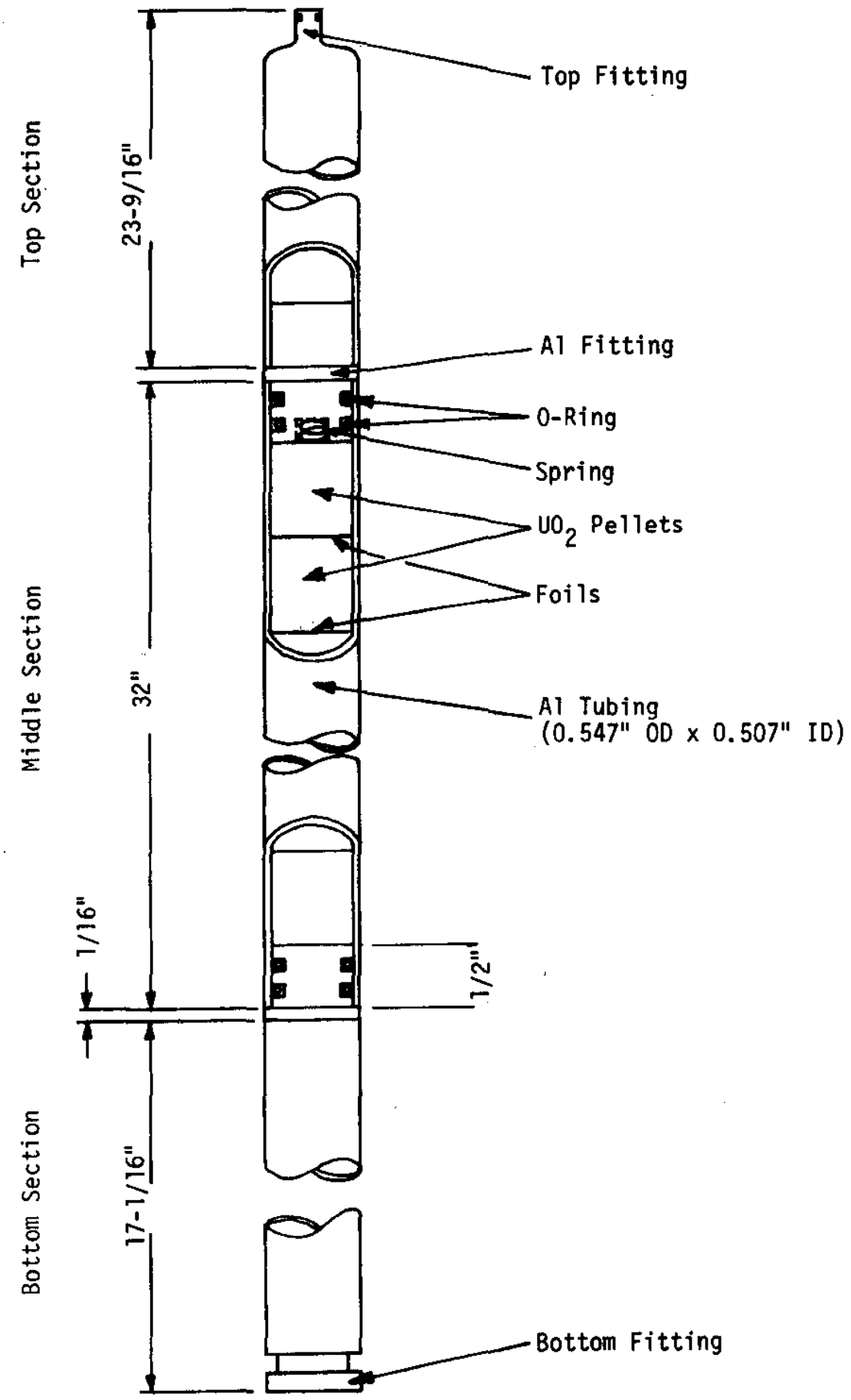

FIG. 21 FOIL IRRADIATION ROD 
0 -rings were used to seal the rods, and a spring was used in the middle rod section to maintain a compact assembly. The irradiation assembly was placed in the center of the SE for all of the experiments except the control rod case shown in Figure 19d. For this experiment, the irradiation assembly was rotated at $1 \mathrm{rpm}$ on its axis during the irradiation to average the flux gradient and asymmetry.

Individual foils were loaded into the middle section of the special irradiation rods as indicated in Figure 22. Epicadmium activations were obtained from foils in cadmium "boxes" consisting of 1/2-inch-diameter $\times 0.032$-inch-thick end pieces with six turns of a 0.005 -inch-thick by $1 / 2$-inch-wide cadmium foil wrapped on the outside surface of the aluminum tubing. A discussion of thermal neutron leakage and effective cadmium cutoff energy for this geometry is given in Appendix B. Foil interval distances were matched for each rod and are summarized in Table 10. The elevations in the different rods were closely matched so that an average elevation, obtained for each foil type, was used for elevation corrections. The elevation corrections for each experiment were obtained by a least squares fit of the function $A=B e^{C Z}-D e^{-C Z}$ where $Z$ is the distance from the top of the housing tube in inches, $A$ is the foil activity, and $B, D$, and $C$ are constants to be fit. The activity data used for the fit were the averages of the six bare copper foil activities at each of the seven elevations containing bare copper foils (Table 10) within the irradiation assembly. The foil elevation corrections derived from the analytic fits are summarized in Table 11.

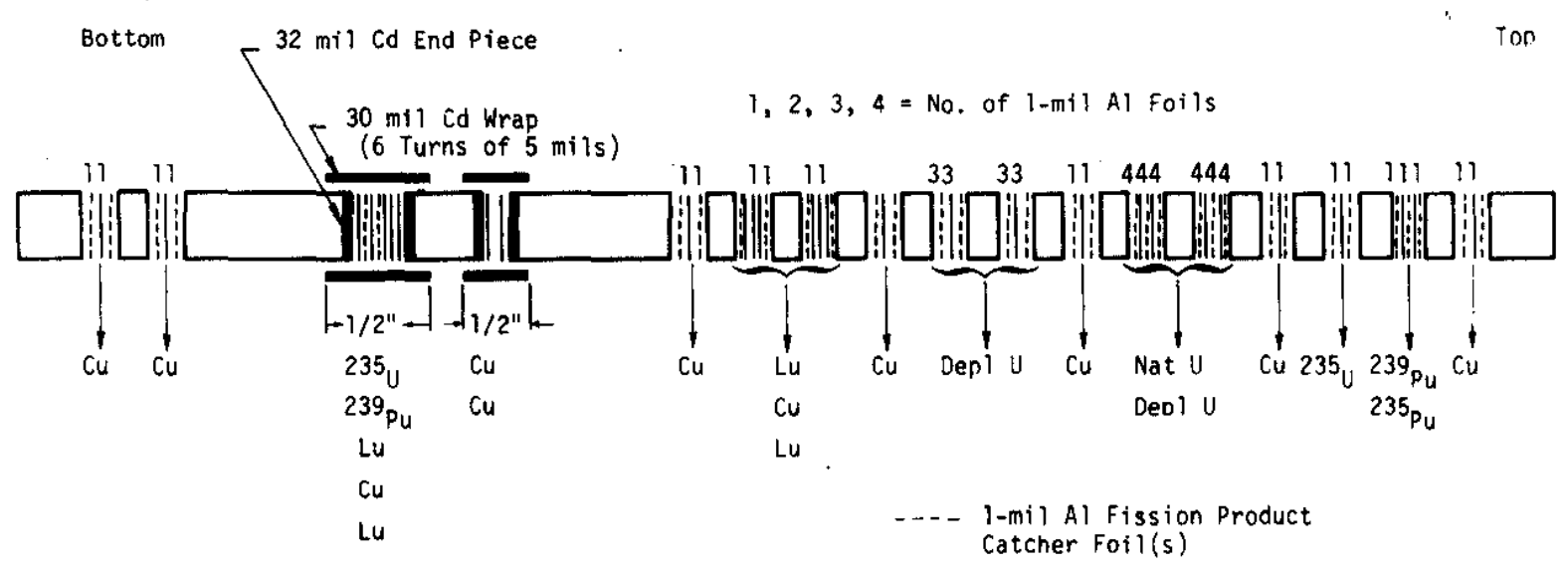

FIG. 22 SCHEMATIC OF FOIL LOADING IN MIDDLE ROD SECTION 
TABLE 10

Fuel Pellet Interval Distances and Average Foll Elevations

\begin{tabular}{|c|c|c|c|c|c|c|c|c|c|}
\hline Foi 1 & $\begin{array}{c}\text { Fue1 } \\
\text { Rod } \\
1 \\
\end{array}$ & $\begin{array}{c}\text { Pellet } \\
\text { Rod } \\
2 \\
\end{array}$ & $\begin{array}{c}\text { Interv } \\
\text { Rod } \\
3 \\
\end{array}$ & $\begin{array}{c}\text { al Dist } \\
\text { Rod } \\
4 \\
\end{array}$ & $\begin{array}{c}\text { nces, } \\
\text { Rod } \\
5 \\
\end{array}$ & $\begin{array}{c}\text { in. } \\
\text { Rod } \\
6 \\
\end{array}$ & Avg & $\begin{array}{c}\text { Foil Packet } \\
\text { Thickness, } \\
\text { in. }\end{array}$ & $\begin{array}{c}\text { Foil } \\
\text { Elevation } \\
\text { in. }\end{array}$ \\
\hline Bottom & 0 & 0 & 0 & 0 & 0 & 0 & 0 & & \\
\hline $\mathrm{Cu}$ & 2.022 & 2.024 & 2.023 & 2.022 & 2.026 & 2.019 & 2.023 & 0.013 & 56.221 \\
\hline $\mathrm{Cu}$ & 0.778 & 0.782 & 0.788 & 0.790 & 0.774 & 0.793 & 0.784 & 0.013 & 55.424 \\
\hline $\begin{array}{ll}\text { Cd } & \text { Lu-Cu-Lu } \\
2{ }^{39} \mathrm{Pu}-235 \mathrm{U}\end{array}$ & 5.710 & 5.705 & 5.704 & 5.701 & 5.701 & 5.706 & 5.705 & 0.138 & 49.643 \\
\hline $\mathrm{Cd} \quad \mathrm{Cu}-\mathrm{Cu}$ & 0.757 & 0.753 & 0.757 & 0.744 & 0.738 & 0.755 & 0.751 & 0.086 & 48.780 \\
\hline $\mathrm{Cu}$ & 5.706 & 5.708 & 5.702 & 5.697 & 5.706 & 5.696 & 5.703 & 0.013 & 43.028 \\
\hline $\mathrm{Lu}-\mathrm{Cu}-\mathrm{Lu}$ & 1.312 & 1.309 & 1.305 & 1.300 & 1.306 & 1.305 & 1.306 & 0.055 & 41.687 \\
\hline $\mathrm{Lu}-\mathrm{Cu}-\mathrm{Lu}$ & 1.213 & 1.211 & 1.211 & 1.214 & 1.214 & 1.222 & 1.214 & 0.055 & 40.419 \\
\hline $\mathrm{Cu}$ & 1.174 & 1.170 & 1.173 & 1.170 & 1.168 & 1.170 & 1.171 & 0.013 & 39.215 \\
\hline Dep 1 U & 1.094 & 1.102 & 1.098 & 1.101 & 1.101 & 1.103 & 1.100 & 0.013 & 38.102 \\
\hline Depl U & 1.095 & 1.096 & 1.093 & 1.100 & 1.097 & 1.096 & 1.096 & 0.013 & 36.993 \\
\hline $\mathrm{Cu}$ & 1.180 & 1.189 & 1.194 & 1.191 & 1.191 & 1.198 & 1.191 & 0.013 & 35.789 \\
\hline Nat U-Dep1 U & 1.182 & 1.185 & 1.180 & 1.185 & 1.185 & 1,187 & 1.184 & 0.024 & 34.586 \\
\hline Nat U-Depl U & 1.040 & 1.042 & 1.040 & 1.044 & 1.042 & 1.050 & 1.043 & 0.024 & 33.519 \\
\hline $\mathrm{Cu}$ & 1.024 & 1.029 & 1.024 & 1.021 & 1.028 & 1.022 & 1.025 & 0.013 & 32.476 \\
\hline $235 \mathrm{U}$ & 1.113 & 1.118 & 1.121 & 1.119 & 1.121 & 1.105 & 1.116 & 0.007 & 31.350 \\
\hline${ }^{239} \mathrm{Pu}-{ }^{235} \mathrm{U}$ & 0.983 & 0.996 & 0.991 & 0.997 & 1.001 & 0.979 & 0.991 & 0.026 & 30.343 \\
\hline $\mathrm{Cu}$ & 1.047 & 1.051 & 1.054 & 1.056 & 1.046 & 1.064 & 1.053 & 0.013 & 29.271 \\
\hline
\end{tabular}

Total 28.430 28.470 28.458 $28.452 \quad 28.445 \quad 28.470 \quad 28.455$

a. Avg foil elevation ref to top of housing, in. 


\section{TABLE 11}

\section{Foil Elevation Corrections}

\begin{tabular}{|c|c|c|c|c|c|c|}
\hline & $\begin{array}{l}\text { Distance from } \\
\text { Top of Housing }\end{array}$ & & Rel & ative $F 1$ & & \\
\hline Foil & Tube, in. & Run 12 & Run 17 & Run 36 & Run 47 & Run 50 \\
\hline $\mathrm{Cu}$ & 56.221 & 1.0015 & 0.9970 & 0.9994 & 0.9985 & 0.9981 \\
\hline $\mathrm{Cu}$ & 55.424 & 0.9656 & 0.9547 & 0.9623 & 0.9576 & 0.9445 \\
\hline${ }_{2{ }^{2}{ }^{L} \mathrm{Pu}_{-}{ }^{2}{ }^{35} \mathrm{Cu}}$ & 49.643 & 0.7414 & 0.6988 & 0.7317 & 0.7078 & 0.6338 \\
\hline $\mathrm{Cu}-\mathrm{Cu}$ & 48.780 & 0.7128 & 0.6673 & 0.7025 & 0.6768 & 0.5974 \\
\hline $\mathrm{Cu}$ & 43.028 & 0.5486 & 0.4923 & 0.5357 & 0.5027 & 0.4046 \\
\hline $\mathrm{Lu}-\mathrm{Cu}-\mathrm{Lu}$ & 41.687 & 0.5162 & 0.4591 & 0.5030 & 0.4694 & 0.3700 \\
\hline $\mathrm{Lu}-\mathrm{Cu}-\mathrm{Lu}$ & 40.419 & 0.4873 & 0.4301 & 0.4740 & 0.4400 & 0.3403 \\
\hline $\begin{array}{l}\text { Surface of } \\
\text { housing }\end{array}$ & 40.25 & 0.4836 & 0.4264 & 0.4703 & 0.4363 & 0.3366 \\
\hline $\mathrm{Cu}$ & 39.215 & 0.4615 & 0.4045 & 0.4481 & 0.4140 & 0.3146 \\
\hline $\begin{array}{l}\text { Cd pillboxes } \\
\text { on ladders }\end{array}$ & 39.15 & 0.4601 & 0.4032 & 0.4467 & 0.4126 & 0.3133 \\
\hline Depl U & 38.102 & 0.4389 & 0.3824 & 0.4254 & 0.3914 & 0.2929 \\
\hline $\begin{array}{l}\text { Bare foils } \\
\text { on ladders }\end{array}$ & 37.18 & 0.4210 & 0.3652 & 0.4076 & 0.3737 & 0.2762 \\
\hline Depl U & 36.993 & 0.4174 & 0.3618 & 0.4041 & 0.3702 & 0.2729 \\
\hline $\mathrm{Cu}$ & 35.789 & 0.3954 & 0.3410 & 0.3821 & 0.3487 & 0.2531 \\
\hline Nat U-Depl U & 34.586 & 0.3746 & 0.3217 & 0.3615 & 0.3286 & 0.2351 \\
\hline Nat U-Dep1 U & 33.519 & 0.3571 & 0.3057 & 0.3441 & 0.3119 & 0.2206 \\
\hline $\mathrm{Cu}$ & 32.476 & 0.3408 & 0.2911 & 0.3281 & 0.2965 & 0.2075 \\
\hline${ }^{235} \mathrm{U}$ & 31.350 & 0.3241 & 0.2765 & 0.3116 & 0.2810 & 0.1946 \\
\hline${ }^{239} \mathrm{Pu}-{ }^{235} \mathrm{U}$ & 30.343 & 0.3099 & 0.2643 & 0.2977 & 0.2679 & 0.1842 \\
\hline $\mathrm{Cu}$ & 29.271 & 0.2956 & 0.2522 & 0.2836 & 0.2548 & 0.1740 \\
\hline
\end{tabular}


A well-thermalized position for activating reference foils in a thermal neutron flux was established 10 inches inside the graphite thermal column of the SP (Figure 23). The reference foils were mounted on aluminum spinner discs that were rotated at $1 \mathrm{rpm}$ during the exposure. Relative exposure histories for the reference foils in the thermal column and the sample foils in the SE lattice were identical because the SP supplied irradiation neutrons simultaneously to both. The measured cadmium ratio (0.032-inch $C d)$ for thin $(0.002$-inch) gold at the thermal reference position is approximately 2800 , which gives an equivalent $1 / v$ cadmium ratio of $3 \times 10^{4}$. No corrections for epicadmium activation were made to the reference foil activities.
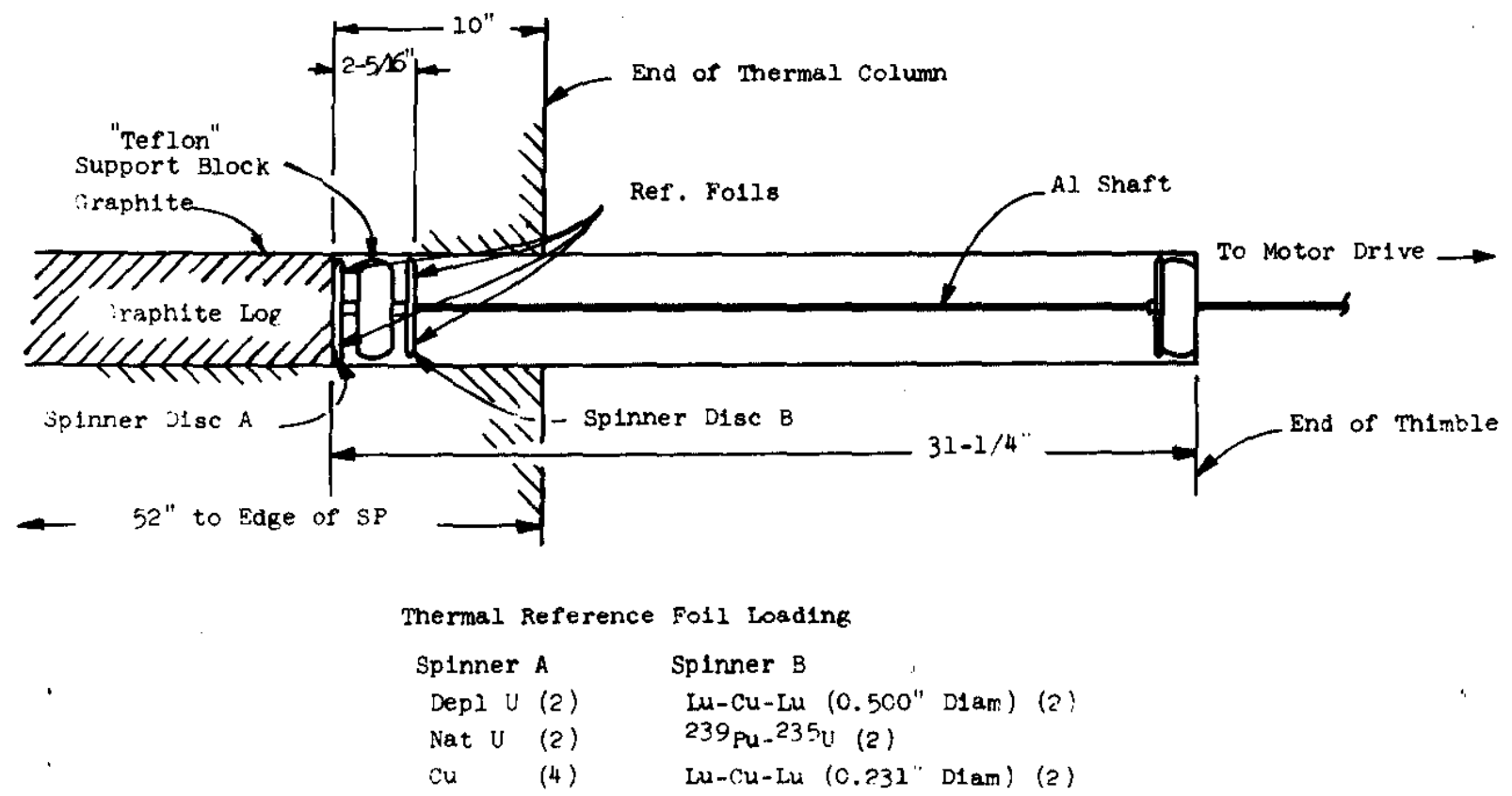

\section{FIG. 23 SP THERMAL COLUMN REFERENCE}

Bare and cadmium-covered Lu-Cu-Lu foil packets and $\mathrm{Cu}$ foils were suspended in the moderator perpendicularly from the irradiation assembly along a line directed midway between adjacent fuel assemblies $\left(45^{\circ}\right)$ and also along a line directed toward the nearest fuel assembly $\left(90^{\circ}\right)$. These "ladders" were formed of 3/32-inch-diameter aluminum wire that was supported at the ends by small aluminum cylinders welded on the surface of the housing tube. The 0.231-inch-diameter foils and the cadmium pillboxes were held between two 0.001 -inch-thick strips of polyester tape that were stretched on the aluminum frames. The foil spacing, loading, and frame arrangement is shown in Figures 24 and 25. Bare and cadmium-covered $\mathrm{Lu}-\mathrm{Cu}-\mathrm{Lu}$ foil packets and $\mathrm{Cu}$ foils also were placed on the surface of the housing tube. Foil elevations are shown in Figures 26 and 27. 


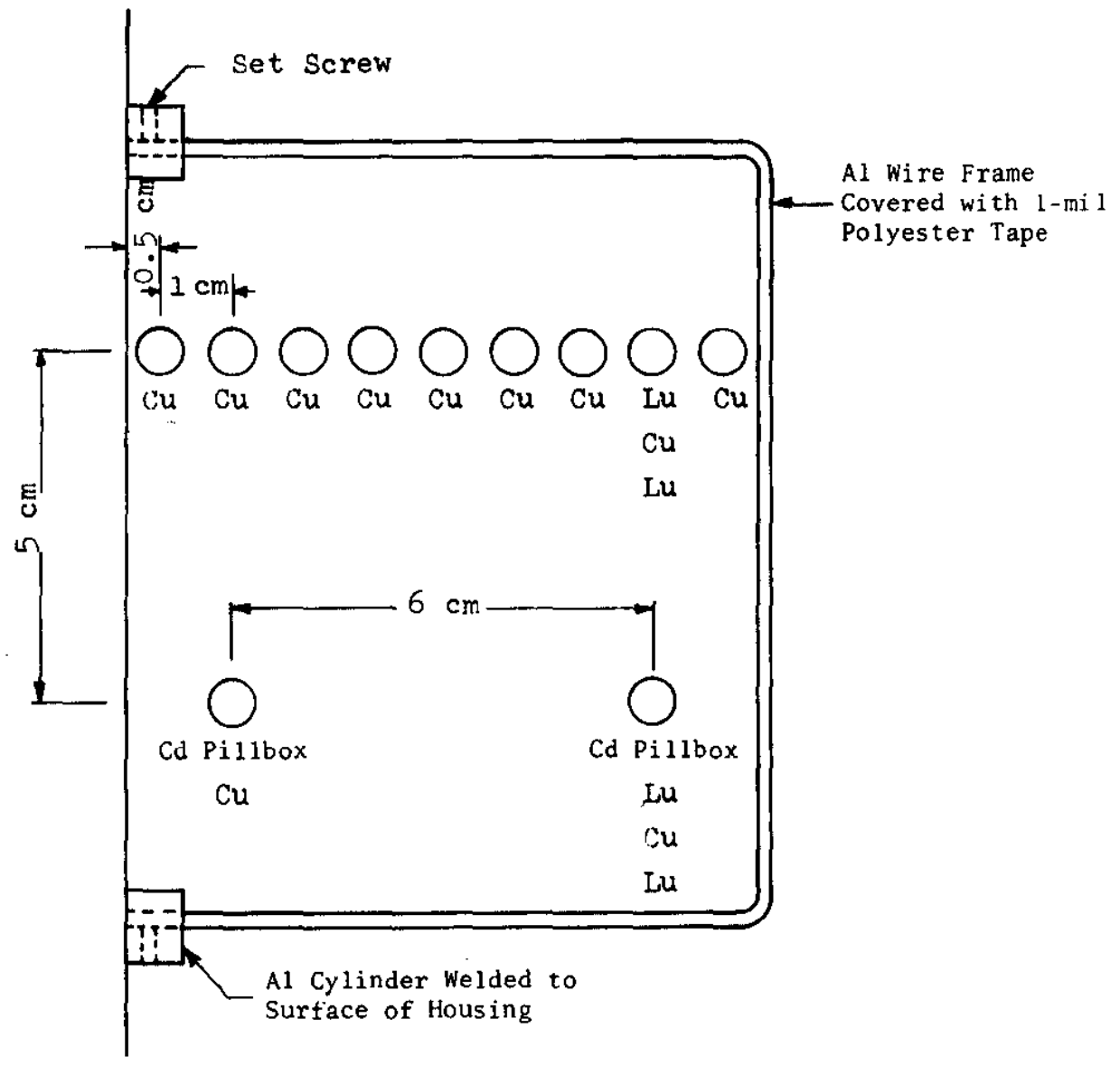

FIG. 24 ALUMINUM WIRE FRAME AND FOIL LOADING

FOR MODERATOR TRAVERSE AT $90^{\circ}$ 


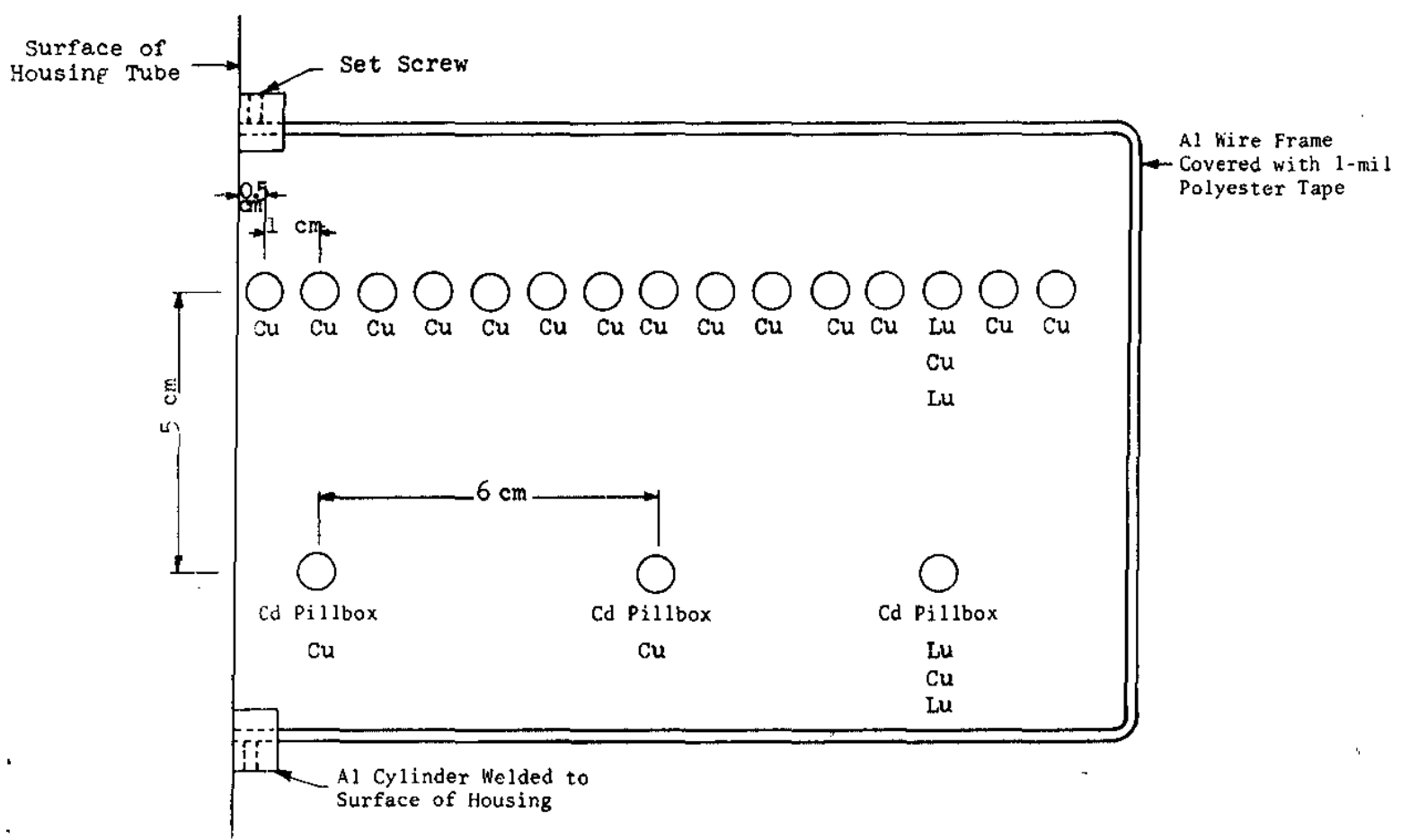

FIG. 25 ALUMINUM WIRE FRAME AND FOIL LOADING FOR MODERATOR TRAVERSE AT $45^{\circ}$ 


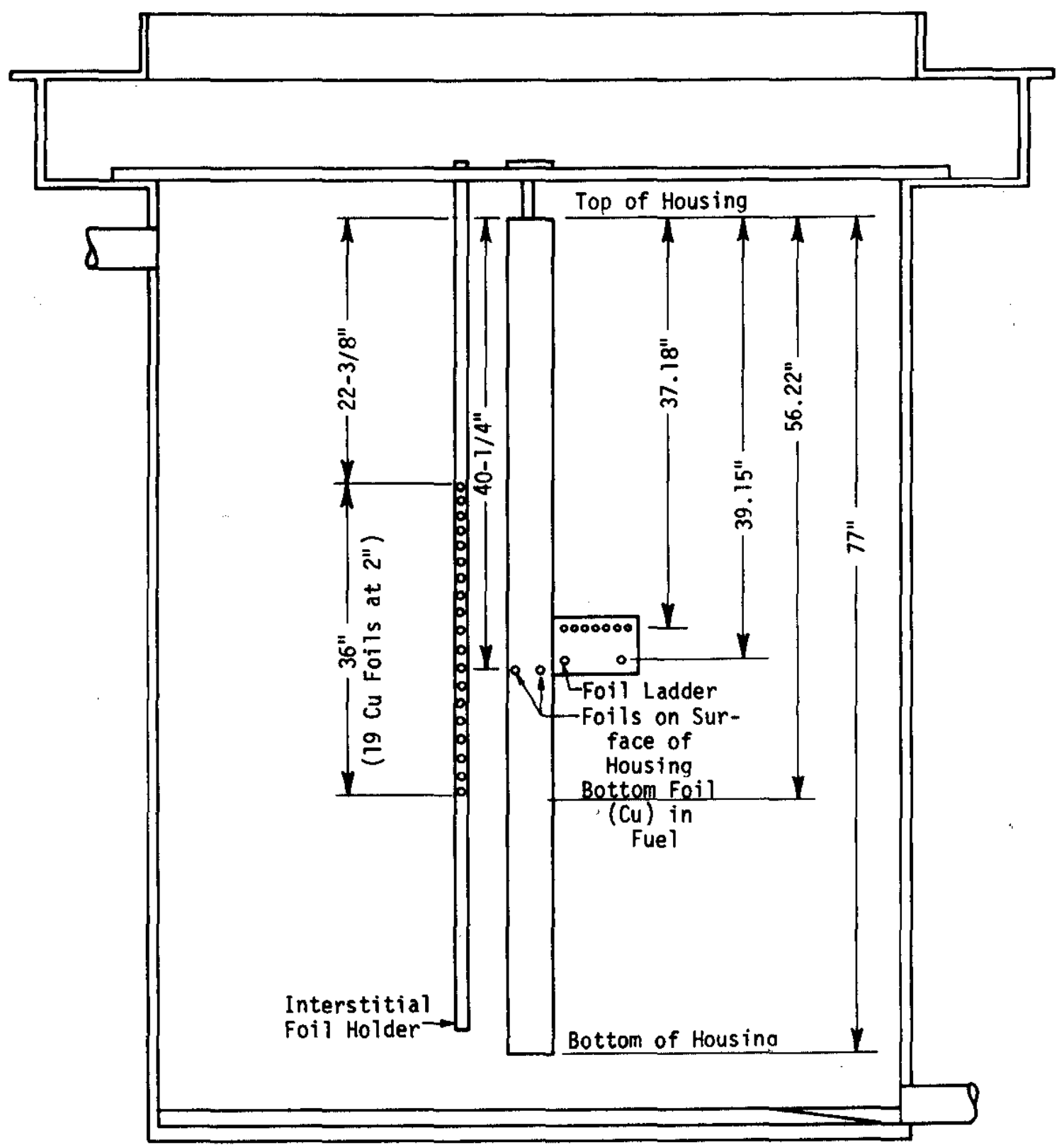

FIG. 26 REFERENCE ELEVATIONS FOR RUNS $12,17,36$, AND 47 


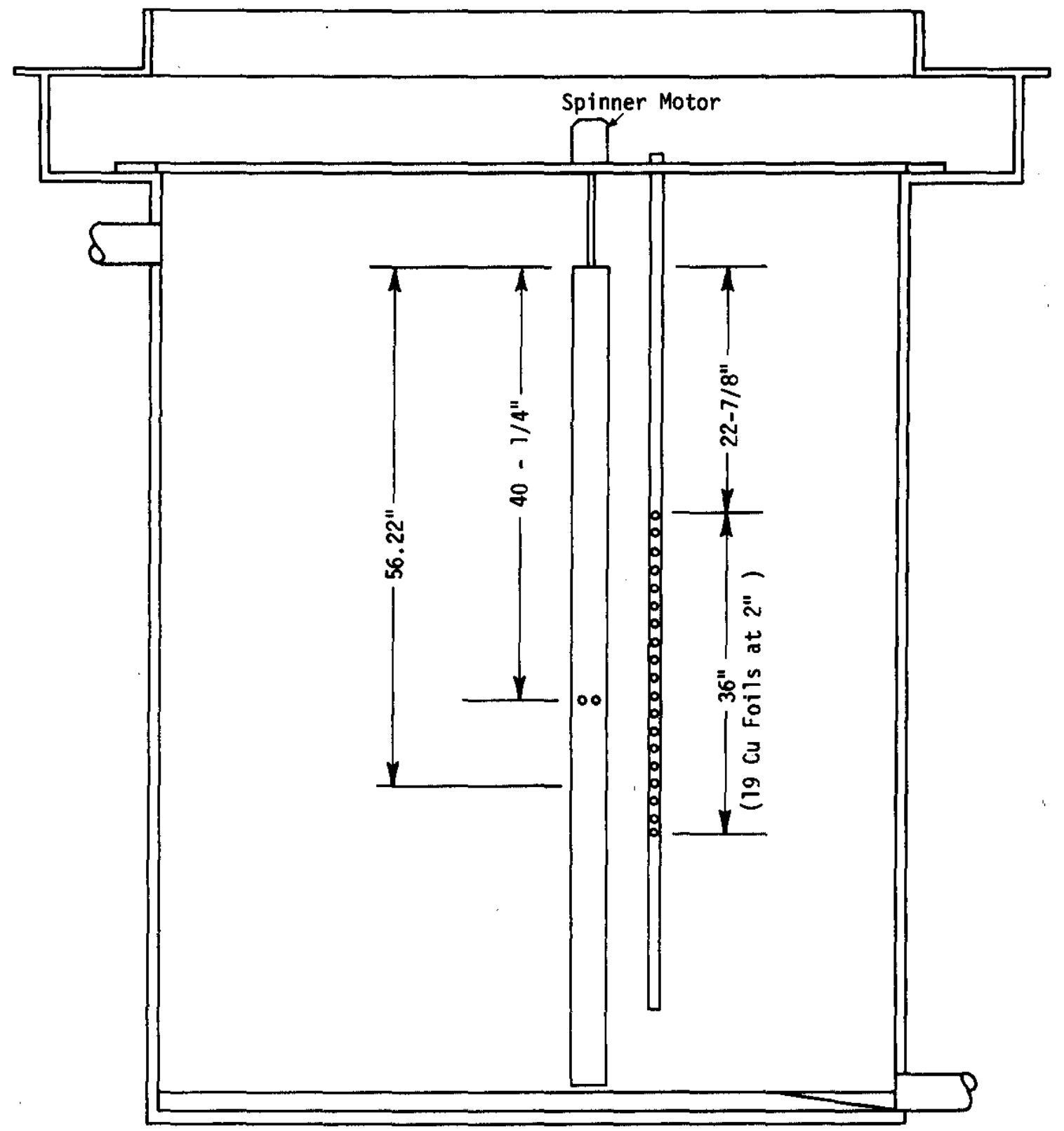

FIG. 27 REFERENCE ELEVATIONS FOR RUN 50 
A description of the foil materials used in the experiments and the gamma counting procedures is summarized in Table 12. The foils were counted for gamma activity with NaI(T1) counters in the arrangement shown schematically in Figure 28 . In the special case of ${ }^{239} \mathrm{~Np}$ counting, both a window (90-116 kev) and an integral bias ( $500 \mathrm{kev}$ ) count were obtained simultaneously in the arrangement of Figure 28. The data output is in the form of IBM cards and typewriter printout. An IBM 360 program is used to correct the foil data for deadtime, background, weight, and decay, and to average and summarize the results.

The foil activation measurements were made to determine:

- Intracell neutron flux distributions in terms of subcadmium ${ }^{63} \mathrm{Cu}$ activations

- Spectral indices in terms of subcadmium ${ }^{176} \mathrm{Lu}-{ }^{6} \mathrm{Cu}$ and ${ }^{239} \mathrm{Pu} /{ }^{235} \mathrm{U}$ activity ratios

- Epithermal neutron fractions in terms of ${ }^{238} \mathrm{U}$ capture, ${ }^{235} \mathrm{U}$ fission, and ${ }^{239} \mathrm{Pu}$ fission cadmium ratios

- Lattice fissions in terms of the ${ }^{238} \mathrm{U} /{ }^{235} \mathrm{U}$ fission ratios

- A modified conversion ratio in terms of ${ }^{238} \mathrm{U}$ captures normalized to ${ }^{235} \mathrm{U}$ fissions

The foil activation experiments and data analyses were designed to complement HAMMER ${ }^{7}$ calculations by deriving results that are directly comparable to HAMMER output data.

TABLE 12

Description of Foils and Gamma Counting Procedures

\begin{tabular}{|c|c|c|c|c|c|c|c|c|}
\hline Detector & Activity & Half-Life & Active Wt $\%$ & Material & $\begin{array}{c}\text { Thiskness, } \\
\text { irch } \\
\end{array}$ & $\begin{array}{c}\text { Di ameter, } \\
\text { inch }^{2}\end{array}$ & $\begin{array}{c}\text { Counter } \\
\text { Bias, kev }\end{array}$ & $\begin{array}{c}\text { Courting } \\
\text { Interval } \\
\text { After } \\
\text { Irradiation } \\
\end{array}$ \\
\hline${ }^{63} \mathrm{Cu}$ & ${ }^{54} \mathrm{Cu}$ & $12.9 \mathrm{hr}$ & $69.1\left({ }^{63} \mathrm{Cu}\right)$ & $\mathrm{Cu}$ & 0.010 & $\begin{array}{l}0.231^{a} \\
0.500\end{array}$ & 400 & $4-18 \mathrm{hr}$ \\
\hline${ }^{276} \mathrm{Lu}$ & $277 \mathrm{Lu}$ & 6.8 days & 5 and $15\left(\mathrm{Lu}_{2} \mathrm{O}_{3}\right)$ & Lu-Al & 0.020 & $\begin{array}{l}0.231^{a} \\
0.500\end{array}$ & $30-250^{b}$ & $2-4$ days \\
\hline${ }^{239} \mathrm{Pu}$ & FP & - & $5\left({ }^{239} \mathrm{Pu}\right)$ & Pu-Al & 0.016 & 0.500 & 200 & $2-4 \mathrm{hr}$ \\
\hline${ }^{235} \mathrm{U}$ & FP & - & $4.4\left({ }^{235} \mathrm{U}\right)$ & $U-A 1$ & 0.005 & 0.500 & 200 & $2-4 \mathrm{hr}$ \\
\hline Nat U & ${ }^{239} \mathrm{~Np}_{\mathrm{p}}$ & 2.35 days & & $u$ & 0.005 & 0.500 & $90-116^{b}$ & $2-4$ days \\
\hline \multirow{3}{*}{ Dep1 U } & $\mathrm{FP}$ & - & $0.714\left({ }^{235} U\right)$ & & & & 660 & $4-6 \mathrm{hr}$ \\
\hline & $239 \mathrm{Pu}$ & 2.35 days & & $u$ & 0.007 & 0.500 & $90-116^{b}$ & $2-4$ days \\
\hline & FP & - & $0.036\left({ }^{235} U\right)$ & & & & 660 & $4-6 \mathrm{hr}$ \\
\hline
\end{tabular}

a. The $0.231-i n c h$ diameter $\mathrm{Cu}$ and $\mathrm{Lu}$ foils were used on a wire frame to determille the spectral index and neutron flux distributions in the moderator.

b. Window 


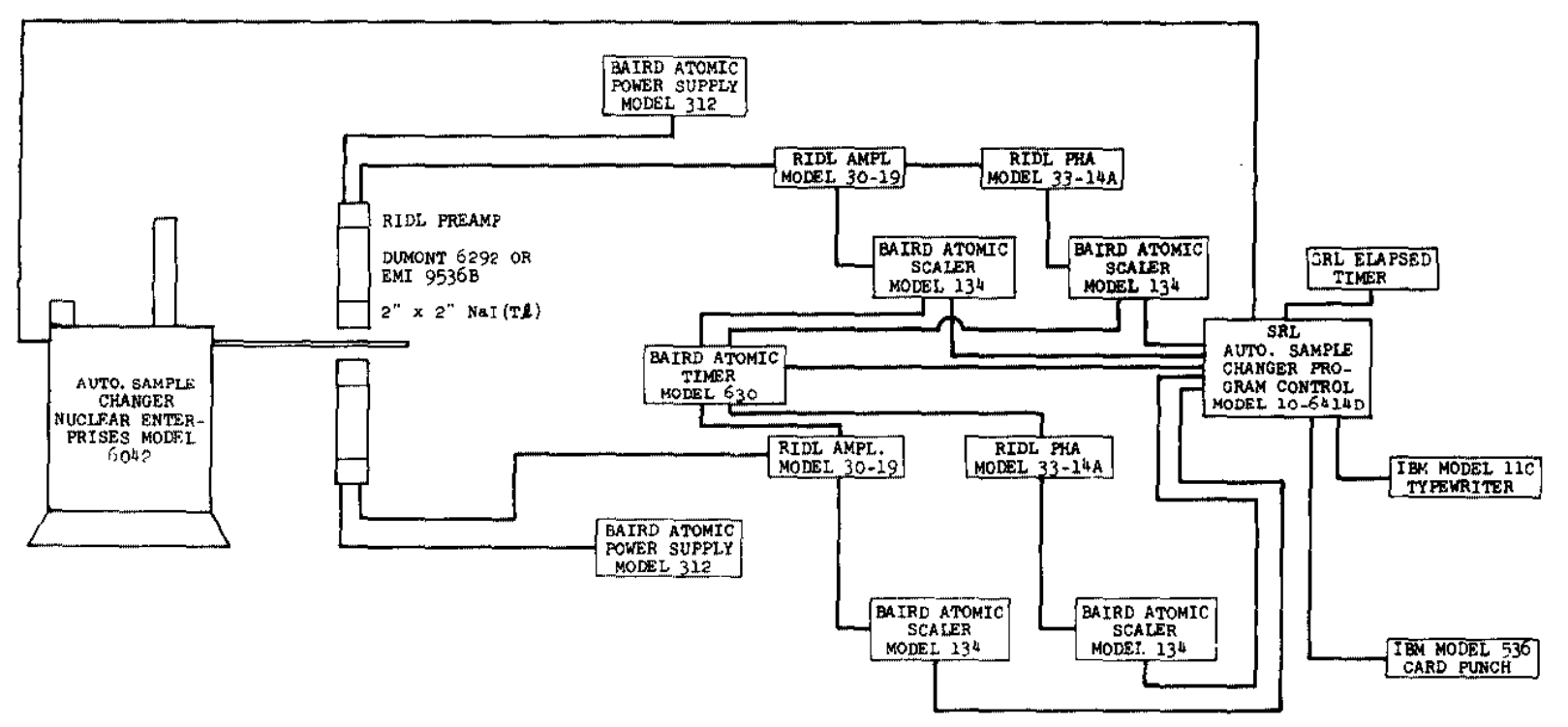

FIG. 28 GAMMA COUNTING ARRANGEMENT

Depleted and natural uranium metal foils were used to determine ${ }^{238} \mathrm{U}$ neutron capture in the oxide rods. The total amount of filler material at the foil position (natural and/or depleted uranium, and aluminum catcher foils) was selected to approximate the average macroscopic thermal absorption cross section and the ${ }^{238} \mathrm{U}$ atom density within the oxide.

The relative numbers of ${ }^{238} U$ captures were measured by counting the 2.3-day activity of ${ }^{239} \mathrm{~Np} \rightarrow{ }^{239} \mathrm{Pu}$. The gamma activities and the $K_{\alpha}$ and $K_{\beta} X$-rays were counted by sodium iodide (thallium activated) scintillators, biased to accept energies in the interval from 90 to $116 \mathrm{kev}$. A simultaneous count was made on each foil at an integral bias of $500 \mathrm{kev}$. This latter bias includes all capture decay and is a monitor of fission product activity. Counts were made from 2 to 4 days after the irradiation to minimize the background fission product activity relative to the desired capture activity. After counting, the normal background corrections (including spontaneous decay) were made. Corrections for small differences in weight and $\gamma$-ray attenuation factors due to small differences in foil thicknesses were also included in the final analys is. The attenuation factors had been determined in an auxiliary experiment using different thicknesses of ${ }^{238} \mathrm{U}$ absorber and irradiated ${ }^{238} \mathrm{U}$ as a source. Foil thicknesses were kept small, and counter geometries were maintained with small acceptance angles to minimize foil edge effects in the gamma attenuation. 
Extrapolation to zero fission product activity was obtained by combining the data from the paired natural and depleted uranium foils. Natural and depleted uranium foils from the thermal reference position were used to obtain the relation between fission product activity in the monitor channel ( $>500 \mathrm{kev}$ ) and the activity due to fission products in the channel defined by the 90 - to 116-kev window. The channel activities needed to obtain this ratio were obtained very simply for the thermal reference foils by subtracting the specific activity of the depleted foil expressed as the counting rate per ${ }^{23}{ }^{8} \mathrm{U}$ atom from that of the natural uranium foil. This ratio can be obtained far more accurately in the thermal. column than in the lattice cell for two reasons. First, in a purely thermal flux the desired fission product activity is larger relative to the ${ }^{239} \mathrm{~Np}$ activity, which for this determination is a nuisance background. Second, this background activity from a nonresonant thermal flux is quite insensitive to the minor geometrical imperfections common to the foils.

An added advantage of this method is that the activities of natural and depleted foils in the $\mathrm{UO}_{2}$ rods are weighted equally, whereas in the conventional method undue weight is given to the depleted foil. (As a corollary, this method makes redundant the use of two foil materials in each rod.) Previous experience shows no systematic differences in $23{ }^{8} \mathrm{U}$ activities deduced from the two foil types. Two assumptions implicit in this method are that the energy distribution of gamma and beta rays from ${ }^{238} \mathrm{U}$ fission is closely that from ${ }^{235} \mathrm{U}$ fission and that the ${ }^{235} \mathrm{U}$ distribution does not depend strongly on the energy of the fissioning neutrons. These assumptions cannot be verified without chemical separation techniques, because no direct count-" ing method is available for obtaining fission capture in ${ }^{238} \mathrm{U}$ without some radiative capture.

Because no cadmium-covered ${ }^{238} \mathrm{U}$ detectors were used, the cadmium ratio [or equivalently $1 / \rho \equiv\left({ }^{238} \mathrm{U} C d\right.$ ratio - 1)] had to be derived indirectly. This was accomplished by noting that the capture cross sections of both ${ }^{238} \mathrm{U}$ and $\mathrm{Cu}$ follow the $1 / v$ law closely in the subcadmium region. Thus the subcadmium copper activity can be used to represent the subcadmium ${ }^{238} \mathrm{U}$ activity in the fuel if the two detector foils are normalized in a thermal flux (thermal column). A similar normalization to ${ }^{235} \mathrm{U}$ in lieu of the copper allows a direct interpretation of the measurements in terms of a modified conversion ratio, $C^{*}$, rather than of $\rho$. 
For this case, the quantity $\mathrm{C}^{*}$ is defined as ${ }^{238} \mathrm{U}$ captures normalized to ${ }^{235} \mathrm{U}$ total fissions, i.e.,

$$
\begin{aligned}
C^{*}=\frac{\left[N g \sigma_{a}\right]^{238}}{\left[N g \sigma_{f}\right]^{235}} \times \frac{238 \mathrm{U} \text { Activity in fuel }}{235 \mathrm{U} \text { Fission Activity in fuel }} \\
\quad \times \frac{{ }^{235} \mathrm{U} \text { Fission Activity in reference }}{{ }^{238} \mathrm{U} \text { Activity in reference }}
\end{aligned}
$$

where the activities are specific (i.e. per atom) fuel average and thermal column reference activities. The values used for $\mathrm{N}, \mathrm{g}$, and $\sigma$ are given in Table 13. The atom number densities (N) refer to the fuel rods, and the effective cross sections, (go) refer to the thermal reference flux. Fission product activities were obtained by subtracting the depleted uranium foil activities from the paired natural uranium foil activities in both the fuel and the reference positions.

TABLE 13

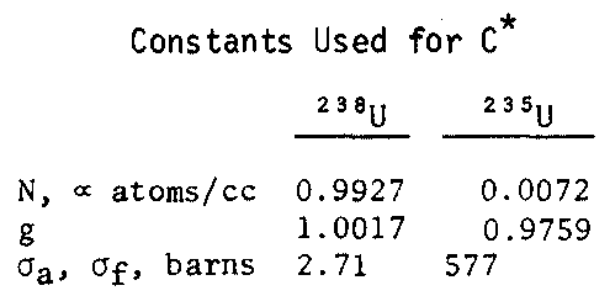

Paired natural and depleted uranium foils were used to determine the fast fission effect. The ratio, $\delta_{O}$, of ${ }^{238} \mathrm{U}$ fast fission to ${ }^{235} \mathrm{U}$ total fission was obtained by counting the paired foils at an integral bias of $500 \mathrm{kev}$ at a time interval from 4 to 6 hours after the irradiation. Because of conflicting demands for counting equipment, it was impossible to standardize counting conditions with regard to such factors as geometry, bias, and time (conditions essential in the normal methods of determining $\delta_{0}$ ). Instead, all measurements were normalized to measurements made in a fixed reference position (with a fixed "known" $\delta_{0}$ value). This reference position consisted of two 1-inch-diameter, 4-inch-long slugs of natural uranium metal embedded in graphite. Fully thermalized neutrons from the SP were fed to a special assembly containing this slug. The arrangement is shown schematically in Figure 29 . The reference foils within the " $\delta_{0}$ reference" rod were a pair of natural and depleted uranium foils identical to those in the lattice. These foils were placed in a shallow circular recess milled into the center face of one of the two 4 -inch-long segments. 


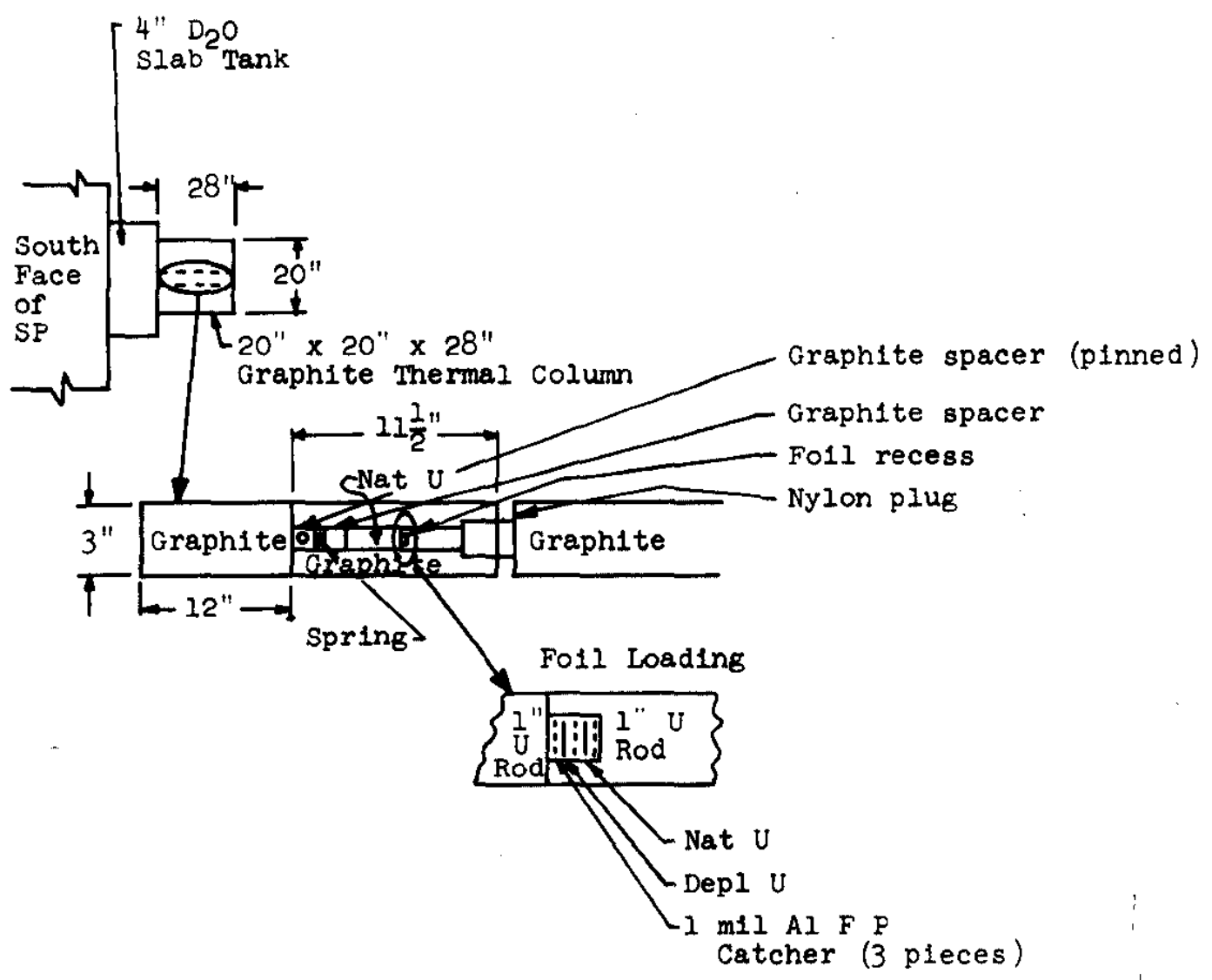

FIG. 29 REFERENCE FLUX POSITION FOR $\delta_{0}$ MEASUREMENT

The relative ${ }^{235} \mathrm{U}$ contents of the depleted and natural uranium foils were assayed by activation of the foils in a fully thermalized neutron flux, thus eliminating fission product activity from fast fission in ${ }^{238} \mathrm{U}$. This method of normalization gives an effective concentration which is the true concentration multiplied by the fission product retention fraction. This retention probability is closely the same for all of the natural foils ( 0.005 mil thick) and depleted foils $\left(0.007 \mathrm{mil}\right.$ thick) separately. With a known fixed value of $\delta_{0}$ in the reference lattice, the quantity, $P(t)$, (which relates the ratio of fission product activities to the true fission ratio for the two isotopes) is readily obtained by maintaining the same neutron exposure conditions and counting times for reference and lattice foils. The values are based on a value of $\delta_{0}=0.070$ for the $1 / 2$-inch foils at the center of the 1-inch-diameter rod. This value was obtained by a comparison of the natural and enriched uranium foil activities at the irradiation position in the center of the l-inch-diameter slug to the activities of similar 1-inch-diameter foils covering the full slug cross section. 
The reference value of $\delta_{0}$ for the 1 -inch foils was taken to be 0.053 . The quoted values of $\bar{\delta}_{0}$ can be altered by a simple ratio of reference values, if it is desired to change the 0.053 value assigned to $\delta_{0}$ for the 1 -inch-diameter reference rod.

Neutron spectral indices were measured by paired foils of ${ }^{2}{ }^{39} \mathrm{Pu}-{ }^{235} \mathrm{U}$ and $\mathrm{Lu}-\mathrm{Cu}-\mathrm{Lu}$ foil sandwiches. All activations are normalized to unity at the thermal reference position. The ratios of Lu-to-Cu and ${ }^{239} \mathrm{Pu}$ to ${ }^{235} \mathrm{U}$ subcadmium activities in the fuel then give the normalized spectral indices. These measured ratios are directly comparable to quantities computed by HAMMER. The exact equivalent ratio from HAMMER is

$$
\left[\frac{\sigma\left({ }^{176} \mathrm{Lu} \text { or }{ }^{239} \mathrm{Pu}\right)}{\sigma\left({ }^{63} \mathrm{Cu} \text { or }{ }^{235} \mathrm{U}\right)}\right]_{\text {HAMMER }}^{\text {Lattice }} \div\left[\frac{\sigma\left({ }^{176} \mathrm{Lu} \text { or }{ }^{239} \mathrm{Pu}\right)}{\sigma\left({ }^{63} \mathrm{Cu} \text { or }{ }^{235} \mathrm{U}\right)}\right]_{\text {HAMMER }}^{\text {Th Ref }}
$$

where the cross sections are averaged by the THERMOS section of HAMMER over the appropriate flux spectra in the energy interval from zero to $0.625 \mathrm{ev}$. The HAMMER library gives for a purely Maxwellian thermal flux at $20^{\circ} \mathrm{C}$ an average value of $\sigma_{176} \mathrm{Lu}=3080.6$ barns and $\sigma_{23}^{\text {Fission }}=681.2$ barns and a value (except for numerical round-off) of $\sqrt{\pi / 4}$ for $\sigma_{63} \mathrm{Cu}$ and 503.7 for $\sigma_{23}{ }_{3} \mathrm{U}$ U normalized at $2200 \mathrm{~m} / \mathrm{sec}$.

The intracell flux profiles were obtained from the subcadmium copper activations. Corrections for radial leakage were made to the experimental data in the moderator. These corrections consisted of dividing all data by $J_{0}\left(B_{R} r\right)$, where $B_{R}^{2}$ is the radial buckling of the $S E$ and $r$ is the radial position of the individual foils. The effective radial buckling was corrected for the effect of the flux booster rods by

$$
\left(B_{R}^{2}\right)_{\text {Eff }}=\left(B_{R}^{2}\right)_{\text {Geom }}+\left(K_{\text {Booster }}^{2}-\kappa_{\text {No Booster }}^{2}\right)
$$

Here $\left(B_{R}^{2}\right)_{G e o m}$ is the geometric radial buckling of the $S E$ (approximately $9.25 \mathrm{~m}^{-2}$ ), and the difference in $\mathrm{K}^{2}$ is the measured difference in the axial buckling due to the addition of the booster rods. An interstitial aluminum foil holder with bare copper foils at 2-inch intervals was included in each experiment to provide data for the $k^{2}$ booster measurement. A least squares fit to the sinh $Z$ function was obtained to determine $k$. The location of the holder for each experiment is shown in Figure 19. 
A $2.4 \%$ correction was applied to account for the flux depression in the 10-mil-thick bare copper foils on the ladders and on the surface of the housing tube. A similar $4.6 \%$ correction was applied to the bare copper foils that were sandwiched by lutetium to permit use of the activity data from these foils for the flux profile.

No corrections were applied for the thermal flux depression at foil locations in the fuel. In each case, the thermal flux depression of the combined foil and aluminum filler very closely matched the flux depression of an equivalent thickness of $\mathrm{UO}_{2}$.

Experimental and HAMMER calculated intrace11 subcadmium $1 / \mathrm{v}$ $(\mathrm{Cu})$ activation profiles are plotted in Figure 30 . The experimental data have been normalized to agree with the HAMMER normalization (unity at $r=0$ ) by requiring the volume-weighted activation value in the fuel to equal that computed by HAMMER. The experimental data points are fuel rod averages plotted at the midpoint radius of each rod. The theoretical curve is drawn as a smooth fit through the computed fuel ring activation averages plotted at the linear averaged radius of each fuel ring. The radii corresponding to the foil rods in the cluster and the HAMMER cylindricized fuel rings are compared in Table 14. The agreement between measured and computed activations in the fuel is good, lending confidence to the use of HAMMER for computing flux and fission power distribution within the cluster. The agreement throughout the cell is good for the extreme cases of pure $\mathrm{H}_{2} \mathrm{O}$ and $\mathrm{D}_{2} \mathrm{O}$ coolant; however, the computations overestimate the activation profile in the moderator for the $70 \% \mathrm{H}_{2} \mathrm{O}-30 \%$ $\mathrm{D}_{2} \mathrm{O}$ cases.

TABLE 14

Comparison of Foil Rod and HAMMER Fuel Radii

\begin{tabular}{|c|c|c|c|}
\hline Foil 1 Rod & $\begin{array}{c}\text { Radius, } \\
\mathrm{cm}\end{array}$ & $\begin{array}{l}\text { HAMMER } \\
\text { Region } a\end{array}$ & $\begin{array}{l}\text { Linear Avg } \\
\text { Radius, cm } \\
\end{array}$ \\
\hline 1 & 0 & 1 & 0 \\
\hline 2 & 1.643 & 3 & 1.578 \\
\hline 3 & 2.846 & 5 & 3.029 \\
\hline 4 & 3.287 & & \\
\hline 5 & 4.348 & 7 & 4.143 \\
\hline 6 & 4.348 & & \\
\hline
\end{tabular}

a. Refer to Figure 9 

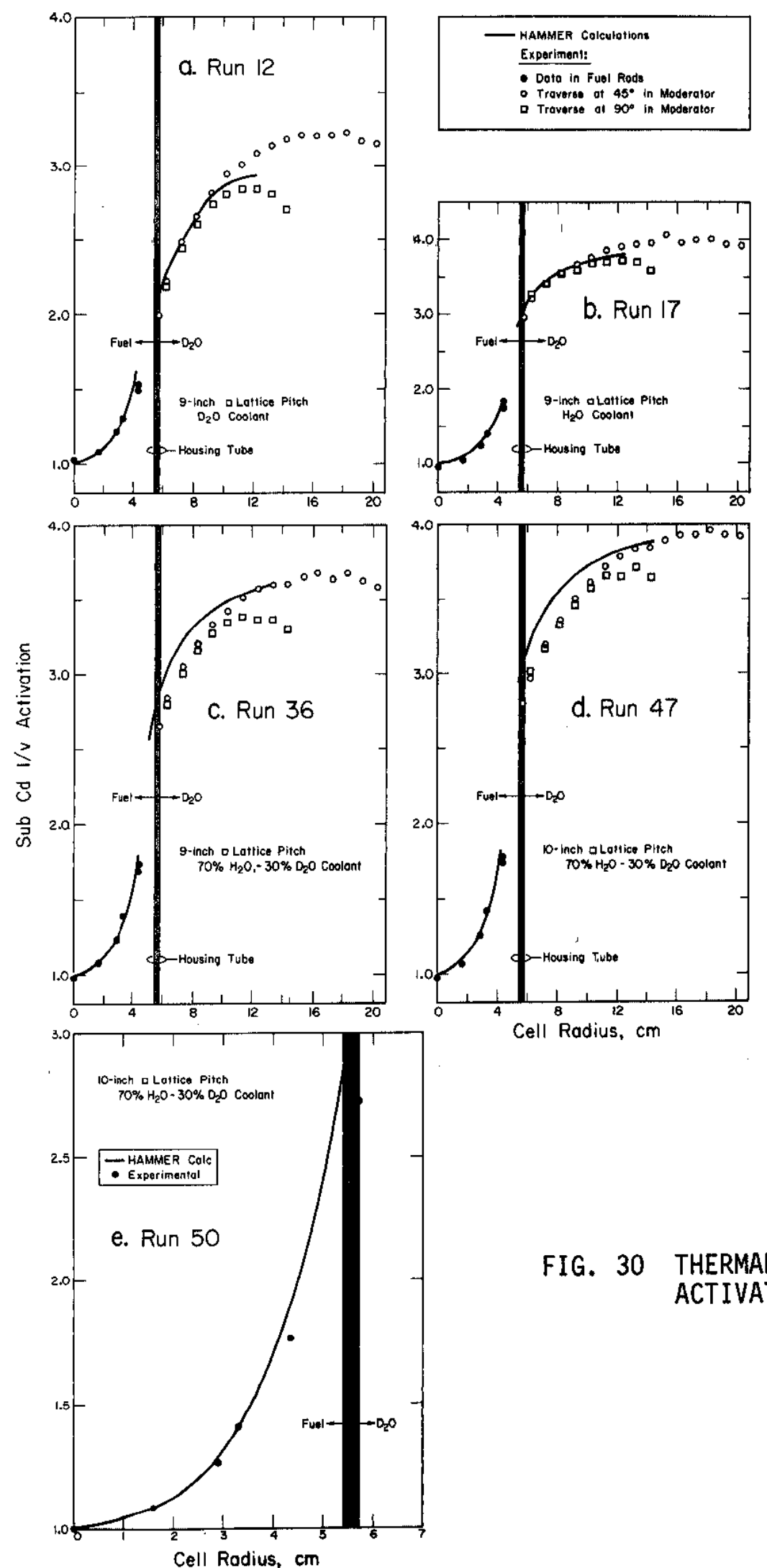

FIG. 30 THERMAL NEUTRON ACTIVATION PROFILES 
The spectral index profiles derived from the ${ }^{176} \mathrm{Lu}-{ }^{63} \mathrm{Cu}$ foil detectors are shown in Figure 31. Profiles derived from the ${ }^{239} \mathrm{Pu}-{ }^{235} \mathrm{U}$ foils are shown in Figure 32 . The experimental values for Run 50 (with the outer control tube centered in the 10-inch lattice) are shown in Figures $31 \mathrm{~d}$ and $32 \mathrm{~d}$ along with the results for the same lattice without the control tube and with the fuel centered in the SE. As expected, the experimental results for the two cases are in close agreement, with the slightly harder spectrum associated with the control tube case. The HAMMER computations properly predict the qualitative behavior of the spectral hardening; however, the magnitude is consistently overestimated by comparison with the ${ }^{176} \mathrm{Lu}-{ }^{63} \mathrm{Cu}$ foil data, and the agreement in magnitude is good by comparison with the ${ }^{239} \mathrm{Pu}-{ }^{235} \mathrm{U}$ data. This anomaly was investigated by comparing HAMMER computed spectral indices for Maxwellian spectra in $\mathrm{D}_{2} \mathrm{O}$ at temperatures from 20 to $220^{\circ} \mathrm{C}$ with calculations performed using the " $g$ " factor tabulations of Westcott for we11-moderated thermal reactor spectra. The agreement was excellent indicating no discrepancy in the HAMMER cross sections. Calibrations of the activity ratio ${ }^{177} \mathrm{Lu} /{ }^{63} \mathrm{Cu}$ and ${ }^{239} \mathrm{Pu} /{ }^{235} \mathrm{U}$ as a function of temperature have been performed by various experimenters, and their results are in good agreement with the Westcott " $g$ " factors. The discrepancy in the HAMMER calculation for the $\mathrm{Lu}-\mathrm{Cu}$ case may be a result of an overestimate of the magnitude of the $1 / E$ flux component near the $0.14-e v$ peak of the ${ }^{176} \mathrm{Lu}$ resonance.

Measured and calculated values of $\vec{\rho}$ are given in Table 2 . The calculated values of $\bar{\rho}$ are approximately $3 \%$ higher than the measured values. A small ( $20.5 \%)$ correction that accounts for known deficiencies in the cluster surface-to-mass ratio using the HAMMER cylindricized model has not been applied but would further improve the agreement between calculation and experiment. The small discrepancy in $\bar{\rho}$, although consistent in direction with the discrepancy in the buckling comparisons, can only account for approximately $0.15 \mathrm{~m}^{-2}$ in terms of its effect on the magnitude of the buckling. This would still leave unresolved the large buckling discrepancies for the low reactivity $\mathrm{H}_{2} \mathrm{O}$ and $\mathrm{H}_{2} \mathrm{O}-\mathrm{D}_{2} \mathrm{O}$ coolant cases.

Table 2 also lists the comparison between measured and calculated values of $C^{*}$. Since $C^{*}$ is dominated by thermal rather than resonance effects, the small discrepancies in $\bar{\rho}$ are even less conspicuous in $\mathrm{C}^{*}$.

The measured and computed values of $\delta_{0}$ are given in Table 2 . The agreement is good. The small discrepancies that do exist have a very small effect on $k_{\text {eff }}$ since $\varepsilon=1+\frac{\nu^{238}-1}{\nu^{235}} \bar{\delta}$ where $v^{238}=2.85$ and $v^{235}=2.43$ for natural uranium. 
${ }^{235} \mathrm{U}$ and ${ }^{239} \mathrm{Pu}$ fission cadmium ratios are given in Table 2 . Corrections for thermal leakage as discussed in Appendix $B$ have been included.

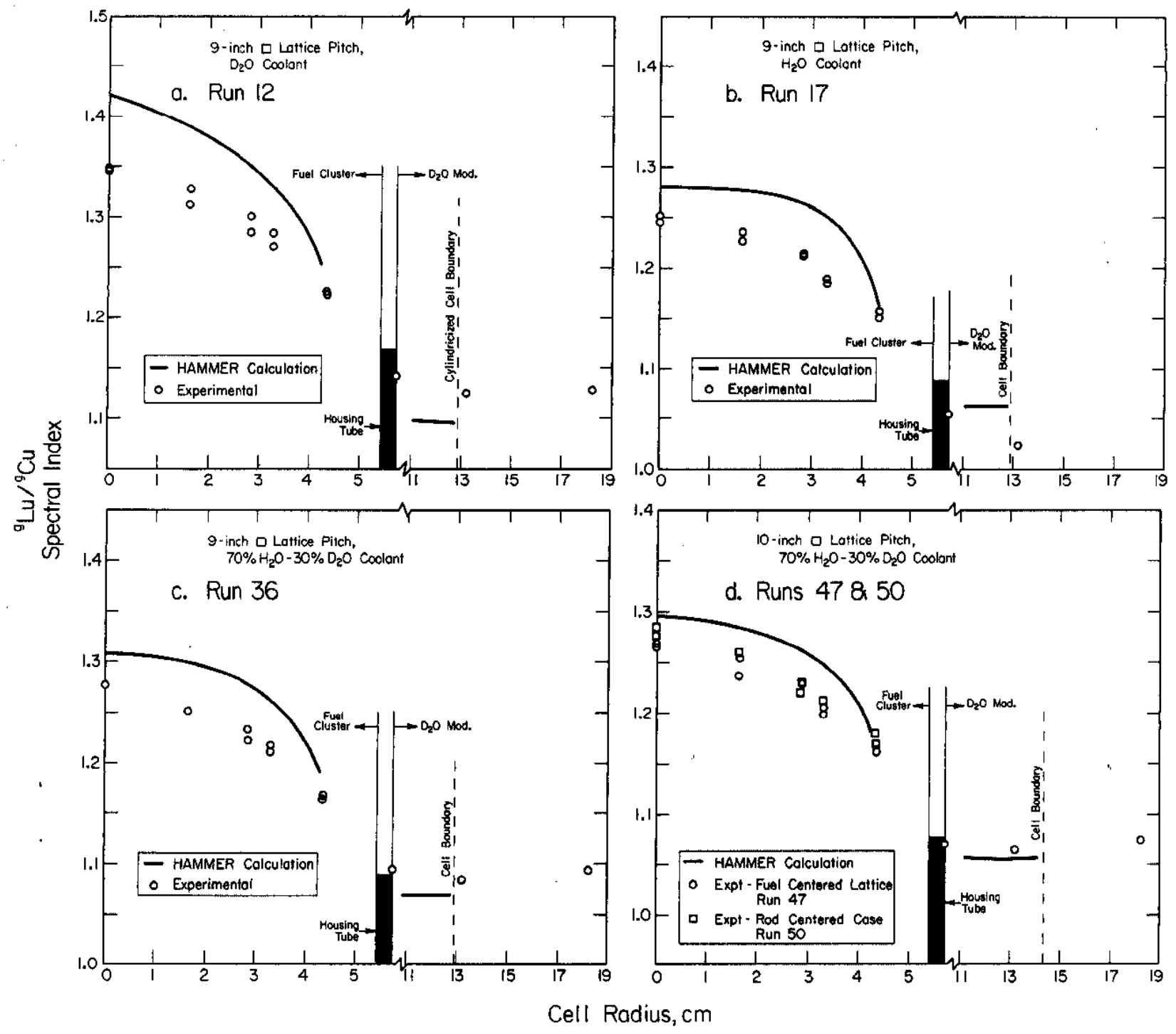

FIG. $311^{176} \mathrm{Lu}-{ }^{63} \mathrm{Cu}$ SPECTRAL INDEX PROFILES 


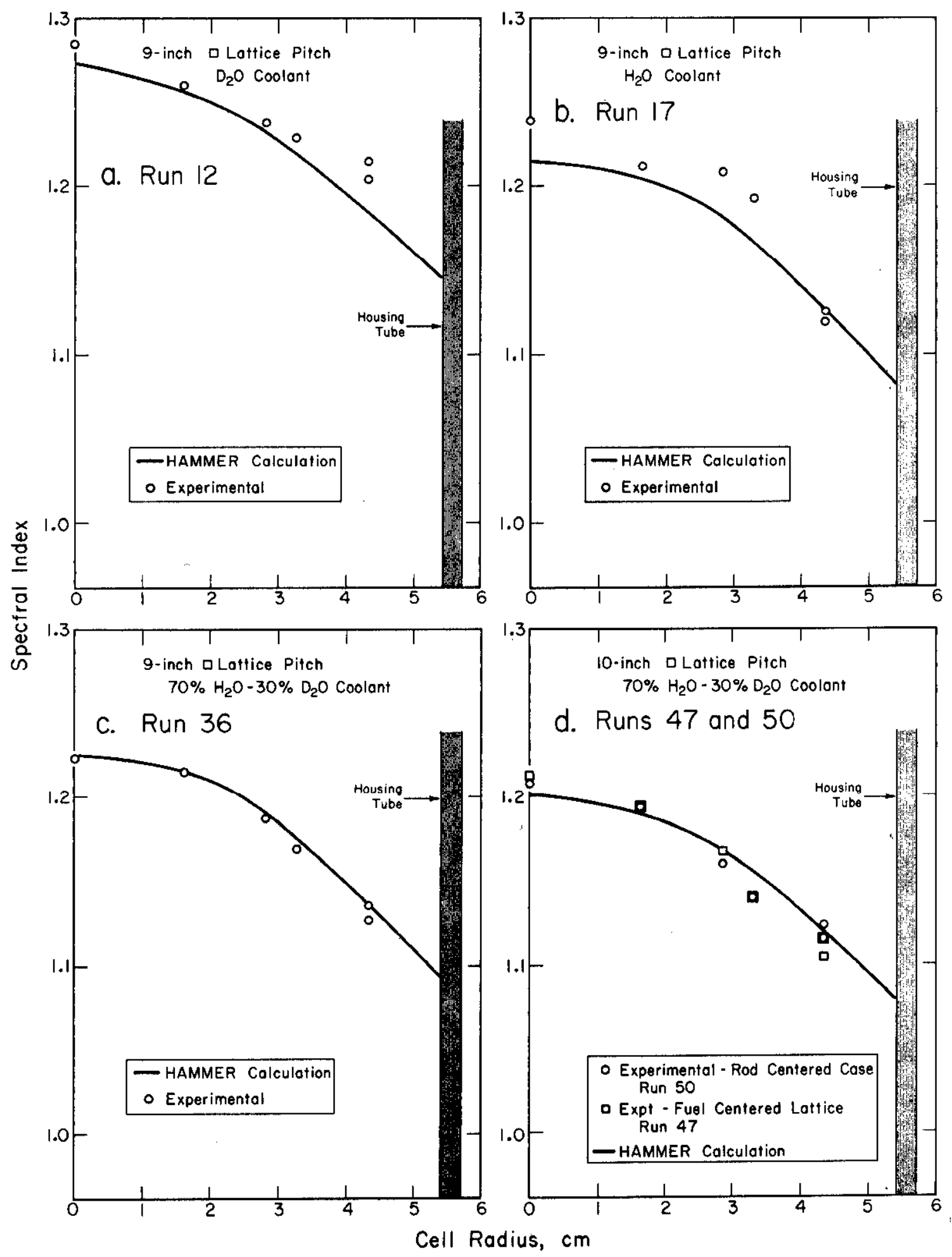

FIG. $32{ }^{239} \mathrm{PU}-{ }^{235} \mathrm{U}$ SPECTRAL INDEX PROFILES 


\section{APPENDIX A}

\section{CONTROL TUBE WORTH MEASUREMENTS IN THE PDP}

The relative worths of the outer, middle, and inner Japanese control tubes were determined by substitution measurements in the PDP. The measurements were made in a partial loading of an SRP production reactor core surrounded by poison rods as shown in Figure 33. The fuel and control assemblies in this lattice are arranged on a 7-inch triangular pitch. The Japanese outer, middle, and inner control tubes were attached to PDP control rod drives in the symmetric positions shown in Figure 33. Each could be withdrawn from or inserted into the core while the PDP was critical. Critical water heights were then measured with no tubes inserted and with each of the Japanese tubes fully inserted, one at a time. Results of these measurements are given in Table 6 . The changes in critical vertical buckling were then used in PDQ calculations to obtain the control tube worths in a flat flux.

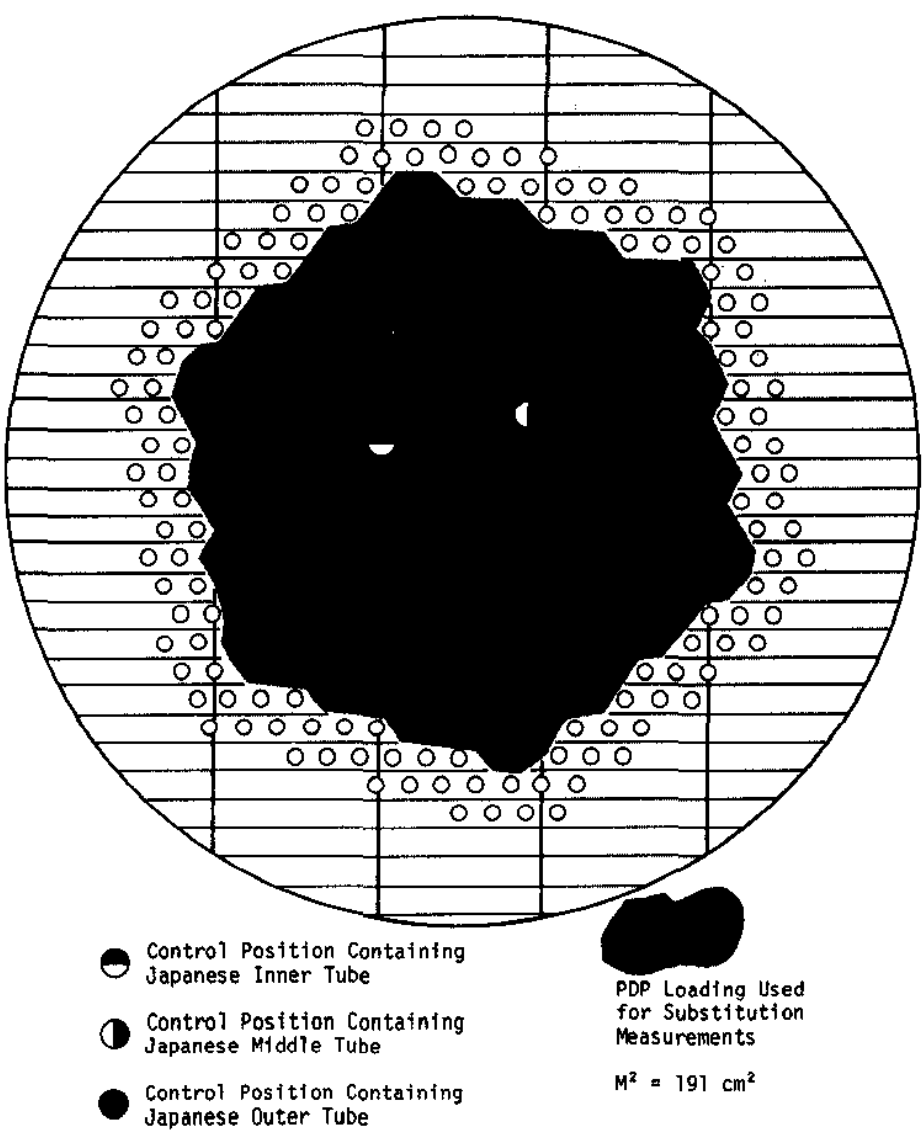

FIG. 33 PDP LOADING USED FOR RELATIVE CONTROL ROD WORTH MEASUREMENTS 
The PDQ analysis consisted of normalizing a PDP mockup of the lattice with no tubes inserted. Then a series of calculations was made with each tube in the reactor. In these calculations, the macroscopic absorption cross sections (thermal and fast) of the control tube cells as calculated with HAMMER were varied until the calculated $\Delta B^{2}$ matched the observed value in each case. These $\sum$ 's were then used in a PDQ calculation of an array of supercells, each supercell consisting of an empty lattice position surrounded by six SRP fuel assemblies. The positions in each supercell were arranged on a 7-inch triangular pitch. The outer, middle, and inner Japanese tubes were inserted, in turn, into the empty lattice position. The results of these calculations are compared with the results of a base case calculation in which the center position of each supercell was vacant to obtain the relative worth of the tube. PDQ results are given in Table 7 .

The Process Development $\mathrm{Pile}^{2}$ is a zero power, $\mathrm{D}_{2} 0$-moderated critical facility. The PDP tank is 16 feet $2-3 / 4$ inches in diameter with a height of 15 feet 6 inches. A system of grid beams at a center-to-center spacing of 6.06 inches is used to top support the lattice components. The control system permits the moderator level to be adjusted to within $\pm 0.002 \mathrm{~cm}$. Vernier water level control is maintained by balancing a variable flow against a small fluid drain. Absolute water heights may be measured to an accuracy of $\pm 0.1 \mathrm{~cm}$ and relative water heights to within $\pm 0.002 \mathrm{~cm}$. Reactor power is monitored by boron-lined ionization chambers connected to picoammeters. Final criticality is determined using differential reactor power instrumentation. The layout of the PDP is given in Figure 34 . 


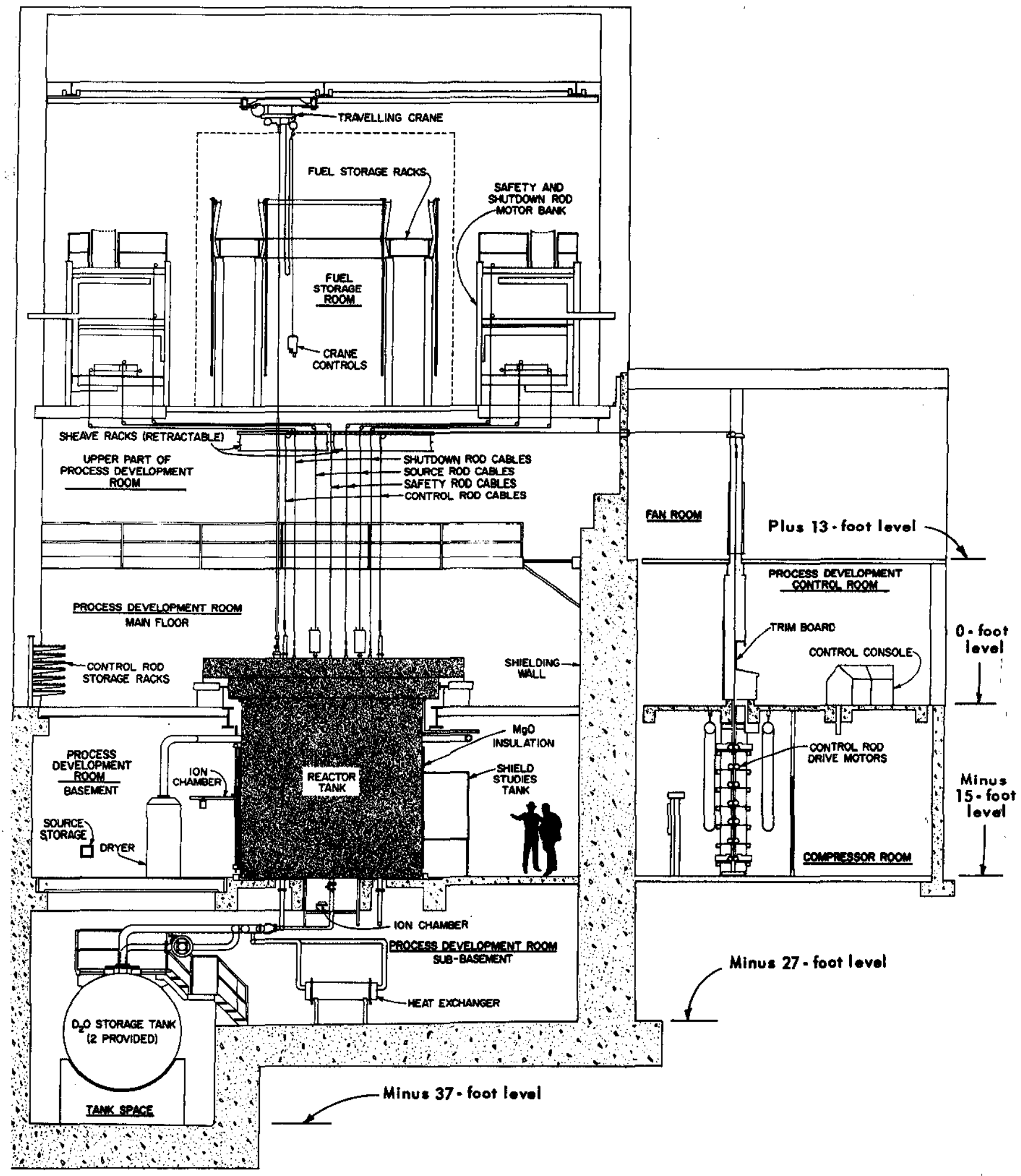

FIG. 34 PROCESS DEVELOPMENT PILE 


\section{APPENDIX B}

\section{EFFECTIVENESS OF CADMIUM COVERS}

The cadmium covers in the present experiments differ in two essential ways from ideality: they are not completely sealed to thermal neutrons and they contain more than the minimum amount of cadmium required so that the effective cadmium wall thickness exceeds that of the ideal cover. Experiments were undertaken to assay the magnitude of the separate effects.

To determine the effect of thermal neutron leakage, a mockup assembly was constructed as shown in Figure 35. A 0.030-inchthick by 0.5 -inch-wide layer of cadmium was wrapped around a 0.5 -inch-long section of the same tubing used to contain the fuel pellets. Detector foils, consisting of a packet of machined 0.500 -inch-diameter ${ }^{235} \mathrm{U}-\mathrm{Al}$ foils was centered as shown. Cadmium discs were positioned as shown with an edge-to-edge separation of 0.080 inch. Aluminum filler material (not shown) was used to maintain the spacing. The completed assembly was irradiated in a cavity in the well-thermalized flux of the thermal column of the SP, along with a bare reference foil. A totally enclosed cadmium-covered foil was also included to correct for the effect of residual epithermal neutrons. The ratio of the total specific activity of the foils in the assembly to that of the bare foil was $5.9 \pm 0.1 \times 10^{-4}$. The corresponding ratio for the totally encased foil was $1.2 \pm 0.1 \times 10^{-4}$, giving a residual of $4.7 \pm 0.2$ $x 10^{-4}$ ascribable to thermal neutron leakage. For the experimental conditions of the lattice irradiations, this leakage translates to a maximum error of approximately $2 \%$ in cadmium ratios and errors of $0.05 \%$ in subcadmium activities. The correction was included only in the cadmium ratio assignments for the ${ }^{235} \mathrm{U}$ and ${ }^{239} \mathrm{Pu}$ foils.

To measure the effective thickness of the cadmium in the lattice experiments, an assembly was constructed identical to that used for determining thermal neutron leakage (Figure 35) except that the aluminum tube was removed and the diameter of the cadmium tube was reduced to eliminate the gap between the cadmium sections. A packet of two 0.010-inch-thick copper foils were centered in the assembly as shown. The assembly was irradiated in the center of the SP along with a second foil packet encased in a tight fitting cadmium pillbox shown in cross section at the left of Figure 35. The specific activity of the separate irradiated foils was determined to a statistical accuracy of $0.1 \%$. The activity of the foils from the special assembly was $0.84 \pm 0.13 \%$ lower than those in the conventional 
compact pillbox. Ascribing all of the effect to the $1 / \mathrm{v}$ component gives a corrected difference of $1.60 \pm 0.25 \%$ (using values of 1.82 barns for the $1 / v$ component and 1.63 barns for the effective resonance component of the ${ }^{63} \mathrm{Cu}$ resonance integral ${ }^{10}$ ). The $1.6 \%$ decrease in specific activity is equivalent to a $3.2 \%$ increase in the effective cadmium cutoff energy over that of the compact pillbox, giving an effective cutoff energy of $0.644 \mathrm{ev}$. This increase is equivalent to that expected from adding 0.004 inch of cadmium uniformly to the reference compact pillbox.

a. Thermal

Neutron

Leakage
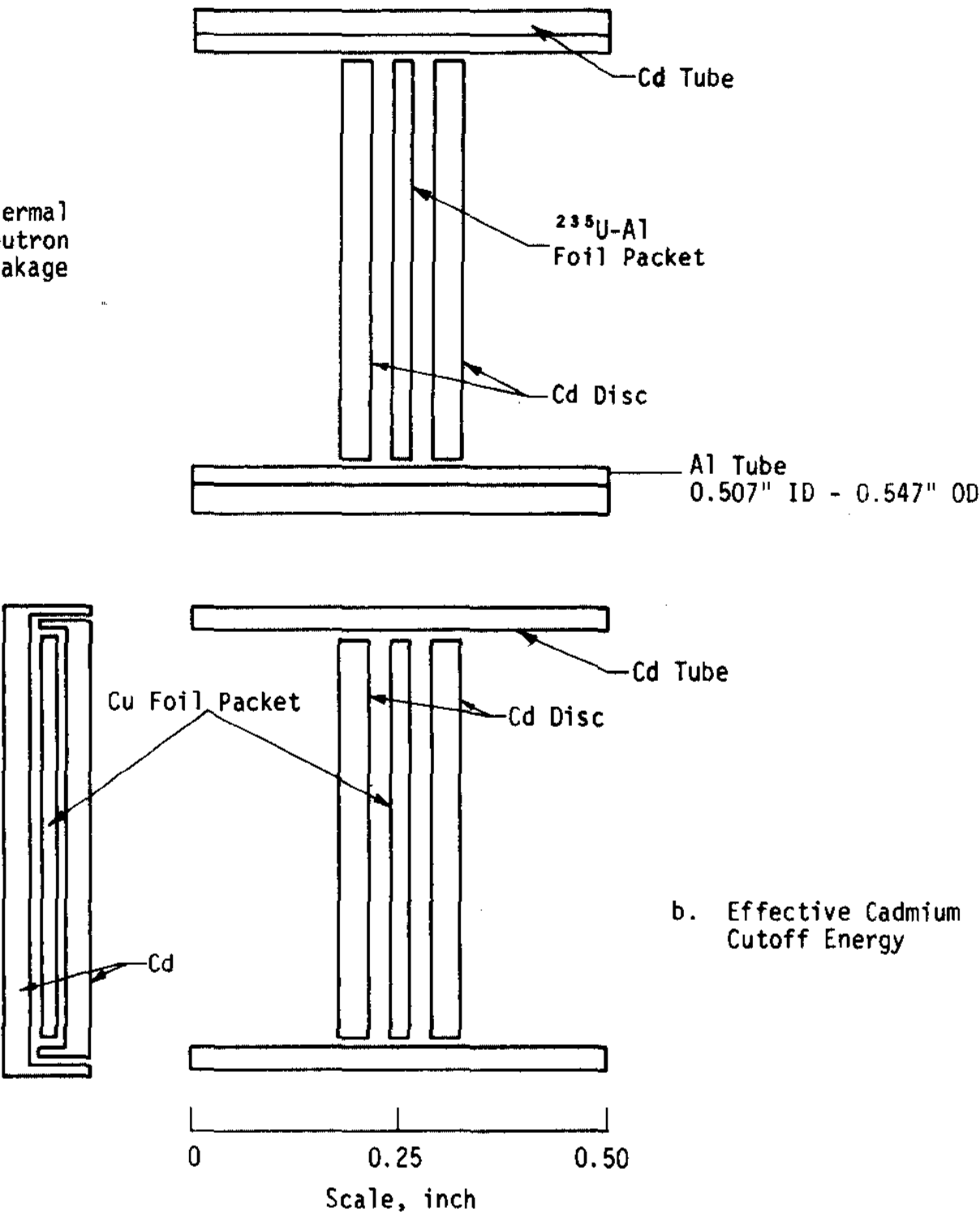

b. Effective Cadmium Cutoff Energy

FIG. 35 EXPERIMENTAL APPARATUS FOR CHECKING NEUTRON LEAKAGE AND EFFECTIVE CADMIUM CUTOFF ENERGY 


\section{APPENDIX C}

\section{SUMMARY OF SE RADIAL FLUX MEASUREMENTS}

Table 15 summarizes the results of radial flux shape measurements made in the SE. The activities of bare copper wire irradiated on fuel assemblies relative to the centermost fuel assembly are listed for the various cases. The position of each assembly is given in Figure 6.

TABLE 15

Radial Flux Shape Measurements Made in the SE

\begin{tabular}{|c|c|c|c|c|c|c|c|}
\hline $\begin{array}{l}\text { Run } \\
\text { (See Table 3) }\end{array}$ & 1,2 & 8,9 & 23,24 & 18,19 & 13,14 & 44,45 & 48,49 \\
\hline Lattice & $7 b$ & $7 a$ & $7 \mathrm{a}$ & $7 a$ & $7 a$ & $7 c$ & $7 c$ \\
\hline Control tubes & None & None & None & None & None & None & OT \\
\hline Fuel coolant & $\mathrm{D}_{2} \mathrm{O}$ & $\mathrm{D}_{2} \mathrm{O}$ & $70-30^{a}$ & $75-25$ & $\mathrm{H}_{2} \mathrm{O}$ & $70-30$ & $70-30$ \\
\hline As sembly & \multicolumn{3}{|c|}{ Activity Relative } & \multicolumn{2}{|c|}{ Centermost } & \multicolumn{2}{|c|}{ Assembly } \\
\hline 1 & 0.367 & 1.000 & 1.000 & 1.000 & 1.000 & 1.000 & 1.000 \\
\hline 2 & 0.763 & 0.880 & 0.894 & 0.892 & 0.891 & 0.854 & 0.845 \\
\hline 3 & 1.005 & 0.754 & 0.875 & 0.870 & 0.868 & 0.837 & 0.802 \\
\hline 4 & 1.003 & 0.873 & 0.881 & 0. & 0.872 & 0.8 & 0.872 \\
\hline 5 & 0.776 & 0.882 & 0.874 & 0.876 & 0.872 & 0.835 & 0.823 \\
\hline 6 & 0.388 & & 0.762 & & & 0.707 & 0.736 \\
\hline 7 & 0.380 & & 0.758 & & & 0.684 & 0.747 \\
\hline 8 & 0.775 & & 0.7 & & & 0 . & 0.723 \\
\hline 9 & 0.996 & & 0.801 & & & 0.726 & 0.670 \\
\hline 10 & 0.997 & 0.572 & 0.570 & 0.565 & 0.5 & 0.481 & 0.571 \\
\hline 11 & 0.752 & 0.568 & 0. & 0.576 & 0.598 & 0.451 & 0.373 \\
\hline 12 & 0.368 & 0.565 & 0. & 0.550 & 0.551 & 0.458 & 0.378 \\
\hline 13 & 0.768 & 0.578 & 0.581 & 0.563 & 0.545 & 0.466 & 0.565 \\
\hline 14 & 0.747 & & & & & 0.374 & 0.426 \\
\hline 15 & 0.381 & & & & & 0.360 & 0.491 \\
\hline 16 & 0.361 & & & & & 0.359 & 0.271 \\
\hline 17 & & & & & & 0.346 & 0.312 \\
\hline 18 & & 0.182 & 0 . & 0.180 & 0.169 & 0.352 & 0.310 \\
\hline 19 & & 0.180 & 0.176 & 0.169 & 0.202 & 0.355 & 0.268 \\
\hline 20 & & 0.174 & 0.187 & 0.168 & 0.124 & 0.355 & 0.487 \\
\hline 21 & & 0.181 & 0.194 & 0.171 & 0.174 & 0.377 & 0.411 \\
\hline
\end{tabular}

a. $70-30=70 \% \mathrm{H}_{2} \mathrm{O}-30 \% \mathrm{D}_{2} \mathrm{O}$.

b. See Figure 6 


\section{APPENDIX D \\ POSSIBLE SYSTEMATIC ERROR IN BUCKLING MEASUREMENTS AT LOW BUCKLINGS}

The increasing disparity between computed and measured bucklings as light water is added to the coolant may be a more general effect associated with extremely low lattice bucklings. Supporting this it is noted that measured reaction rates from foil activations are in uniformly good agreement with computed reaction rates for all uniform lattices. Inasmuch as measured reaction rates agree but measured bucklings disagree with the computations, one of two alternative explanations appear most likely; there is a systematic error either in the buckling measurements or in the critical equation used in HAMMER to relate reaction rates to buckling. The latter choice appears quite unlikely to be of sufficient size to explain the effect.

Such systematic errors in relaxation length measurements due to energy dependent transport effects are well known in nonmultiplying systems. An example is the relaxation length in deeply poisoned moderators with a thermal neutron source (Corngold limit exceeded). A second example is the relaxation length in poisoned or unpoisoned $\mathrm{H}_{2} \mathrm{O}$ with a fission source. From the critical equation, the relaxation length should be equal to $\sqrt{\mathrm{M}} \simeq 6 \mathrm{~cm}$ for pure $\mathrm{H}_{2} \mathrm{O}$ and less if poisoned. From shielding experiments, it is known that the relaxation length exceeds twice this value in thick $\mathrm{H}_{2} \mathrm{O}$ shields.

If the effect is indeed due to energy dependent transport, the result on the buckling measurements would be to make all measured bucklings higher than proper. The effect would be negligible for high reactivity lattices $\left(B_{m}^{2}>5 \mathrm{~m}^{-2}\right)$ but would become appreciable for low reactivity lattices $\left(\mathrm{B}_{\mathrm{m}}^{2}<0 \mathrm{~m}^{-2}\right)$. Specifically, the experiments would underestimate the effect of replacing $\mathrm{D}_{2} \mathrm{O}$ with $\mathrm{H}_{2} \mathrm{O}$ and the reactivity worth of control rods. 
$-70-$ 


\section{REFERENCES}

1. A. E. Dunk1ee and C. E. Jewe11. Zero-Power Measurements on a High-Flux Demonstration Lattice. USAEC Report DP-1076, E. I. du Pont de Nemours and Co., Savannah River Laboratory, Aiken, S. C. (1967).

2. A. E. Dunklee. The Heavy Water System of the Process Development Pile. USAEC Report DP-567, E. I. du Pont de Nemours and Co., Savannah River Laboratory, Aiken, S. C. (1961).

3. Control Rod for Advanced Thermal Reactor. Sumitomo Electric Industries Ltd., Nuclear Fuels Division, February, 1969.

4. R. C. Axtmann, L. A. Heinrich, R. C. Robinson, O. A. Towler, and $\mathrm{J}$. W. Wade. Initial Operation of the Standard Pile. USAEC Report DP-32, E. I. du Pont de Nemours and Co., Savannah River Laboratory, Aiken, S. C. (1953) (Declassified 1957).

5. W. J. Woodward. A Traveling Flux Monitor for Exponential Piles. USAEC Report DP-659, E. I. du Pont de Nemours and Co., Savannah River Laboratory, Aiken, S. C. (1961).

6. W. R. Cadwe11, P. F. Buerger, and C. J. Pfeifer. The PDQ-5 and $P D Q-6$ Programs for the Solution of the Two-Dimensional Neutron Diffusion-Depletion Problem. USAEC Report WAPT-TM477, Westinghouse Electric Corporation, Bettis Atomic Power Laboratory, Pittsburgh, Pa. (1965).

7. J. E. Suich and H. C. Honeck. The HAMMER System. USAEC Report DP-1064, E. I. du Pont de Nemours and Co., Savannah River Laboratory, Aiken, S. C. (1967).

8. W. P. Stinson, L. C. Schmid, and R. E. Heineman. "An Investigation of Effective Neutron Temperatures." Nucl. Sci. Eng. ?, 435-441 (1960).

9. L. C. Schmid and W. P. Stinson. "Calibration of Lutetium for" Measurements of Effective Neutron Temperatures." Nucl. Sci. Eng. 7, 477-478 (1960).

10. N. P. Baumann. Resonance Integrals and Self-Shielding Eactors for Detector Foils. USAEC Report DP-817, E. I. du Pont de Nemours and Co., Savannah River Laboratory, Aiken, S. C. (1963).

$\mathrm{EQN}: \mathrm{mbh}$ 